National Water Quality Program

\title{
Model Methodology for Estimating Pesticide Concentration Extremes Based on Sparse Monitoring Data
}

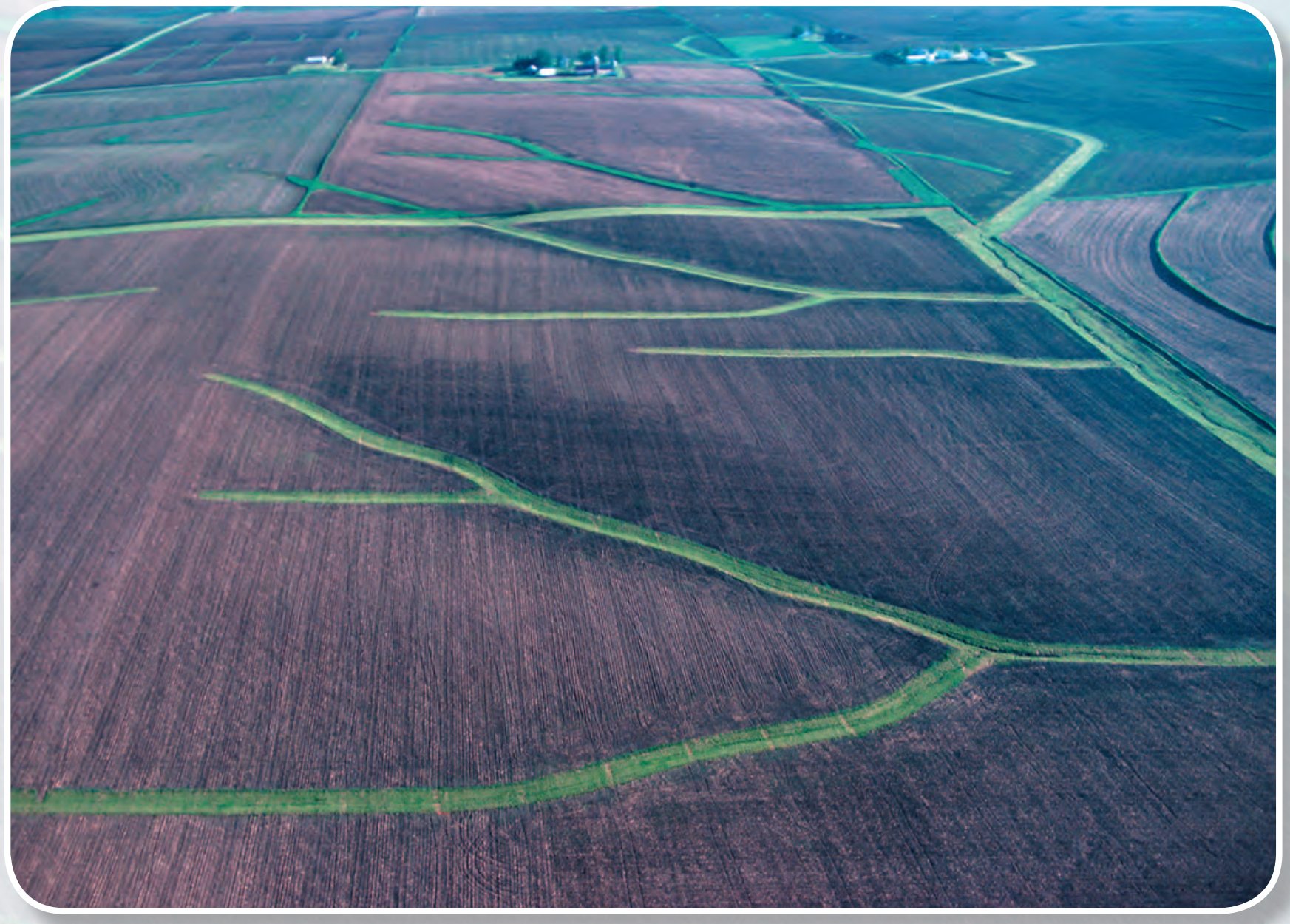

Scientific Investigations Report 2017-5159 
Cover. Photograph showing grassed waterways that carry runoff from crop fields preventing erosion (photograph by Lynn Betts, U.S. Department of Agriculture, 1999). 


\section{Model Methodology for Estimating \\ Pesticide Concentration Extremes Based on Sparse Monitoring Data}

By Aldo V. Vecchia

National Water Quality Program

Scientific Investigations Report 2017-5159 


\title{
U.S. Department of the Interior \\ RYAN K. ZINKE, Secretary
}

\section{U.S. Geological Survey William H. Werkheiser, Acting Director exercising the authority of the Director}

\author{
U.S. Geological Survey, Reston, Virginia: 2018
}

For more information on the USGS - the Federal source for science about the Earth, its natural and living resources, natural hazards, and the environment-visit https://www.usgs.gov or call 1-888-ASK-USGS.

For an overview of USGS information products, including maps, imagery, and publications, visit https://store.usgs.gov.

Any use of trade, firm, or product names is for descriptive purposes only and does not imply endorsement by the U.S. Government.

Although this information product, for the most part, is in the public domain, it also may contain copyrighted materials as noted in the text. Permission to reproduce copyrighted items must be secured from the copyright owner.

\footnotetext{
Suggested citation:

Vecchia, A.V., 2018, Model methodology for estimating pesticide concentration extremes based on sparse monitoring data: U.S. Geological Survey Scientific Investigations Report 2017-5159, 47 p., https://doi.org/10.3133/sir20175159.

ISSN 2328-0328 (online)
} 


\title{
Foreword
}

Sustaining the quality of the Nation's water resources and the health of our diverse ecosystems depends on the availability of sound water-resources data and information to develop effective, science-based policies. Effective management of water resources also brings more certainty and efficiency to important economic sectors. Taken together, these actions lead to immediate and long-term economic, social, and environmental benefits that make a difference to the lives of the almost 400 million people projected to live in the United States by 2050.

In 1991, Congress established the National Water-Quality Assessment (NAWQA) to address where, when, why, and how the Nation's water quality has changed, or is likely to change in the future, in response to human activities and natural factors. Since then, NAWQA has been a leading source of scientific data and knowledge used by national, regional, state, and local agencies to develop science-based policies and management strategies to improve and protect water resources used for drinking water, recreation, irrigation, energy development, and ecosystem needs (https://water.usgs.gov/nawqa/applications/). Plans for the third decade of NAWQA (2013-23) address priority water-quality issues and science needs identified by NAWQA stakeholders, such as the Advisory Committee on Water Information and the National Research Council, and are designed to meet increasing challenges related to population growth, increasing needs for clean water, and changing land-use and weather patterns.

Understanding the occurrence and distribution of pesticides in the Nation's waters is one priority water-quality issue. Pesticides in drinking water and aquatic ecosystems have the potential to adversely impact humans and aquatic life. The evaluation of pesticide exposure has traditionally required high-frequency (for example, daily) sampling. However, because of the prohibitive cost of daily sampling, most monitoring sites have sparse (weekly or less frequent) sampling. This report provides a modeling methodology for using sparse pesticide monitoring data to generate synthetic time series of daily concentrations that reproduce the statistical properties of actual daily time series data. The synthetic data can be used in future studies to better understand pesticide exposure risk and uncertainty in our Nation's rivers and streams.

The purpose of this publication is to provide insight and information to meet water-resource needs and to foster increased citizen awareness and involvement in the protection and restoration of our Nation's waters. The information in this report is intended primarily for those interested or involved in resource management and protection, conservation, regulation, and policymaking at the regional and national levels.

\author{
Dr. Donald W. Cline \\ Associate Director for Water \\ U.S. Geological Survey
}




\section{Acknowledgments}

James Hetrick, Rochelle Bohaty, Charles Peck, Sarah Hafner, Christine Hartless, and Dana Spatz with the U.S. Environmental Protection Agency and Matthew Bischof with the Washington State Department of Agriculture provided valuable assistance throughout the process of devel-oping and testing the methods described in this report. 


\section{Contents}

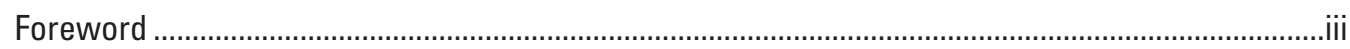

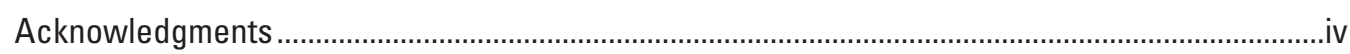

Abstract

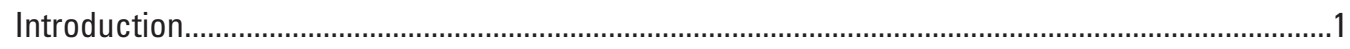

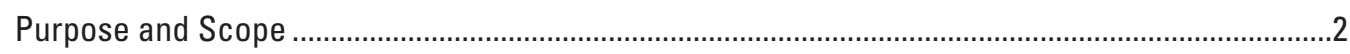

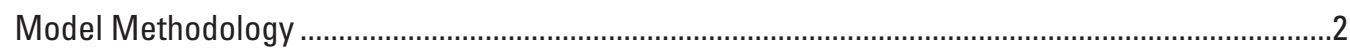

SEAWAVE-0

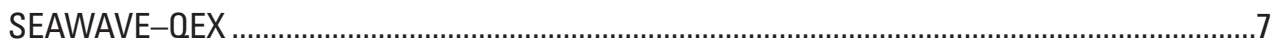

Regression Analysis and Selection of the Best-Fit Seasonal Wave .................................7

Estimation of Seasonal Standard Deviation and Serial Correlation Parameters..............9

Generation of Conditional Traces of Daily Concentration...................................................9

Estimation of Concentration Extremes using Generated Conditional Traces....................9

Examples of SEAWAVE-OEX Model Results.............................................................................10

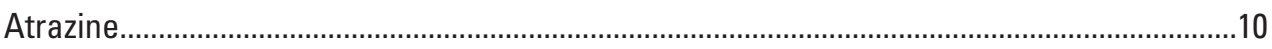

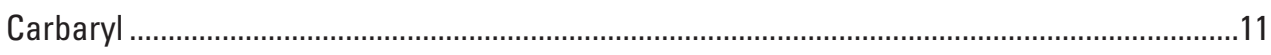

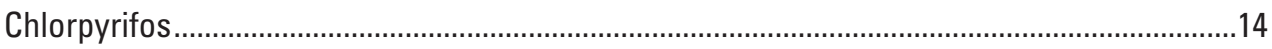

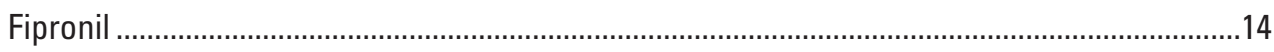

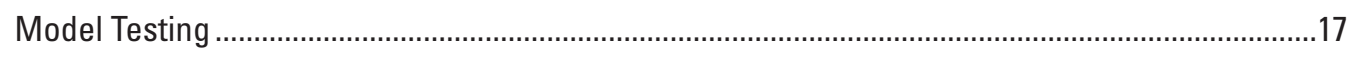

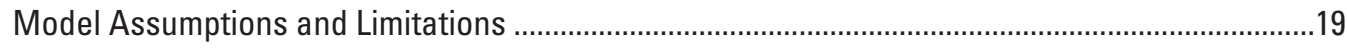

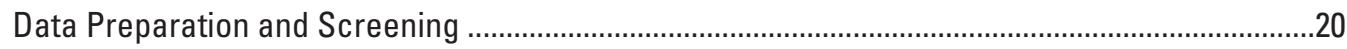

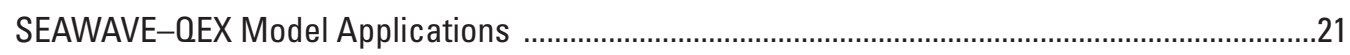

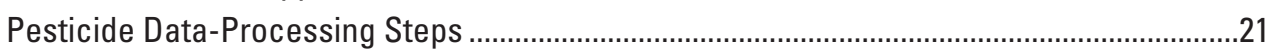

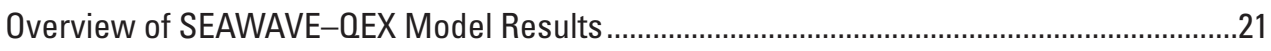

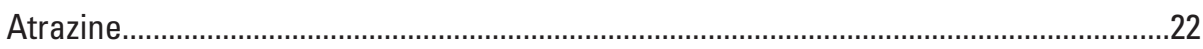

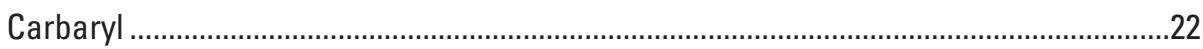

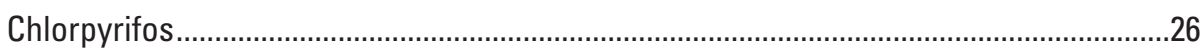

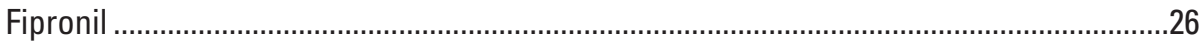

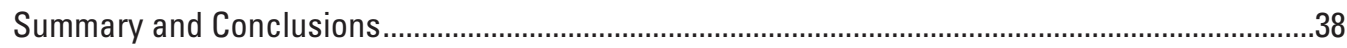

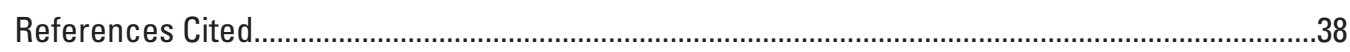

Appendix. Description of R Functions and Model Archive for Running SEAWAVE-OEX ...............41

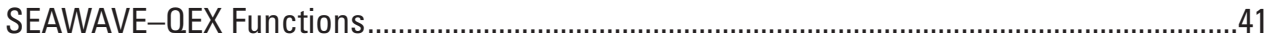

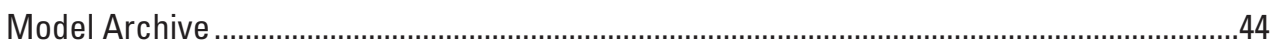

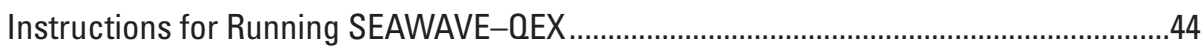

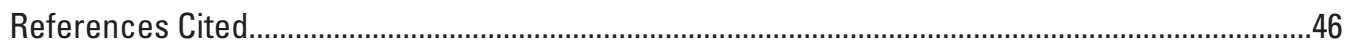




\section{Figures}

1. Graphs showing examples of seasonal waves for wave class 1, consisting of pulse input models with one application season of various durations

2. Graphs showing examples of seasonal waves for wave class 2, consisting of pulse input models with two application seasons of various durations.....

3. Graph showing daily streamflow for Sope Creek near Marietta, Georgia, for 2006-09, showing mid-term flow anomaly and short-term flow anomaly .......................................6

4. Flow chart showing SEAWAVE-QEX modeling methodology.

5. Graph showing observed atrazine concentrations, simulated conditional trace of daily concentrations, and estimated annual maximum daily concentrations for Little Buck Creek near Indianapolis, Indiana, for 1993-2002

6. Graph showing adjusted atrazine concentrations, fitted seasonal wave, and fitted seasonal standard deviation for Little Buck Creek near Indianapolis, Indiana, for 1993-2002

7. Graph showing normalized residuals from SEAWAVE-OEX model for atrazine concentration for Little Buck Creek near Indianapolis, Indiana, for 1993-2002.

8. Graph showing empirical correlogram and fitted exponential correlation function for normalized residuals from SEAWAVE-QEX model for atrazine concentration for Little Buck Creek near Indianapolis, Indiana, for 1993-2002...

9. Graph showing observed carbaryl concentrations, simulated conditional trace of daily concentrations, and estimated annual maximum daily concentrations for Kisco River near Mount Kisco, New York, for 2000-2008.

10. Graph showing adjusted carbaryl concentrations, fitted seasonal wave, and fitted seasonal standard deviation for Kisco River near Mount Kisco, New York, for 2000-2008

11. Graph showing observed chlorpyrifos concentrations, simulated conditional trace of daily concentrations, and estimated annual maximum daily concentrations for Sope Creek near Marietta, Georgia, for 1993-2002

12. Graph showing adjusted chlorpyrifos concentrations, fitted seasonal wave, and fitted seasonal standard deviation for Sope Creek near Marietta, Georgia, for 1993-2002.

13. Graph showing observed fipronil concentrations, simulated conditional trace of daily concentrations, and estimated annual maximum daily concentrations for Sope Creek near Marietta, Georgia, for 2003-12.

14. Graph showing adjusted fipronil concentrations, fitted seasonal wave, and fitted seasonal standard deviation for Sope Creek near Marietta, Georgia, for 2003-12.........16

15. Graphs showing estimated regression coefficients from SEAWAVE-QEX model results for atrazine.

16. Graphs showing estimated seasonal standard deviations and correlation time scales from SEAWAVE-QEX model results for atrazine

17. Graphs showing estimated regression coefficients from SEAWAVE-QEX model results for carbaryl 
18. Graphs showing estimated seasonal standard deviations and correlation time scales from SEAWAVE-QEX model results for carbaryl.

19. Graphs showing estimated regression coefficients from SEAWAVE-QEX model results for chlorpyrifos......

20. Graphs showing estimated seasonal standard deviations and correlation time scales from SEAWAVE-OEX model results for chlorpyrifos

21. Graphs showing estimated regression coefficients from SEAWAVE-QEX model results for fipronil.

22. Graphs showing estimated seasonal standard deviations and correlation time scales from SEAWAVE-OEX model results for fipronil

\section{Tables}

1. SEAWAVE-OEX model testing results based on simulated data from the atrazine, carbaryl, and chlorpyrifos models with record length 3 years ...

2. U.S. Geological Survey water-quality sampling sites, period of record, and number of observations used for application of SEAWAVE-QEX model for atrazine.

3. U.S. Geological Survey water-quality sampling sites, period of record, and number of observations used for application of SEAWAVE-QEX model for carbaryl.

4. U.S. Geological Survey water-quality sampling sites, period of record, and number of observations used for application of SEAWAVE-QEX model for chlorpyrifos .32

5. U.S. Geological Survey fipronil water-quality sampling sites, period of record, and number of observations used for application of SEAWAVE-QEX model 


\section{Conversion Factors}

U.S. customary units to International System of Units

\begin{tabular}{lll}
\hline \multicolumn{1}{c}{ Multiply } & By & \multicolumn{1}{c}{ To obtain } \\
\hline & Area & \\
\hline square mile $\left(\mathrm{mi}^{2}\right)$ & 2.590 & square kilometer $\left(\mathrm{km}^{2}\right)$ \\
\hline & Flow rate & \\
\hline cubic foot per second $\left(\mathrm{ft}^{3} / \mathrm{s}\right)$ & 0.02832 & cubic meter per second $\left(\mathrm{m}^{3} / \mathrm{s}\right)$ \\
\hline
\end{tabular}

\section{Supplemental Information}

Concentrations of chemical constituents in water are given in micrograms per liter ( $\mu \mathrm{g} / \mathrm{L})$.

\section{Abbreviations}

$\begin{array}{ll}\text { AMDC } & \text { annual maximum daily concentration } \\ \text { ASF } & \text { annual sampling frequency } \\ \text { CR } & \text { censoring rate } \\ \text { CTS } & \text { correlation time scale } \\ \text { maxLT-MDL } & \text { maximum long-term method detection level } \\ \text { MTFA } & \text { mid-term flow anomaly } \\ \text { NAWOA } & \text { National Water-Quality Assessment } \\ \text { NOBS } & \text { total number of pesticide observations } \\ \text { NOBSG } & \text { number of pesticide observations in a generic year } \\ \text { NUCG } & \text { number of uncensored pesticide observations in a generic year } \\ \text { NWON } & \text { National Water Quality Network } \\ \text { PUC } & \text { percent of pesticide observations that are uncensored } \\ \text { qlow50 } & \text { median concentration of low-level detections } \\ \text { RL } & \text { record length } \\ \text { SEAWAVE-0 } & \text { seasonal wave with streamflow adjustment } \\ \text { SEAWAVE-0EX } & \text { seasonal wave with streamflow adjustment with extended capability } \\ \text { SSD } & \text { seasonal standard deviation } \\ \text { STFA } & \text { short-term flow anomaly } \\ \text { USGS } & \end{array}$




\title{
Model Methodology for Estimating Pesticide Concentration Extremes Based on Sparse Monitoring Data
}

\author{
By Aldo V. Vecchia
}

\section{Abstract}

This report describes a new methodology for using sparse (weekly or less frequent observations) and potentially highly censored pesticide monitoring data to simulate daily pesticide concentrations and associated quantities used for acute and chronic exposure assessments, such as the annual maximum daily concentration. The new methodology is based on a statistical model that expresses log-transformed daily pesticide concentration in terms of a seasonal wave, flow-related variability, long-term trend, and serially correlated errors. Methods are described for estimating the model parameters, generating conditional simulations of daily pesticide concentration given sparse (weekly or less frequent) and potentially highly censored observations, and estimating concentration extremes based on the conditional simulations. The model can be applied to datasets with as few as 3 years of record, as few as 30 total observations, and as few as 10 uncensored observations. The model was applied to atrazine, carbaryl, chlorpyrifos, and fipronil data for U.S. Geological Survey pesticide sampling sites with sufficient data for applying the model. A total of 112 sites were analyzed for atrazine, 38 for carbaryl, 34 for chlorpyrifos, and 33 for fipronil. The results are summarized in this report; and, $\mathrm{R}$ functions, described in this report and provided in an accompanying model archive, can be used to fit the model parameters and generate conditional simulations of daily concentrations for use in investigations involving pesticide exposure risk and uncertainty.

\section{Introduction}

Potential human and ecological exposure to pesticides in streams and rivers commonly is evaluated by comparing measured or predicted pesticide concentrations or concentration statistics to acute and chronic water-quality benchmarks for human health and aquatic life. An accurate assessment of water-quality conditions, therefore, is dependent on characterization of the highest pesticide concentrations that may have occurred. Predicting when the highest concentrations of a pesticide may occur in a stream or river is difficult because of temporal and spatial complexity of pesticide use, pesticide transport, and hydrology. Likewise, systematic sampling, such as monthly or weekly sampling, may not accurately characterize high concentrations, especially in small, flashy streams. Exposure estimates calculated from water samples collected as frequently as every 4 days were determined to be biased low in comparison to estimates calculated from more frequent sampling (Lerch and others, 2011). Simulation analysis was used by Crawford (2004) to indicate that, for small streams, a sampling frequency of 10 times per month produced estimates of the time-weighted 99th percentile concentrations that were within 50 percent of the true concentrations most of the time. The problems with characterizing acute pesticide exposure in streams and rivers based on existing pesticide monitoring data have been described and discussed during Federal Insecticide, Fungicide, and Rodenticide Act Science Advisory Panel meetings regarding atrazine (U.S. Environmental Protection Agency, 2010a, 2010b, 2011, 2012).

To accurately characterize extreme pesticide concentrations in streams, daily sampling may be necessary during active pesticide runoff periods. The cost of sample collection and analysis prohibits this high sampling frequency for most monitoring programs. Sampling frequencies of every 4 days, 10 times per month, or more frequently also are uncommon among programs monitoring pesticide concentrations in streams. Sampling frequencies of weekly to monthly are more common and are referred to in this report as sparse monitoring data.

Approaches to estimate extreme pesticide concentrations from temporally sparse data include the use of sampling bias factors developed from high-frequency monitoring sites (U.S. Environmental Protection Agency, 2012). In this approach, concentration extremes computed from various subsamples of the high-frequency monitoring data, such as monthly or weekly sampling, are compared to the actual concentration extremes to compute bias factors. The resulting bias factors are related to available data on pesticide use, soil characteristic, and other properties of the upstream basins in order to estimate bias factors for sites with sparse sampling. However, the estimated bias factors may be highly uncertain, especially for sites that are not well represented by the small subset of sites with high-frequency sampling.

A new model methodology was developed by the U.S. Geological Survey (USGS) to address the need for using 
sparse and potentially highly censored pesticide monitoring data to estimate pesticide concentration extremes, such as the annual maximum daily concentration. The new methodology is based on a statistical model that expresses log-transformed daily pesticide concentration in terms of a seasonal wave, flow-related variability, long-term trend, and serially correlated errors. The seasonal wave models seasonality in pesticide concentration because of site-specific timing and duration of the pesticide application season. Flow-related variability is modeled using two variables that are called mid-term and short-term flow anomalies, and the variables are computed using antecedent daily discharge. The model errors are assumed to have seasonal standard deviation that can increase with increasing pesticide concentration and serial correlation that is modeled using an exponential correlation function. The statistical model can be used to simulate daily concentrations that are equal to (for days with uncensored observations) or less than (for days with censored observations) the monitoring data and that consist of model-generated values for days with no observations. The simulated daily concentrations reproduce the statistical time series characteristics of actual daily pesticide concentrations, such as serial correlation, seasonal means and variances, and flow-related variability. The simulated daily concentrations are called conditional simulations, because the simulated concentrations are conditioned on the observed monitoring data. The conditional simulations can be used to estimate exposure metrics, such as the annual maximum daily or 7-day moving average concentration, and to evaluate bias factors.

Pesticide concentration data from the USGS National Water Quality Network (NWQN) were used to develop this methodology (Vecchia and Williams-Sether, 2017). The USGS National Water-Quality Assessment (NAWQA) project maintains the NWQN with the goal of understanding the nation's water quality, including the occurrence of pesticides in natural waters (Rowe and others, 2013). A primary consideration in developing the methodology was to maximize the number of pesticide sampling sites that could be analyzed with the model, so that whenever possible, monitoring data could be used to estimate daily concentrations and associated exposure metrics. Given the short historical records, sparse sampling frequencies, and often highly censored concentration data available for many of the sites and pesticides, the methodology needed to be as simple and robust as possible while still providing unbiased and informative estimates of concentration extremes.

The starting point for the new methodology is a regression model for analyzing pesticide concentration trends developed by Vecchia and others (2008) and referred to in later applications as the seasonal wave with streamflow adjustment (SEAWAVE-Q) model. The SEAWAVE-Q model has been used in a number of studies to analyze long-term trends in annual median pesticide concentrations for agricultural, urban, and mixed land-use streams (Sullivan and others, 2009; Vecchia and others, 2009; Ryberg and others, 2010; Ryberg and Gilliom, 2015). For simulating daily pesticide concentrations, several enhancements to the SEAWAVE-Q model were required. These enhancements include algorithms for estimating serial correlation and nonconstant variance of the model errors and generating conditional simulations of daily concentrations. The enhanced model is referred to as seasonal wave with streamflow adjustment and extended capability (SEAWAVE-QEX), where the "EX" stands for extended capability to produce simulated daily concentrations.

\section{Purpose and Scope}

This report describes the SEAWAVE-QEX model methodology and associated R (R core team, 2016) functions for estimating the model parameters and generating conditional simulations of daily pesticide concentration. Model test results for selected atrazine, carbaryl, chlorpyifos, and fipronil datasets demonstrate the robust properties of the SEAWAVE-QEX model for sparse and potentially highly censored datasets. The effects of serial correlation, degree of censoring, and sampling frequency on the simulated daily concentrations and associated concentration extremes are evaluated. Model application results are summarized for atrazine, carbaryl, chlorpyrifos, and fipronil datasets for USGS pesticide sampling sites with sufficient data for applying the model. The conditional simulations of daily pesticide concentrations produced by the model can be used in investigations involving pesticide exposure risk and uncertainty.

The SEAWAVE-QEX model is intended for use with sparse (weekly or less frequent) monitoring data, and the model is not a replacement for other methods when highfrequency monitoring data are available. Simulated daily concentrations from the model are intended for use in regional to national scale assessments of pesticide exposure risk and uncertainty. Model-simulated concentrations for individual sites may be highly uncertain, and should not be used for sitespecific evaluation of concentration extremes without careful consideration of model assumptions and uncertainty.

\section{Model Methodology}

The SEAWAVE-Q model is a regression model that was used in previous investigations for analyzing seasonality, flowrelated variability, and trends in pesticide concentrations. The SEAWAVE-QEX model is an extension to the SEAWAVE-Q model to include seasonal variance and serial correlation in the model errors. The following sections describe the underlying principles and equations used for the SEAWAVE-Q and SEAWAVE-QEX models. 


\section{SEAWAVE-0}

The SEAWAVE-Q model was introduced by Vecchia and others (2008) and has been used as the basis for a number of pesticide trend analysis studies (Sullivan and others, 2009; Vecchia and others, 2009; Ryberg and others, 2010; Johnson and others, 2011; Kalkhoff and others, 2012; Ryberg and others, 2014). The model is expressed as

$$
\begin{gathered}
\log \{C(t)\}=\beta_{0}+\beta_{1} W(t)+\beta_{2} A_{M T}(t) \\
+\beta_{3} A_{S T}(t)+\beta_{4}\left(t-t_{m}\right)+\varepsilon(t)
\end{gathered}
$$

where

$$
\begin{aligned}
\log & \text { is the base-10 logarithm; } \\
C(t) & \text { is concentration, in micrograms per liter; } \\
\beta_{0}, \beta_{1}, \ldots, \beta_{4} & \text { are regression coefficients; } \\
W(t) & \text { is the seasonal wave described later in this } \\
& \text { section (dimensionless); } \\
A_{M T}(t) & \text { is the mid-term flow anomaly described later } \\
& \text { in this section (dimensionless); } \\
A_{S T}(t) & \text { is the short-term flow anomaly described later } \\
& \text { in this section (dimensionless); } \\
t & \text { is the time in decimal years; } \\
t_{m} & \text { is the midpoint of the time interval being } \\
\varepsilon(t) & \text { analyzed; and }
\end{aligned}
$$

The seasonal wave $(W)$ models seasonality in log-transformed pesticide concentration resulting from site-specific timing and duration of the pesticide application season. It is computed using a conceptual storage model in which the pesticide is being applied in the upstream basin during one or more distinct application seasons (Vecchia and others, 2008). For the sake of model simplicity, the number of distinct application seasons is assumed to be, at most, two seasons. This conceptual storage model is called a pulse input model. For this report, two classes of seasonal wave models were used, one with a single application season and the other with two distinct application seasons,

$$
\begin{gathered}
W(t) \in \text { Wave } C L 1=\{S W 1(m, h, s) ; \\
m=1,2, \ldots, 6 ; h=1,2,3,4 ; s=0, .5,1, \ldots, 11.5\} \\
W(t) \in \text { WaveCL } 2=\{S W 2(m, h, s) ; \\
m=1,2, \ldots, 12 ; h=1,2 ; s=0, .5,1, \ldots, 11.5\}
\end{gathered}
$$

\footnotetext{
where

WaveCL1 is wave class 1 ,

SW1 is a seasonal wave from class 1,

$m$ denotes the pulse input model,

$h$ is the decay rate (decimal month),

$s \quad$ is the phase shift (decimal month),

WaveCL2 is wave class 2, and

$S W 2$ is a seasonal wave from class 2.
}

In equation 2, there are 576 seasonal waves in each class (24 choices for $[m, h]$ times 24 choices for the phase shift), or a total of 1,152 seasonal waves. For notational convenience, the decimal year is divided into 12 equal-length decimal months instead of calendar months. So, for example, a phase shift of 0.5 decimal month corresponds to $1 / 24$ decimal year, or approximately $15.5(365 / 24)$ days.

Examples of the seasonal waves for WaveCLS1 are shown in figure 1 for the six choices of pulse input model $(m)$ consisting of single application seasons of durations $1,2,3,4,6$, or 9 months, and for $h=1$ (left plots) and $h=4$ (right plots). In each case the phase shift was selected so that the beginning of the application season corresponded with the end of the first decimal month. Each wave ranges from -0.5 to +0.5 , increases during the application season, and decreases exponentially (at a rate determined by $h$ ) after the end of the application season. Increasing $h$ has the effect of lessening the rate of increase during the beginning of the application season and lessening the rate of decrease after the end of the application season. In previous investigations, $h$ was referred to as the "half-life," but is an empirical coefficient and should not be confused with the chemical half-life of the pesticide. The seasonal waves are analogous to sine and cosine functions, which are often used to model seasonality in hydrologic and water-quality time series data. However, in the case of pesticides, the seasonal waves generally work much better than sine and cosine functions for representing seasonality. Examples of the seasonal waves for WaveCL2 are shown in figure 2 for the 12 choices of pulse input model and for $h=1$. Each pulse input model consists of two application seasons of durations 2,3 , or 4 months separated by nonapplication seasons of durations 2,3 , or 4 months. For pulse input models $m=1$ through $m=6$ (left plots), the application rate is the same for both seasons, and for models $m=7$ through $m=12$ (right plots), the application rate is higher for the first season. The higher $h$-values ( 3 and 4) are not included for WaveCL2 because in those cases, the double peak becomes less distinct and the waves are not easily distinguishable from waves with a single application season.

The seasonal wave generally is the most important term in the SEAWAVE-Q model (eq. 1) because the seasonal wave usually explains the most variability in concentrations compared to the other variables in the regression model. However, flow-related variability also is an important consideration. The two flow-anomaly terms in equation 1 are dimensionless variables calculated from a daily streamflow record assumed to be available from a streamflow-gaging station at or near the site being modeled. The mid-term flow anomaly (MTFA) is computed using log-transformed daily streamflow for 30 days up to and including the current time as follows:

$$
A_{M T}(t)=\frac{1}{30} \sum_{j=0}^{29}\{\log Q(\tilde{t}-j)-M\}
$$




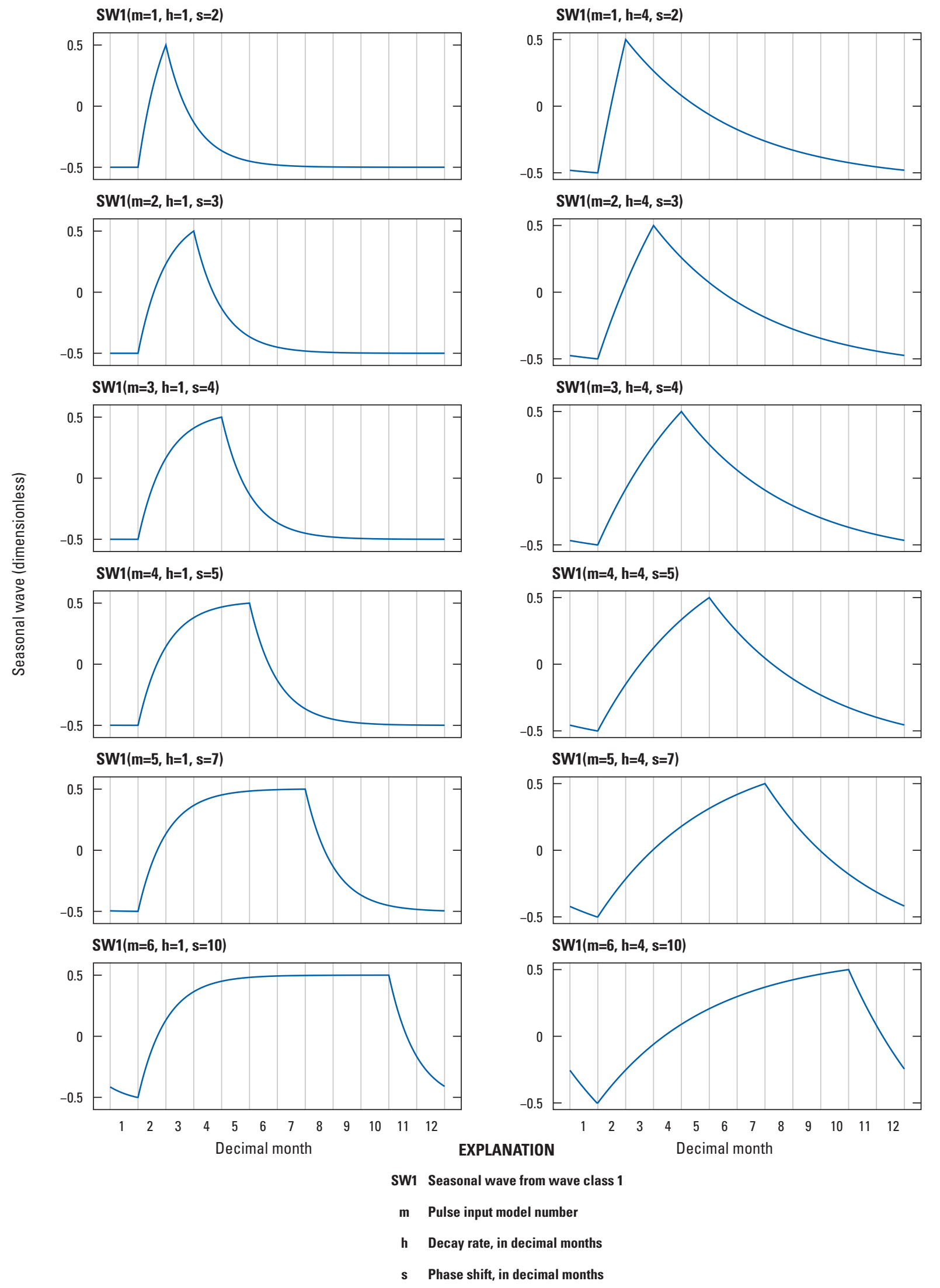

Figure 1. Examples of seasonal waves for wave class 1, consisting of pulse input models with one application season of various durations. 

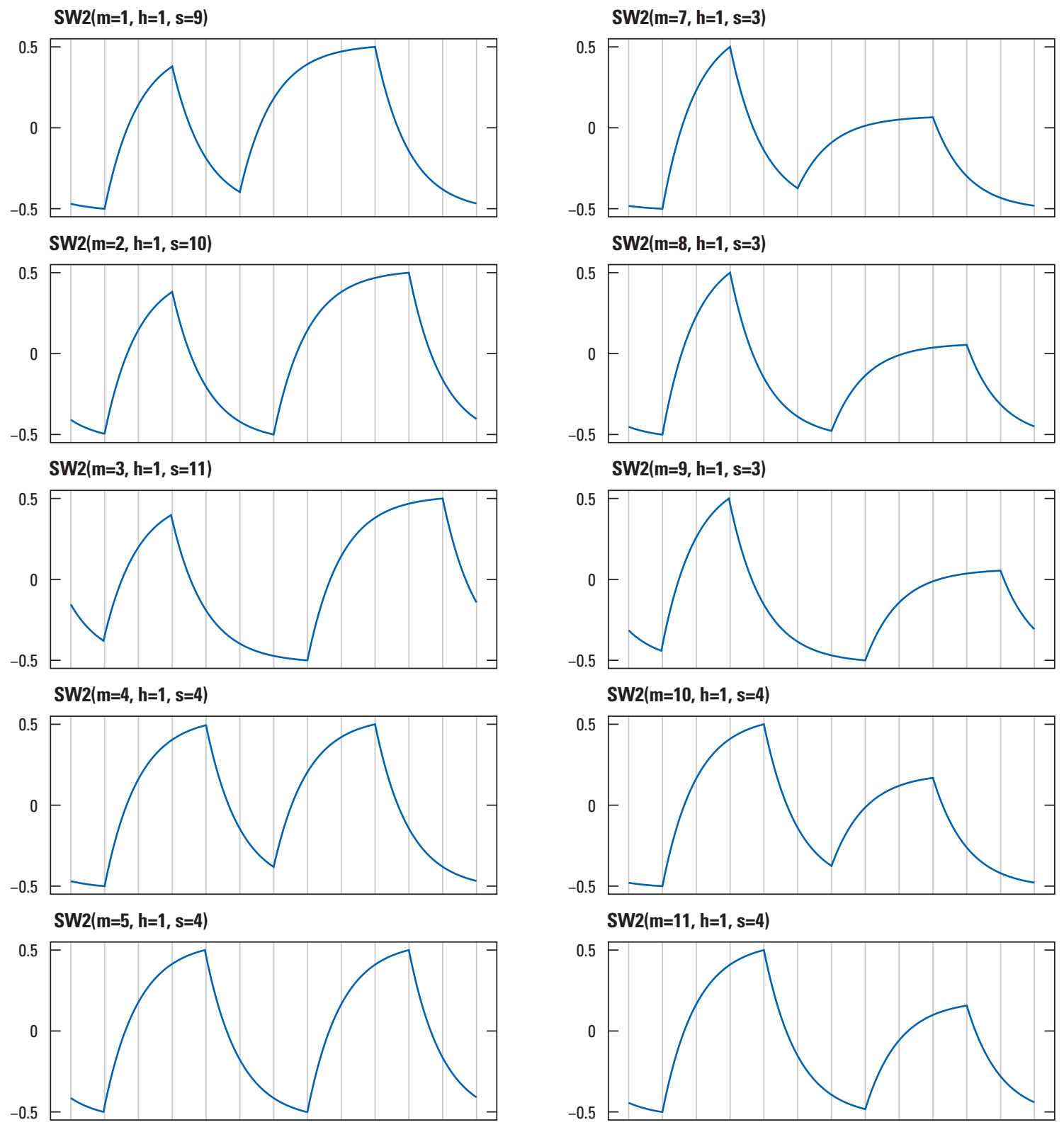

$S W 2(m=6, h=1, s=5)$
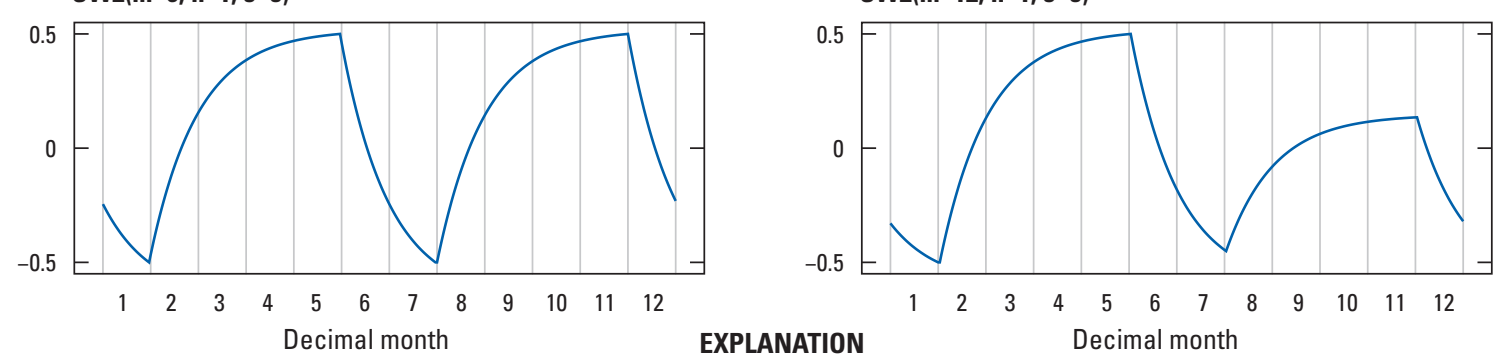

SW2 Seasonal wave from wave class 2

m Pulse input model number

h Decay rate, in decimal months

s Phase shift, in decimal months

Figure 2. Examples of seasonal waves for wave class 2, consisting of pulse input models with two application seasons of various durations. 
where

$$
\begin{aligned}
A_{M T}(t) & \text { is the MTFA; } \\
j & \text { is the time lag, in days; } \\
\log & \text { is the base-10 logarithm; } \\
Q & \text { is daily mean streamflow, in cubic feet per } \\
\tilde{t} & \text { is the integer day associated with the current } \\
M & \text { is the mean of log-transformed daily flow for } \\
& \text { the period being analyzed. }
\end{aligned}
$$

The short-term flow anomaly (STFA) is computed by subtracting the mean and the MTFA from log-transformed flow,

$$
A_{S T}(t)=\log Q(t)-M-A_{M T}(t)
$$

where

$$
A_{S T}(t) \quad \text { is the STFA. }
$$

An example of the flow anomalies for Sope Creek near Marietta, Georgia (USGS station number 02335870; U.S. Geological Survey, 2017) is shown in figure 3. MTFA captures seasonal variability relative to the long-term mean $(M)$, and STFA captures higher-frequency variability relative to the long-term mean plus MTFA. As is typically the case for small, flashy streams such as Sope Creek, STFA tends to be highly positively skewed compared to MTFA. Including both anomalies in the model generally explains more variability in pesticide concentrations than including only log-transformed flow. Often the coefficient for MTFA will be negative, indicating that dilution is the primary process at the seasonal scale, and the coefficient for STFA will be positive, indicating that shortterm increases in the hydrograph (such as from a rainfall-runoff event) cause concentrations to increase. If daily streamflow is not available, surrogate variables computed using estimated precipitation from the watershed may be considered in place of streamflow (Johnson and others, 2011). The fifth term on the right-hand side of the SEAWAVE-Q model (eq. 1) is a linear trend term for modeling gradual increases or decreases in concentration on a longer (interannual) time scale.

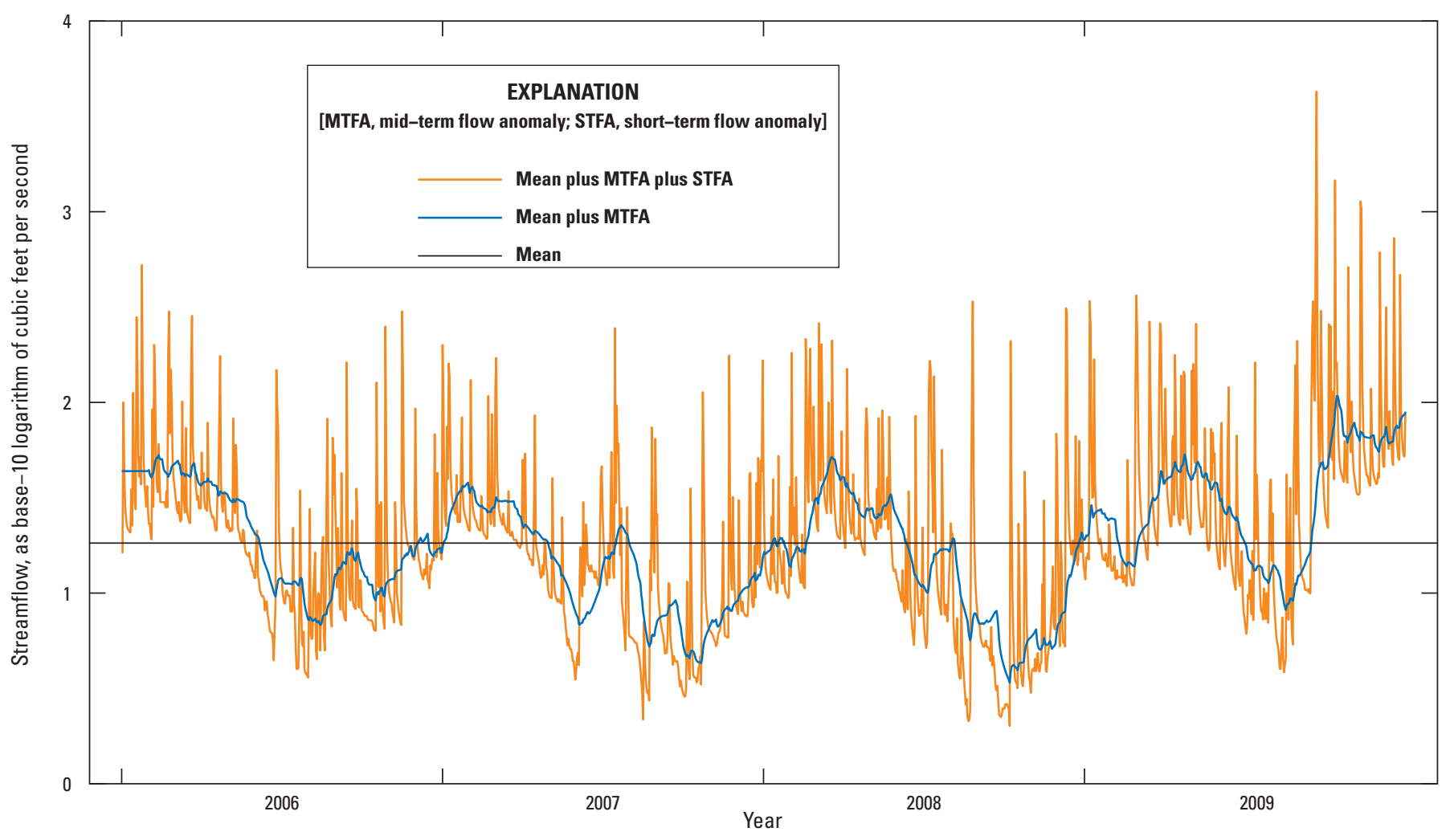

Figure 3. Daily streamflow for Sope Creek near Marietta, Georgia (U.S. Geological Survey station number 02335870) for 2006-09, showing mid-term flow anomaly and short-term flow anomaly. 


\section{SEAWAVE-0EX}

Analyzing long-term trends was the primary objective in previous investigations using the SEAWAVE-Q model. For analyzing trends with sparse monitoring data, the error term in equation 1 generally can be assumed to consist of independent normal random variables with constant variance. However, for the objective of this study, namely simulating daily concentrations, the properties of the error term needed to be more carefully considered. In particular, nonconstant (seasonal) variance as well as serial correlation between errors for closely spaced observations are important considerations for simulating realistic daily concentrations.

The SEAWAVE-QEX model consists of the SEAWAVE$Q$ model (eq. 1) modified to include seasonal variance and serial correlation in the model errors,

$$
\begin{gathered}
\log \{C(t)\}=\beta_{0}+\beta_{1} W(t)+\beta_{2} A_{M T}(t) \\
+\beta_{3} A_{S T}(t)+\beta_{4}\left(t-t_{m}\right)+S S D(t) Z(t) \\
S S D(t)=\sigma[1+\alpha W(t)]^{1 / 2}
\end{gathered}
$$

where

$\begin{aligned} \log & \text { is the base-10 logarithm; } \\ C(t) & \text { is concentration, in micrograms per liter; } \\ \beta_{0}, \beta_{1}, \ldots, \beta_{4} & \text { are regression coefficients; } \\ W(t) & \text { is a seasonal wave (eq. 2); } \\ A_{M T}(t) & \text { is the mid-term flow anomaly (eq. 3); } \\ A_{S T}(t) & \text { is the short-term flow anomaly (eq. 4); } \\ t & \text { is the time, in decimal years; } \\ t_{m} & \text { is the midpoint of the time interval being } \\ S S D(t) & \text { is the seasonal standard deviation } \\ \sigma>0 & \text { (dimensionless); } \\ 0 \leq \alpha<2 & \text { is a seasonal standard deviation parameter; } \\ Z(t) & \text { is the normalized model error. }\end{aligned}$

The normalized model errors are assumed to have a normal distribution with mean zero, variance one, and serial correlation function

$$
\operatorname{Corr}(k)=E V[Z(\tilde{t}) Z(\tilde{t}+k)]=e^{-|k| / C T S}
$$

where

$\begin{aligned} \operatorname{Corr}(k) & \text { is the serial correlation function; } \\ k & \text { is the time lag, in days, between observations; } \\ E V[.] & \text { denotes expected value; } \\ Z & \text { is the normalized model error (eq. 5); } \\ \tilde{t} & \text { is the integer day associated with decimal } \\ & \text { time } t ; \\ e T S>0 & \text { is Euler's constant; and }\end{aligned}$

The correlation function (eq. 7) is an exponential correlation function that is parameterized in terms of the correlation time scale $(C T S)$, which is the time lag for which the correlation equals $e^{-1}$, or approximately 0.37 . The correlation between observations separated by 1 day, or lag-1 correlation, equals $e^{-1 / \mathrm{CTS}}$. For example, a 15-day CTS is equivalent to a lag-1 correlation of $e^{-1 / 15}=0.936$. The rationale for using an exponential correlation function is discussed later in the "Examples of SEAWAVE-QEX Model Results" section.

The methodology for estimating the SEAWAVE-QEX model parameters, generating conditional simulations of daily pesticide concentration, and using the conditional simulations for estimating pesticide concentration extremes is summarized in figure 4 . The first step in analyzing a pesticide dataset for a particular site is to prepare the data for analysis and determine if the data are sufficient for applying the SEAWAVE-QEX model (fig. 4). This step will be explained in detail in the "Data Preparation and Screening" section of this report. The remaining steps of the methodology are described in nontechnical terms in the remainder of this section, and examples are provided in the "Examples of SEAWAVE-QX Model Results" section to illustrate model output and interpretation. Details of the methodology and self-contained R code for completing the computations are described in the appendix.

\section{Regression Analysis and Selection of the Best- Fit Seasonal Wave}

The second step of the analysis is to estimate the regression coefficients $\left(\beta_{0}, \beta_{1}, \ldots, \beta_{4}\right.$ in equation 5$)$ and select the best-fit seasonal wave (fig. 4). For this step, the seasonal standard deviation (SSD) is assumed to be constant $(\alpha=0$ in equation 6) and correlation is ignored $(C T S=0$ in equation 7 , equivalent to uncorrelated observations). Censored regression (survreg function in the survival library in R) is used to estimate the regression coefficients for each of the 1,152 choices for the seasonal wave (eq. 2). The seasonal wave with the largest value of the likelihood function is selected as the best-fit seasonal wave. Fitted values for log-transformed concentration are computed from equation 5 with the estimated regression coefficients in place of the true coefficients and the normalized errors equal to zero as follows:

$$
F V\left(t_{i}\right)=b_{0}+b_{1} W *\left(t_{i}\right)+b_{2} A_{M T}\left(t_{i}\right)+b_{3} A_{S T}\left(t_{i}\right)+b_{4}\left(t_{i}-t_{m}\right)
$$

where

$F V\left(t_{i}\right) \quad$ is the fitted value of log-transformed concentration for the $i$ th observation, $t_{i} \quad$ is the observation time for the $i$ th observation, $b_{0}, b_{1}, \ldots, b_{4} \quad$ are the estimated regression coefficients, and $W^{*}\left(t_{i}\right) \quad$ is the best-fit seasonal wave.

The fitted values represent variability in log-transformed concentration that is explained by the seasonal wave, the flow anomalies, and the trend. The regression residuals are 


\section{Analysis step}

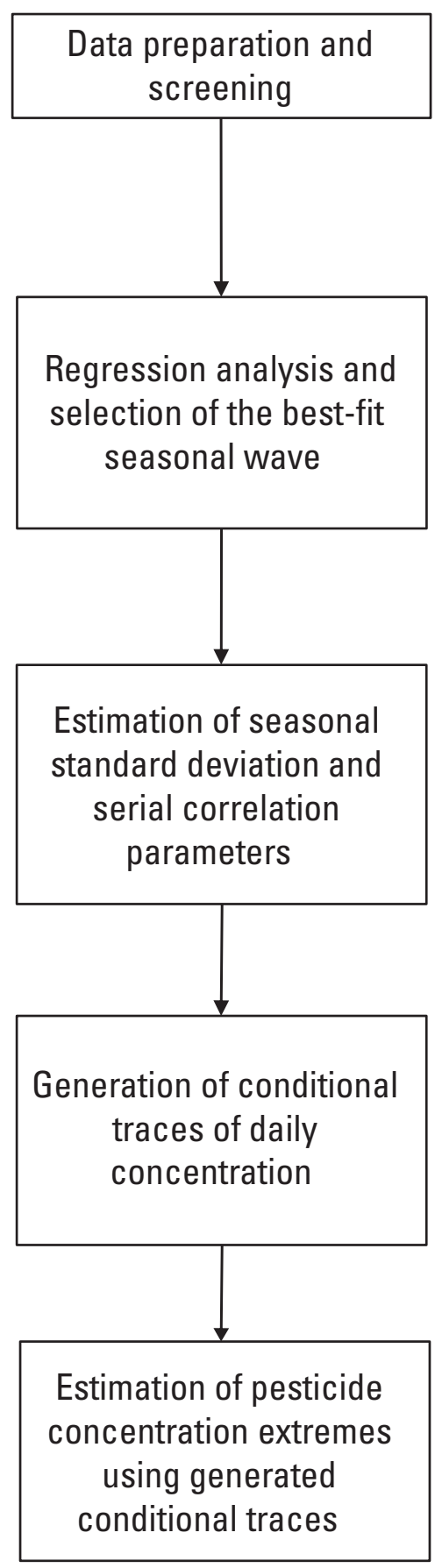

\section{Description}

- Download daily discharge data and compute flow anomalies

- Merge concentration data and flow anomalies

- Determine appropriate period of record

- Determine if data meet minimum screening requirements

- Ignore serial correlation and assume constant seasonal standard deviation $(\alpha=0)$

- Estimate regression coefficients for seasonal wave, flow anomalies, and trend

- Choice of 1,152 seasonal waves

- Best-fit seasonal wave (largest likelihood function) selected

- Compute fitted values from regression equation

- Compute regression residuals (includes censored values)

- Using regression residuals, compute maximum pseudo-likelihood estimates of seasonal standard deviation parameters $(\sigma$ and $\alpha$ ) and correlation time scale (CTS)

- Divide regression residuals by estimated seasonal standard deviation to obtain normalized residuals (includes censored values)

- Generate values for censored normalized residuals

- Generate normalized residuals for days with no observations

- Multiply normalized residuals by seasonal standard deviation and add fitted values

- Reverse log transformation

- Repeat to obtain specified number of equally likely conditional traces

- Compute simulated values of concentration extremes (for example, annual maximum daily concentrations or bias factors) from the simulated traces of daily concentration

- Use simulated values to obtain point estimates (mean of simulated values) or confidence intervals (quantiles of simulated values)

\section{R user library (UL) or SEAWAVE-0EX function}

waterData (UL)

swaveqexMerge

survival (UL)

swaveqexFit tmvtnorm (UL) swaveqexFit swaveqexPESTpdo estsigxx Evalmodlikxx Compwaveconvxx evalmodlikxx tmvtnorm (UL) swaveqexCSIM impcenvals condsim

Figure 4. SEAWAVE-OEX modeling methodology. 
obtained by subtracting the fitted values from the observations as follows:

$$
R R\left(t_{i}\right)=\left\{\begin{array}{c}
\log \left\{C\left(t_{i}\right)\right\}-F V\left(t_{i}\right), \\
\text { if the } i \text { th observation is not censored } \\
\log \left\{L_{i}\right\}-F V\left(t_{i}\right), \\
\text { if the } i \text { th observation is censored }
\end{array}\right\}
$$

where

$$
\begin{gathered}
R R\left(t_{i}\right) \quad \begin{array}{l}
\text { is the regression residual for the } i \text { th } \\
\text { observation, and }
\end{array} \\
L_{i} \quad \text { is the censoring limit for the } i \text { th observation if } \\
\text { the observation is censored }\left(C\left(t_{i}\right)<L_{i}\right) .
\end{gathered}
$$

Note that regression residuals for censored observations also are censored values. The regression residuals represent variability in log-transformed concentration remaining after removing variability explained by the seasonal wave, the flow anomalies, and the trend. For isolating the seasonal variability, it is useful to compute adjusted concentrations by removing the flow-related variability and the trend as follows:

$$
A C\left(t_{i}\right)=\left\{\begin{array}{c}
\log \left\{C\left(t_{i}\right)\right\}-b_{2} A_{M T}\left(t_{i}\right)-b_{3} A_{S T}\left(t_{i}\right)-b_{4}\left(t_{i}-t_{m}\right), \\
\text { if } i \text { th observation is not censored; } \\
\log \left\{L_{i}\right\}-b_{2} A_{M T}\left(t_{i}\right)-b_{3} A_{S T}\left(t_{i}\right)-b_{4}\left(t_{i}-t_{m}\right), \\
\text { if } i \text { th observation is censored }
\end{array}\right\}
$$

where

$$
\begin{gathered}
A C\left(t_{i}\right) \quad \begin{array}{l}
\text { is the adjusted concentration for the } i \text { th } \\
\text { observation. }
\end{array}
\end{gathered}
$$

\section{Estimation of Seasonal Standard Deviation and Serial Correlation Parameters}

The third step in the analysis is to estimate the SSD parameters $(\sigma$ and $\alpha)$ in equation 6 and the correlation time scale (CTS) in equation 7 (fig. 4). These parameters are estimated using the regression residuals (eq. 9) along with an estimation method known as maximum pseudo-likelihood estimation (see appendix). The normalized residuals are computed by dividing the regression residuals by the estimated SSD as follows:

$$
N R\left(t_{i}\right)=R R\left(t_{i}\right) / S S D^{*} ; S S D^{*}=\sigma^{*}\left[1+\alpha^{*} W^{*}\left(t_{i}\right)\right]^{1 / 2}
$$

where

$$
\begin{array}{cl}
N R\left(t_{i}\right) & \text { is the normalized residual for the } i \text { th } \\
\text { observation, }
\end{array}
$$

The normalized residuals, which are estimates of the normalized model errors ( $Z$ in eq. 5), are useful for model diagnostic purposes.

\section{Generation of Conditional Traces of Daily Concentration}

The fourth step in the analysis is to generate conditional traces of daily concentration given the parameter estimates, fitted values, and normalized residuals from the previous steps (fig. 4). First, a conditional trace of the normalized residuals is generated as described in the appendix. The generated values of the normalized residuals for days with uncensored observations are equal to the observed values. However, normalized residuals for days with censored observations and normalized residuals for days with no observations differ for each trace and are randomly generated in such a way that the statistical time series characteristics of the data are maintained. After generating a conditional trace of the normalized residuals, the normalized residuals are multiplied by the estimated SSD and added to the fitted values from the regression model to obtain generated values for log-transformed concentration. Note that the fitted values from the regression model can be computed for each day of record provided there are no missing values for the flow anomalies. If some days are missing flow anomalies, the generated concentrations for those days also will be missing values. After generating a conditional trace for log-transformed concentration, the log transformation is reversed to obtain a conditional trace of untransformed concentration. The generated daily concentrations from the conditional trace are equal to the observed concentrations for days with uncensored observations; are less than the censoring limit for days with censored observations; and for days with no observations, the generated concentrations should be indistinguishable (statistically) from values that could have occurred if samples had been collected daily. The trace is referred to as "conditional" trace because it is conditioned on the observed concentrations. The process for generating a conditional trace is repeated to obtain a specified number $(\mathrm{N})$ of randomly generated conditional traces, where guidelines for specifying $\mathrm{N}$ are discussed in the next step.

\section{Estimation of Concentration Extremes using Generated Conditional Traces}

The fifth step in the analysis is to use the conditional traces of daily concentration from the previous step to estimate pesticide concentration extremes (fig. 4). This step depends on the particular objectives of the analysis. For example, one objective might be to obtain an estimated value or confidence interval for the annual maximum daily concentration (AMDC). For this application, it may be appropriate to generate $\mathrm{N}=100$ conditional traces, where each trace consists of $n$ years of generated daily values and $n$ is the record length $(\mathrm{RL})$. For each year of record, there are $\mathrm{N}=100$ simulated 
values for the AMDC. The mean of the 100 simulated values is the estimated value for the AMDC and the 10th and 90th percentiles of the simulated values provide an approximate 80 percent confidence interval for the AMDC. If a higher confidence level is required, generating more than 100 traces may be necessary. For example, to obtain a 95 percent confidence interval, $\mathrm{N}=250$ traces may be required. Generally, to obtain a confidence level of $\mathrm{P}$ percent, $\mathrm{N}(1-\mathrm{P} / 100)$ should be at least 20 to obtain a reasonable confidence interval. The same technique described for AMDC can be used to estimate other exposure metrics, such as the annual maximum 7-day or 30-day moving average concentration. Another objective may be to obtain estimates of bias factors (U.S. Environmental Protection Agency, 2012). For estimating bias factors, $N=50$ conditional traces may be sufficient provided a constant bias factor for a particular site is used, rather than bias factors that vary by year. In the former case there would be 50 times $\mathrm{n}$ generated values of the bias factors (for all $\mathrm{n}$ simulation years combined), or at least 150 values if the RL (n) is at least 3 years.

\section{Examples of SEAWAVE-0EX Model Results}

Several examples are presented in this section to illustrate the SEAWAVE-QEX modeling methodology and to help reinforce the definitions, terminology, and interpretation of model output. Details of the data sources, sample collection and preservation methods, laboratory analytical methods, and other data considerations are described later in the "SEAWAVEQEX Model Applications" section and are not important for purposes of this section.

\section{Atrazine}

The first example is for atrazine concentration for Little Buck Creek near Indianapolis, Indiana (USGS station number 03353637) for 1993-2002 (fig. 5). This site has a drainage area of 44 square kilometers $\left(\mathrm{km}^{2}\right)$ and mixed urban and agricultural (mostly corn and soybeans) land use, and atrazine

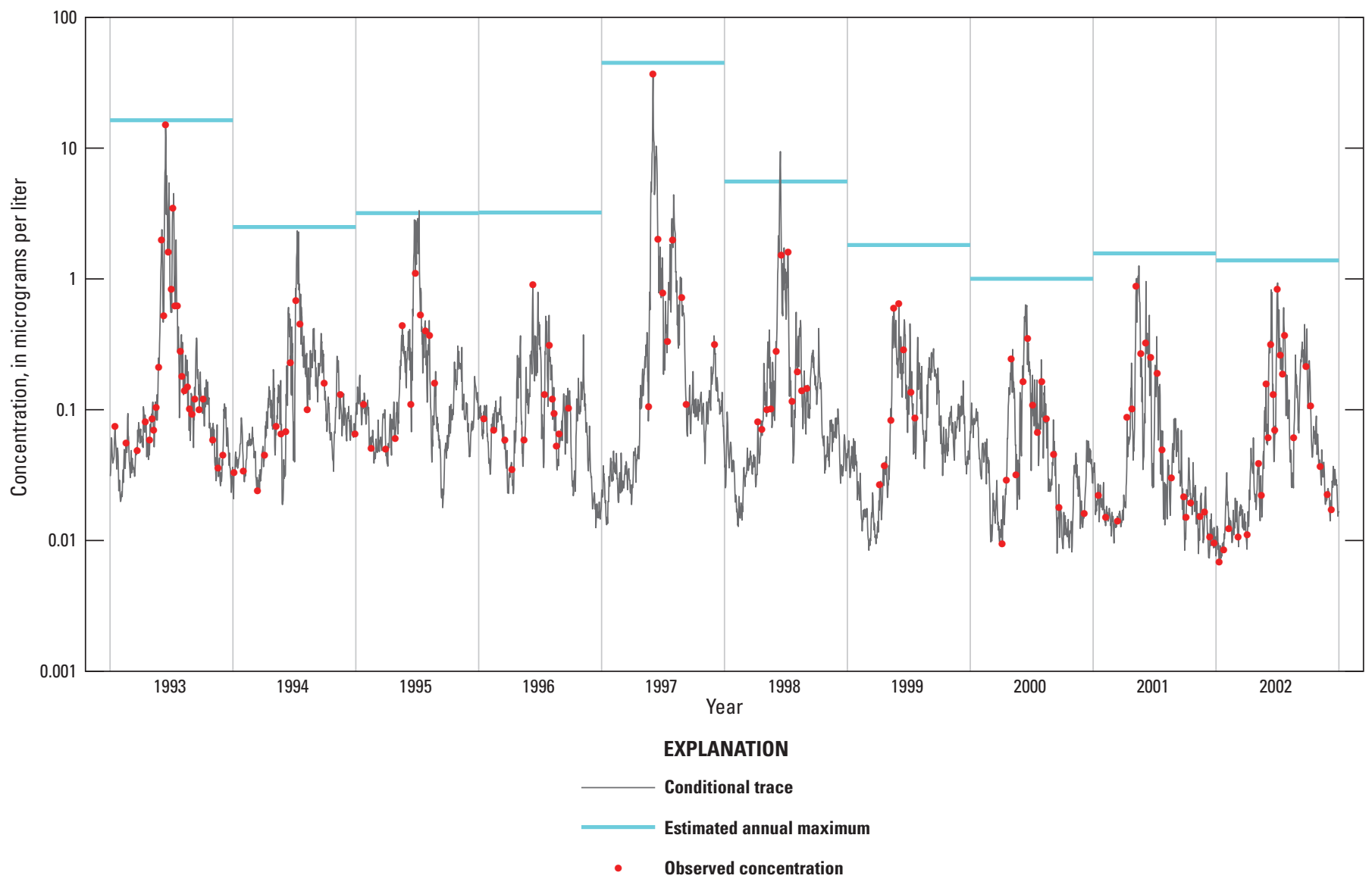

Figure 5. Observed atrazine concentrations, simulated conditional trace of daily concentrations, and estimated annual maximum daily concentrations for Little Buck Creek near Indianapolis, Indiana (U.S. Geological Survey station number 03353637) for 1993-2002. 
is an agricultural herbicide used mostly on corn (Ryberg and others, 2010). The red points in figure 5 indicate observed concentrations. There are no censored values for this dataset. The dataset has 148 observations, or an average annual sampling frequency (ASF) of about 15 observations per year. However, ASF was variable, ranging from 28 samples in 1993 to 8 samples in 1999. The grey line in figure 5 shows a single conditional trace (out of 100) generated from the SEAWAVE-QEX model, which is equal to the observed atrazine concentration values during observation days and hypothetical randomly generated values for the remaining days. The horizontal blue lines show the estimated annual maximum concentration for each year, which is the average of the annual maxima for all 100 conditional traces.

The best-fit seasonal wave $\left(W^{*}\right)$, estimated linear regression coefficients $\left(b_{0}, b_{1}, \ldots, b_{4}\right)$, estimated SSD parameters $\left(\sigma^{*}\right.$ and $\alpha^{*}$ ), and estimated CTS (CTS*) for this dataset were as follows:

$$
\begin{aligned}
& W^{*}=S W 1(m=3, h=2, s=6) ; \\
& b_{0}=-0.88, b_{1}=1.35, b_{2}=-0.30, b_{3}=0.16, b_{4}=-0.06 ; \text { and } \\
& \sigma^{*}=0.379, \alpha^{*}=1.11, C T S^{*}=15.1 .
\end{aligned}
$$

The regression coefficients for the seasonal wave (1.35), MTFA (-0.30), STFA (0.16), and trend (-0.06) were significant ( $p$-values less than 0.05 ; note that the $p$-values are approximate because they are based on assumption of constant variance and no serial correlation). The downward trend probably resulted from increasing urban land use (and decreasing corn acreage) during the analysis period (Ryberg and others, 2010). The best-fit seasonal wave $\left(b_{0}+b_{1} W^{*}\right)$ is shown in figure 6 . For this example, $W^{*}$ was from wave class 1 and the pulse input model consisted of a 3-month application season $(m=3)$, decay rate $(h)$ of 2 months, and phase shift $(s)$ of 6 months. The application season extends from early April through early July. The points in figure 6 show adjusted concentrations (eq. 10) to highlight the seasonal variability along with the fitted seasonal wave. Observations are shown for all years combined. Also shown are lines at plus and minus 2 times the estimated SSD $\left(b_{0}+b_{1} W^{*+}+-2\right.$ $\left.\sigma^{*}\left(1+\alpha^{*} W^{*}\right)^{1 / 2}\right)$. For these data, $\alpha^{*}=1.11$, thus the seasonal standard deviation was considerably higher during the application season than during other times of the year.

The normalized residuals (eq. 11) for this example are shown in figure 7. No obvious problems with lack-of-fit (nonconstant mean or variance, skewness, outliers, and so on) are indicated, with the possible exception of three residuals equal to 3 , which may be outliers. In the estimation algorithms described in the appendix, to reduce the effects of potential outliers on the parameter estimates, the normalized residuals were truncated at plus or minus 3 . In this case, three of the residuals were truncated at plus 3 . Further examination of the simulation results indicated that only one of the truncated residuals, during June 1997, may have adversely affected the estimated annual maximum concentration for that year. Further examination of the data for that observation may be warranted. Note that serial correlation may produce apparent clustering in the normalized residuals, and such clustering should not adversely affect the results. In this case, clustering is apparent during May through August, during which concentrations (and sampling frequencies) were highest. The fitted exponential correlation function (eq. 7) for this example is shown in figure 8. The estimated CTS for this example was about 15 days $\left(C T S^{*}=15.1\right)$. The points in figure 8 show empirical estimates of the correlation function at selected lags and were computed directly from the normalized residuals using methods for estimating the empirical variogram (Cressie, 1991, p. 74) and converting the empirical variogram to the empirical correlogram. The exponential correlation function provided a reasonable approximation to the empirical correlogram for this example. The exponential correlation function has been found generally to be a reasonable approximation to the empirical correlogram for datasets (such as this one) that have sampling frequencies sufficient for computing the empirical correlogram for short time lags. The exponential correlation function has two features that have considerable influence on the conditional simulations - the assumption that the correlation function approaches one as the time lag approaches zero and the assumption of an exponential decay rate as the time lag increases. Measurement error (differences between actual and measured concentrations because of factors such as sample collection and preservation techniques or laboratory analytical techniques) could cause a discontinuity in the correlation function at lag zero. For USGS pesticide data analyzed for this report, measurement error generally can be considered to be negligible in relation to natural variability.

\section{Carbaryl}

The next example is for carbaryl concentration for Kisco River below Mount Kisco, New York (USGS station number 01374987) for 2000-2008 (fig. 9). This site has a drainage area of $49 \mathrm{~km}^{2}$ and mixed urban and agricultural land use, and carbaryl is an insecticide with many urban and agricultural uses (Ryberg and others, 2010). The dataset includes 186 observations with ASF ranging from 28 in 2002 to 15 in 2008. This example is typical of the high censoring rate (CR) for many pesticides. About 71 percent (134) of the observations were censored. The censored values in figure 9 and in subsequent figures are shown as open circles; and, for plotting purposes, the values are equal to the randomly generated value from the conditional trace. The best-fit seasonal wave model, estimated linear regression coefficients, estimated SSD parameters, and estimated CTS for this site were as follows:

$$
\begin{aligned}
& W^{*}=S W 1(m=4, h=3, s=6.5) ; \\
& b_{0}=-2.42, b_{1}=0.906, b_{2}=0.17, b_{3}=0.75, b_{4}=0.04 ; \text { and } \\
& \sigma^{*}=0.542, \alpha^{*}=0, C T S^{*}=4.7 .
\end{aligned}
$$

The regression coefficients for the seasonal wave (0.906) and STFA (0.75) were significant. The best-fit seasonal wave for this example (fig. 10) was from wave class 1 and consisted of a 4-month application season from late March through late July ( $m=4$ and $s=6.5$ ) and a decay rate of 3 months $(h=3)$. The estimated SSD was constant $\left(\alpha^{*}=0\right)$ and the estimated CTS was about 5 days $\left(C T S^{*}=4.7\right)$. Note that a lower bound of zero was assumed for the estimated value of $\alpha\left(\alpha^{*} \geq 0\right)$ and for this example the estimate was equal to the lower bound. 


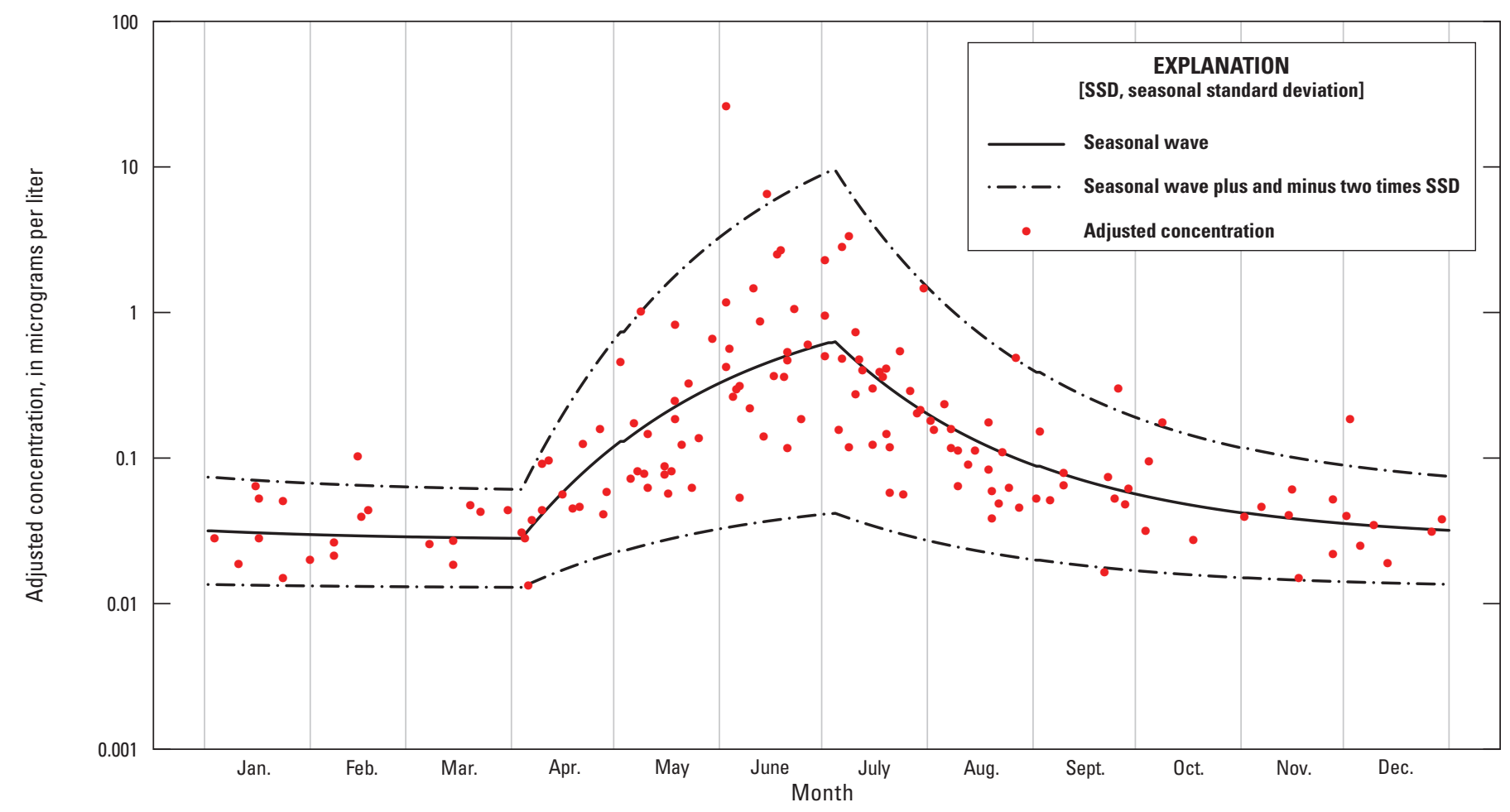

Figure 6. Adjusted (minus trend and flow-related variability) atrazine concentrations, fitted seasonal wave, and fitted seasonal standard deviation for Little Buck Creek near Indianapolis, Indiana (U.S. Geological Survey station number 03353637) for 1993-2002.

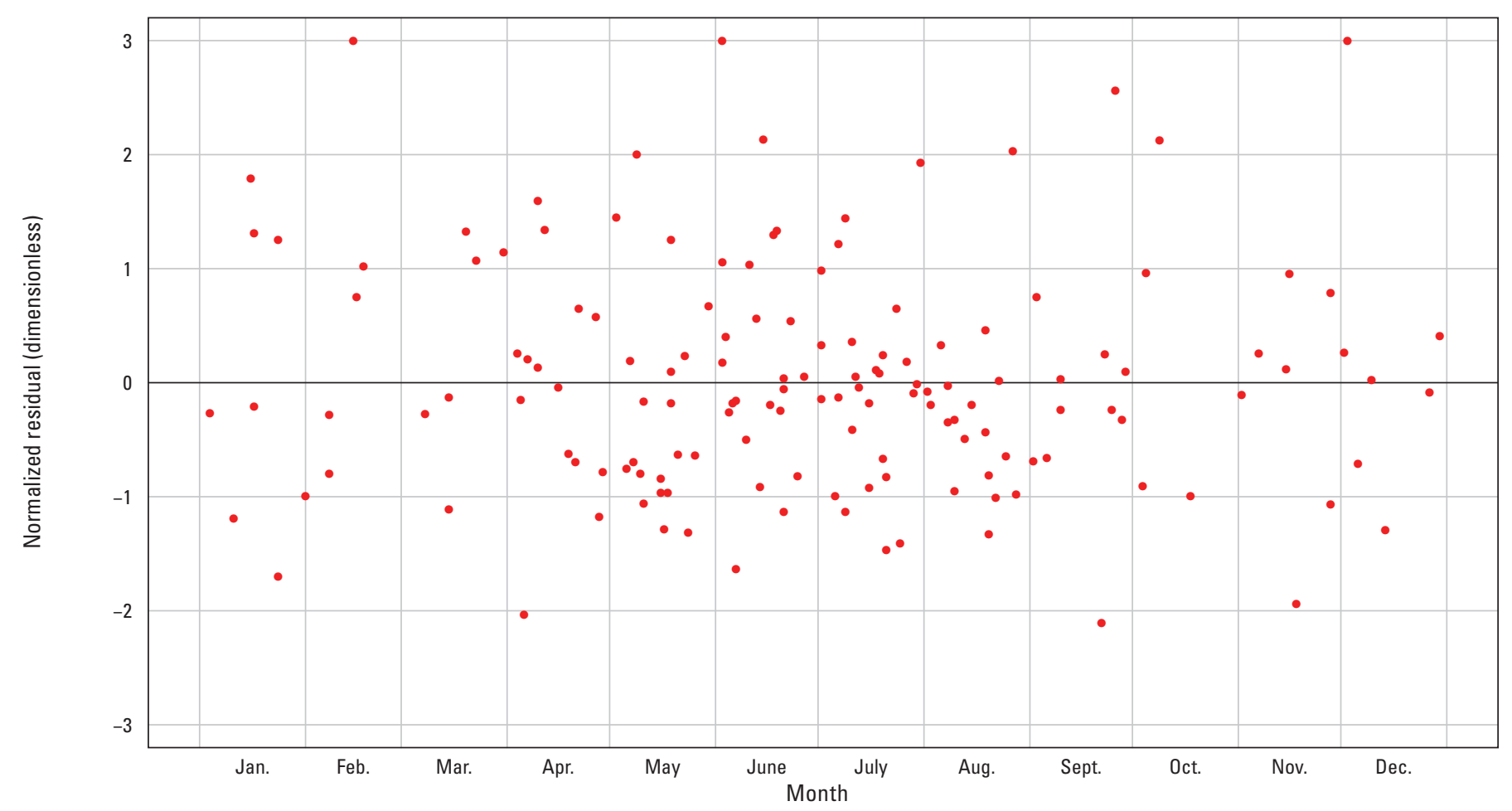

Figure 7. Normalized residuals from SEAWAVE-OEX model for atrazine concentration for Little Buck Creek near Indianapolis, Indiana (U.S. Geological Survey station number 03353637) for 1993-2002. 


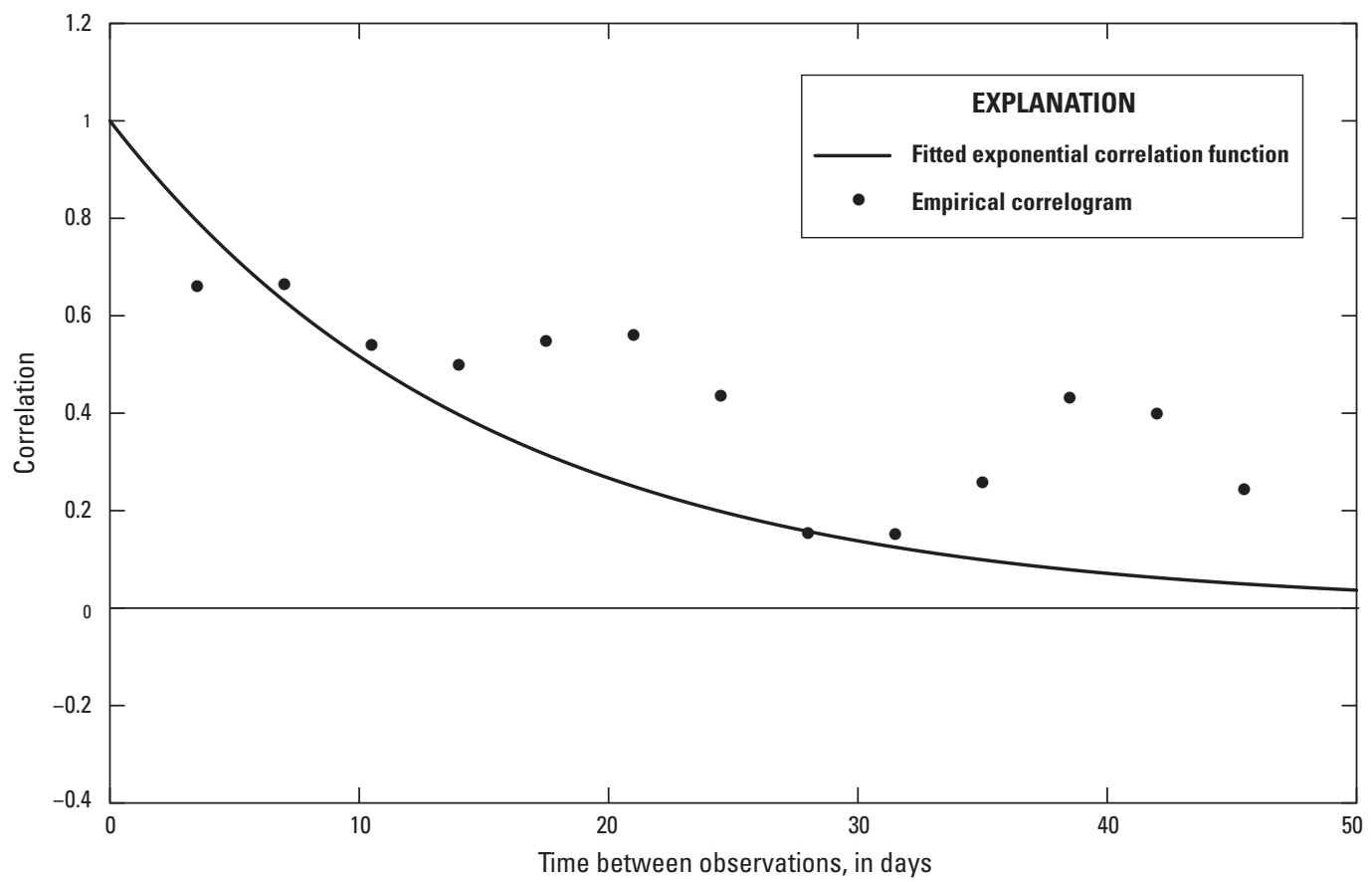

Figure 8. Empirical correlogram and fitted exponential correlation function for normalized residuals from SEAWAVEQEX model for atrazine concentration for Little Buck Creek near Indianapolis, Indiana (U.S. Geological Survey station number 03353637) for 1993-2002.

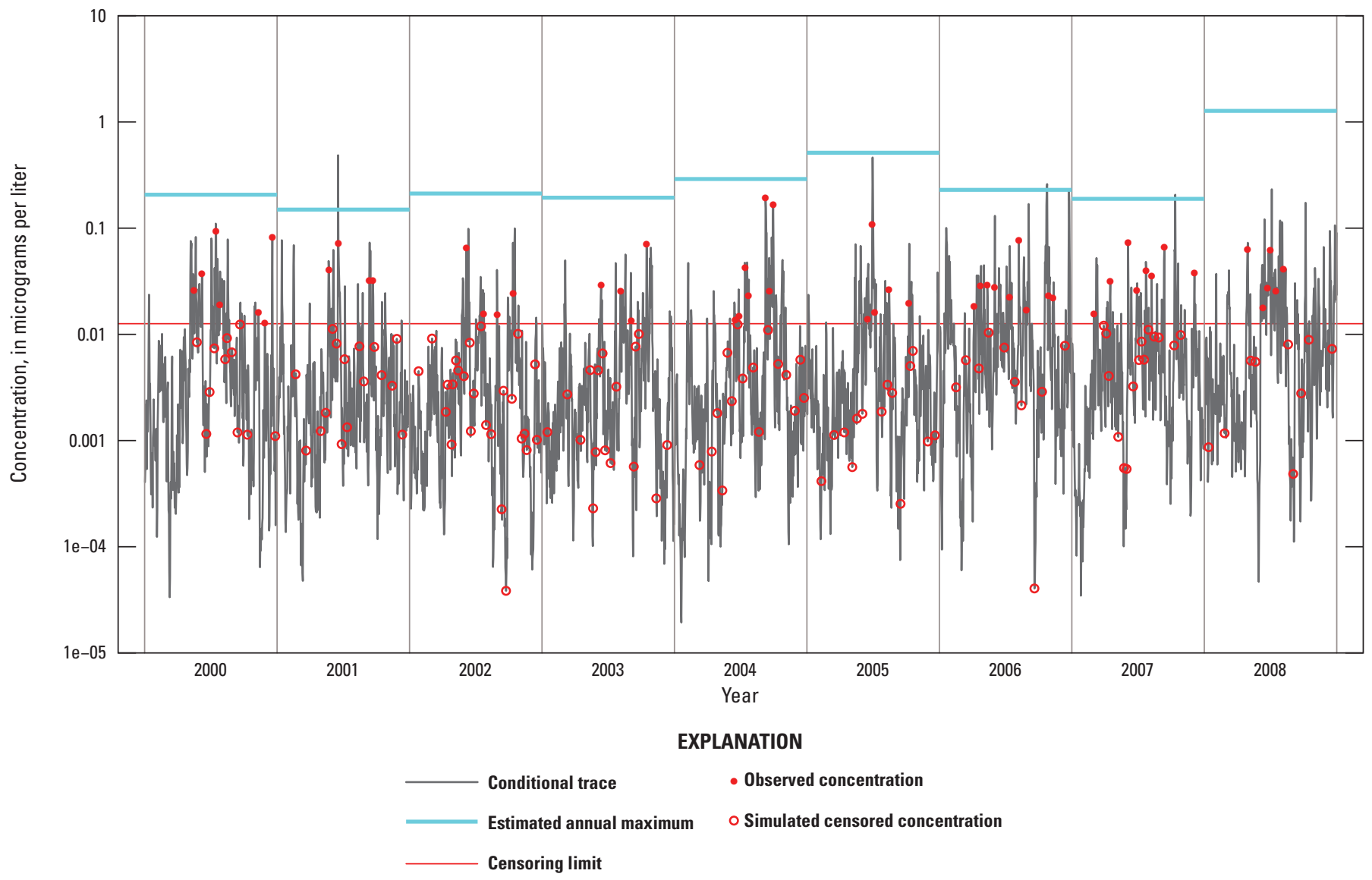

Figure 9. Observed carbaryl concentrations, simulated conditional trace of daily concentrations, and estimated annual maximum daily concentrations for Kisco River near Mount Kisco, New York (U.S. Geological Survey station number 01374987) for 2000-2008. 


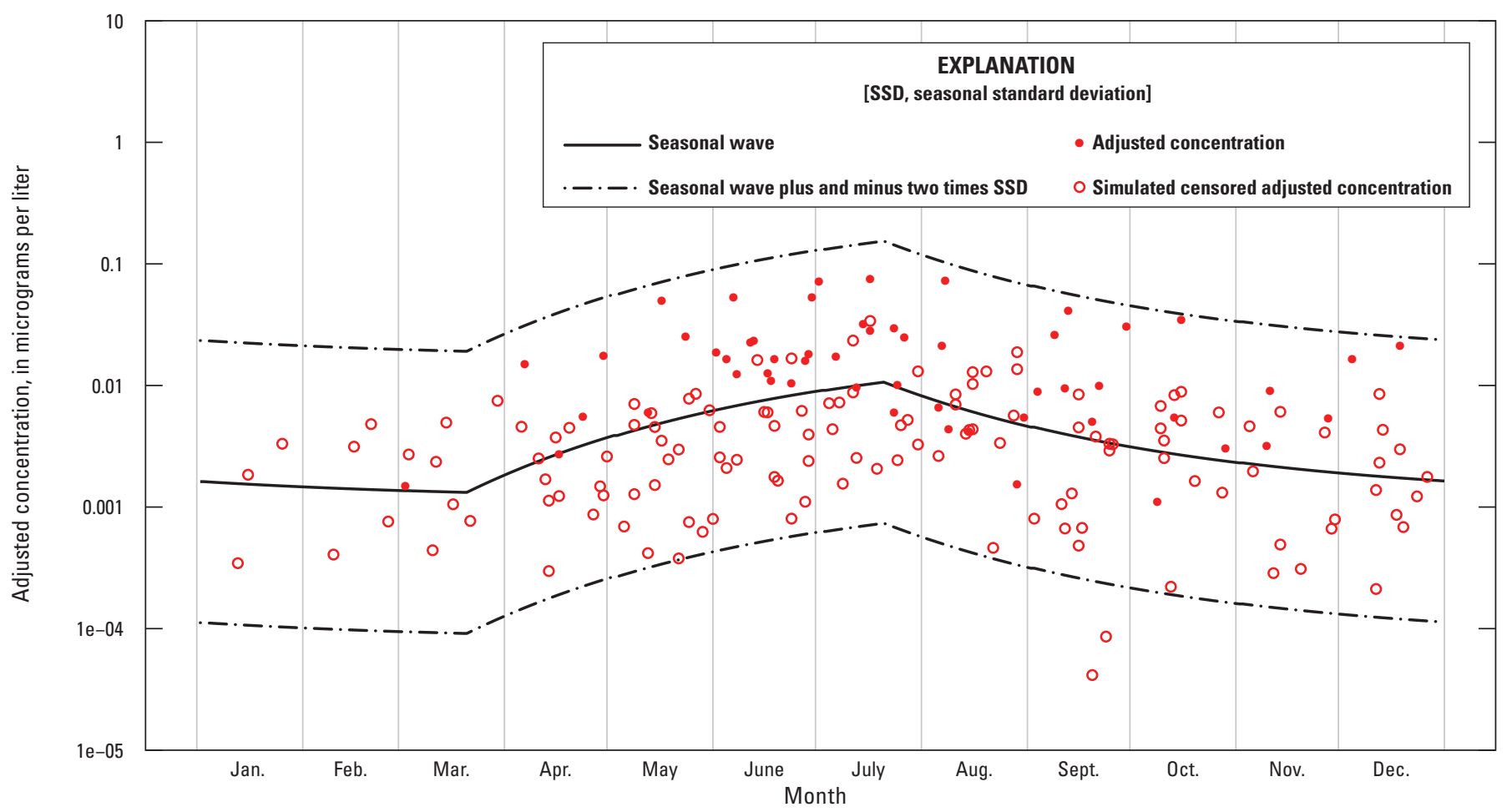

Figure 10. Adjusted (minus trend and flow-related variability) carbaryl concentrations, fitted seasonal wave, and fitted seasonal standard deviation for Kisco River near Mount Kisco, New York (U.S. Geological Survey station number 01374987) for 2000-2008.

\section{Chlorpyrifos}

The next example is for chlorpyrifos concentration for Sope Creek near Marietta, Georgia (USGS station number 02335870), for 1993-2002 (fig. 11). This site has a drainage area of about $80 \mathrm{~km}^{2}$ and urban land use of about 70 percent (Ryberg and others, 2010). During 1993-2002, chlorpyrifos was a widely used insecticide in a variety of urban and agricultural settings, but residential use was phased out starting in about 1997 and essentially eliminated by 2002 (Ryberg and others, 2010). The dataset includes 118 observations with ASF of 32 in 1993, 23 in 2002, and from 0 to 12 in the other years. About 70 percent (83) of the values were censored. The best-fit wave model, estimated linear regression coefficients, estimated SSD parameters, and estimated CTS for this example were as follows:

$$
\begin{aligned}
& W^{*}=S W 2(m=4, h=2, s=5.5) ; \\
& b_{0}=-2.78, b_{1}=0.80, b_{2}=0.92, b_{3}=0.61, b_{4}=-0.06 ; \text { and } \\
& \sigma^{*}=0.374, \alpha^{*}=0, C T S^{*}=3.5 .
\end{aligned}
$$

The regression coefficients for the seasonal wave $(0.80)$, MTFA (0.92), STFA (0.61), and trend (-0.06) all were significant. The downtrend probably resulted from the aforementioned phasing out of residential uses. The best-fit seasonal wave for this example (fig. 12) was from wave class 2 and consisted of two 3-month application seasons, from mid-October through mid-January and from mid-March through midJune ( $m=4$ and $s=5.5)$, and a decay rate of 2 months $(h=2)$. The estimated SSD was constant $\left(\alpha^{*}=0\right)$ and the estimated
CTS was 3.5 days. Note that a lower bound for the estimated CTS of 3.5 days $\left(C T S^{*} \geq 3.5\right)$ was assumed because sampling frequencies are rarely sufficient to discern correlation structure at such small time lags. For this example, $C T S^{*}$ was equal to the lower bound.

\section{Fipronil}

The final example is for fipronil concentration for Sope Creek near Marietta, Georgia (U.S. Geological Survey station number 02335870) for 2003-12 (fig. 13). Fipronil is an insecticide that was first registered for use in 1996 and quickly gained widespread use by 2002 as a replacement for other insecticides, such as diazinon and chlorpyrifos, that were being phased out for residential use (Ryberg and others, 2010). The dataset includes 127 observations with ASF ranging from 22 in 2008 to 6 in several other years. The dataset includes 68 censored observations (about 54 percent). The best-fit seasonal wave model, estimated linear regression coefficients, estimated SSD parameters, and estimated CTS for this site were as follows:

$$
\begin{aligned}
& W^{*}=S W 2(m=5, h=1, s=7) ; \\
& b_{0}=-2.15, b_{1}=0.17, b_{2}=0.14, b_{3}=0.29, b_{4}=0.01 ; \text { and } \\
& \sigma^{*}=0.201, \alpha^{*}=0.218, C T S^{*}=5.9 .
\end{aligned}
$$

The regression coefficients for the seasonal wave (0.17), MTFA (0.14), and STFA (0.29) all were significant. The bestfit seasonal wave (fig. 14) was from wave class 2 and consisted 


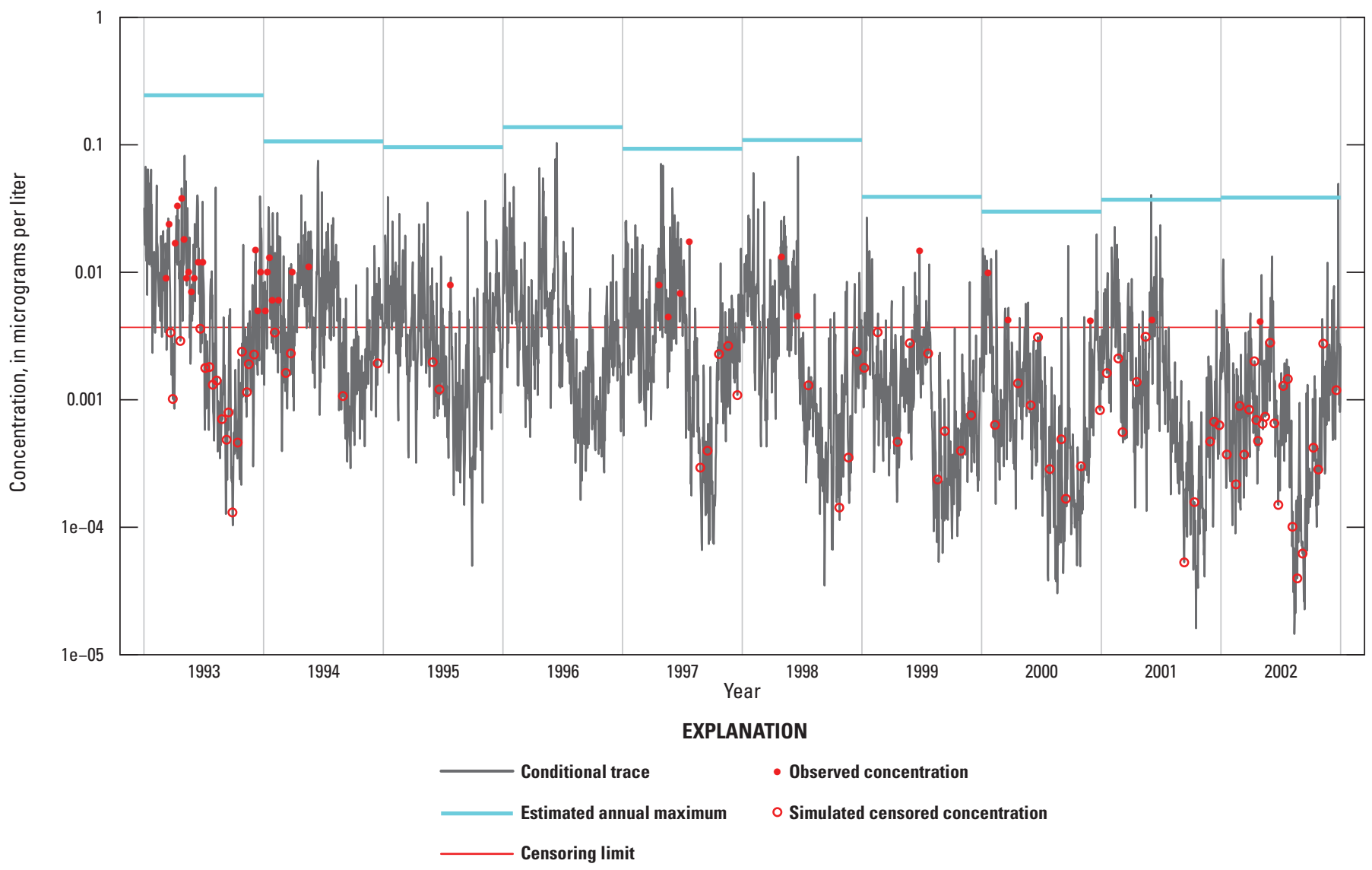

Figure 11. Observed chlorpyrifos concentrations, simulated conditional trace of daily concentrations, and estimated annual maximum daily concentrations for Sope Creek near Marietta, Georgia (U.S. Geological Survey station number 02335870) for 1993-2002.

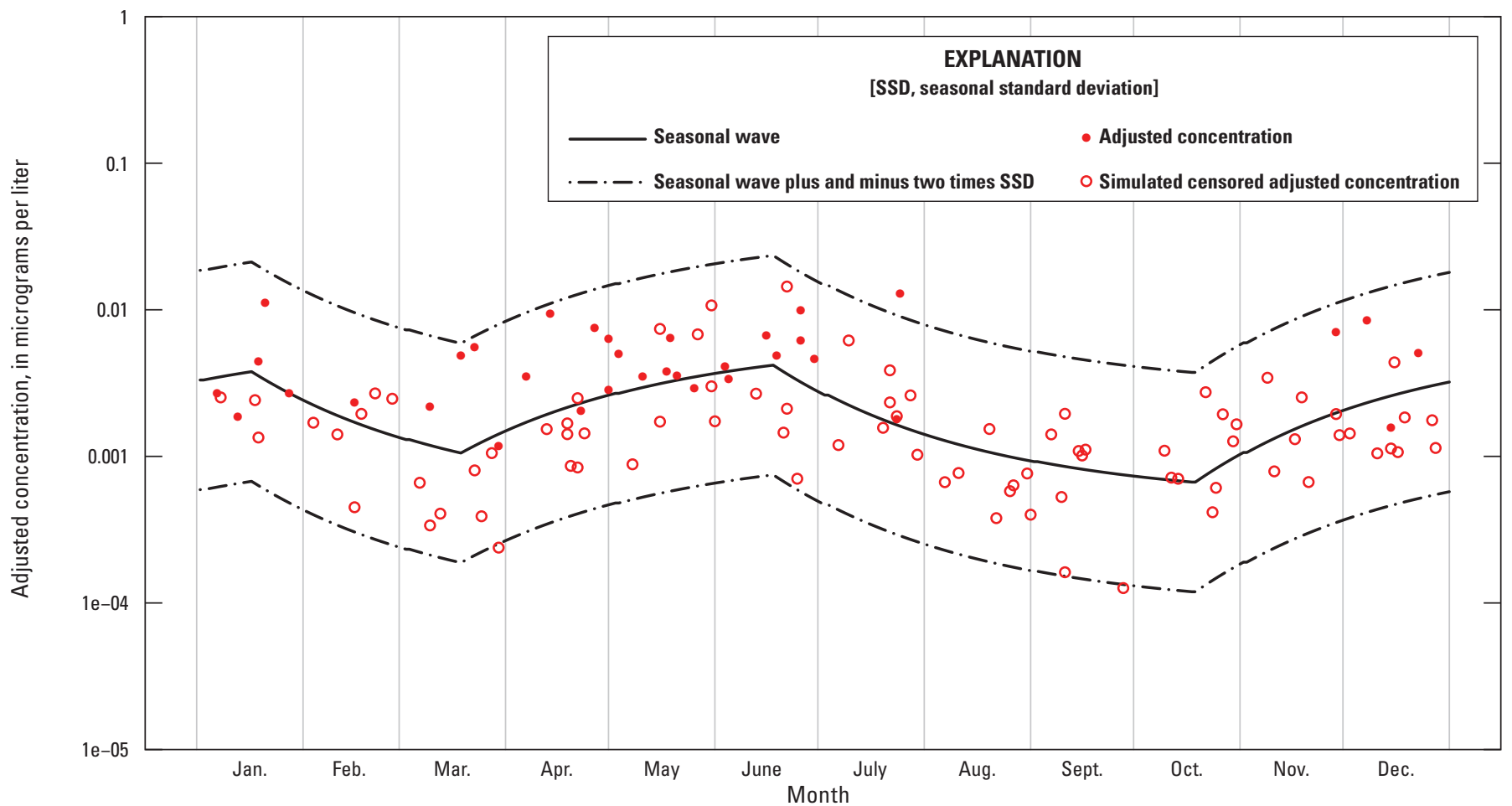

Figure 12. Adjusted (minus trend and flow-related variability) chlorpyrifos concentrations, fitted seasonal wave, and fitted seasonal standard deviation for Sope Creek near Marietta, Georgia (U.S. Geological Survey station number 02335870) for 1993-2002. 


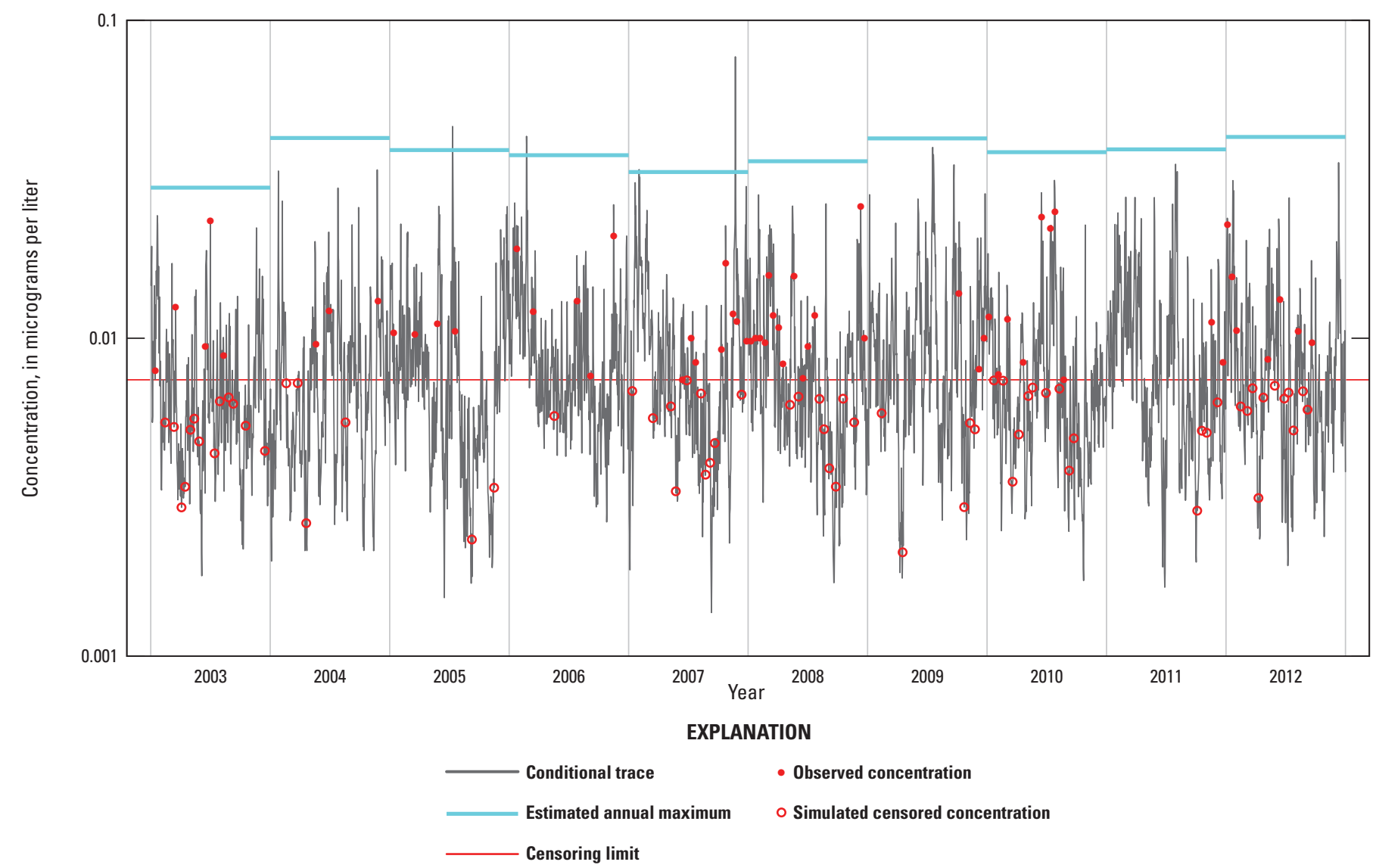

Figure 13. Observed fipronil concentrations, simulated conditional trace of daily concentrations, and estimated annual maximum daily concentrations for Sope Creek near Marietta, Georgia (U.S. Geological Survey station number 02335870) for 2003-12.

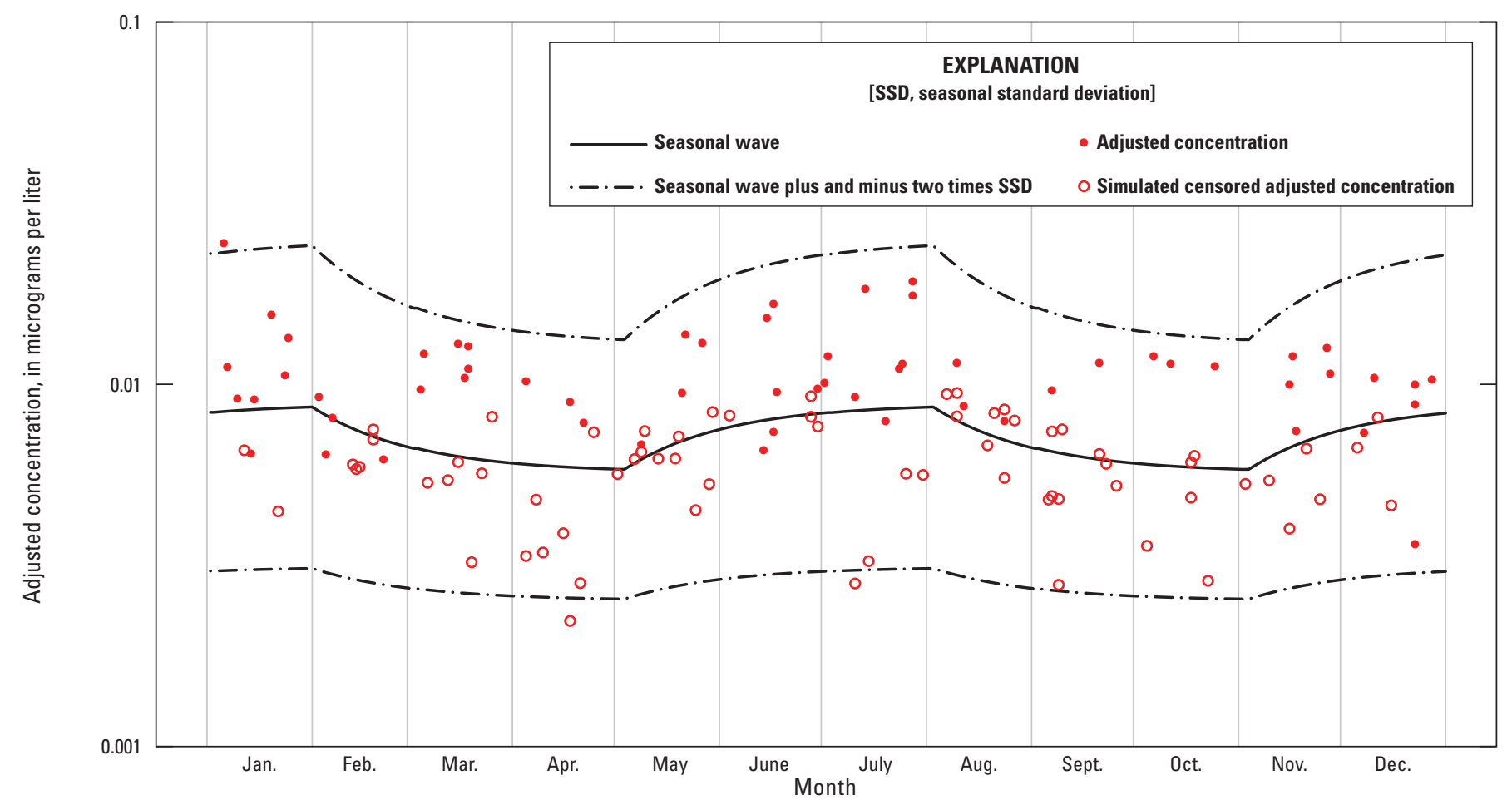

Figure 14. Adjusted (minus trend and flow-related variability) fipronil concentrations, fitted seasonal wave, and fitted seasonal standard deviation for Sope Creek near Marietta, Georgia (U.S. Geological Survey station number 02335870) for 2003-12. 
of two 3-month application seasons, from early November through early February and from early May through early August ( $m=5$ and $s=7$ ), and a decay rate of 1 month $(h=1)$. The seasonal wave for fipronil was similar to the seasonal wave for chlorpyrifos (fig. 12), but with somewhat different timing of the application seasons and faster decay rate. The SSD had a small degree of seasonality $\left(\alpha^{*}=0.24\right)$, and the estimated CTS was about 6 days $\left(C T S^{*}=5.9\right)$.

\section{Model Testing}

Simulation experiments were used to test the SEAWAVE-QEX model and determine limits for the RL, ASF, and CR for applying the model. The objective of the SEAWAVE-QEX model is to provide a robust tool that can be used to generate conditional simulations of daily concentration and estimate associated statistics, such as the AMDC, for as many pesticide monitoring sites as possible and for pesticides (such as carbaryl, chlorpyrifos, and fipronil) that may have short records, sparse sampling frequencies, or a high percentage of censored data. Important considerations for verifying any statistical model include (1) verification of model assumptions and (2) verification of model results. The first consideration will be discussed later in the "Model Limitations" section of this report. The simulation experiments described in this section were designed with the second consideration in mind, namely, given that the model assumptions are satisfied, does the model provide reasonable estimates of concentration extremes? How do properties of the estimates (for example, bias and uncertainty) depend on RL, ASF, and CR?

For the simulation experiments, the atrazine, carbaryl, and chlorpyrifos examples described in the "Examples of SEAWAVE-QEX Model Results" section were used to randomly generate time series of "known" daily pesticide concentrations assuming the true model was given by the fitted model for the respective examples, except for CTS, which was varied. The "known" daily pesticide concentrations (which have no censored values or days with missing observations) are referred to as model-generated traces to distinguish them from the conditional traces described previously. For each model-generated trace, the RL, ASF, CTS, and CR were varied to represent a reasonable range of values that may be expected. In particular, all combinations of two RLs ( $R L=3$ and 6 years), three ASFs (ASF=12, 24, and 48 samples per year), three CTSs (CTS $=7,15$, and 30 days), and two CRs $(\mathrm{CR}=30$ and 70 percent) were considered. For each pesticide and each combination of RL, ASF, CTS, and CR, 100 modelgenerated traces were generated from the SEAWAVE-QEX model. The flow anomalies for each model-generated trace were computed using consecutive years of daily streamflow from the period of record used for the examples, where the beginning year was selected at random for each trace. For example, for the atrazine model (where the period of record used for the example was 1993-2002) and $\mathrm{RL}=3$, the starting year was selected at random from eight possibilities (1993-2000). The lowest ASF (ASF=12) represents approximate monthly sampling. For that case, the data used for fitting the model were assumed to consist of 12 observations per year, where the first observation was selected at random from days 1 to 30 and the remaining 11 observations were selected every 30 days thereafter. For ASF=24, representing approximate bimonthly sampling, the first observation was selected at random from days 1 to 15 and the remaining 23 observations were selected every 15 days thereafter. For $\mathrm{ASF}=48$, representing approximate weekly sampling, 24 additional observations were added to the $\mathrm{ASF}=24$ design each year (about midway between adjacent observations for the ASF $=24$ design, resulting in alternating 7- or 8-day spacing between observations). After selecting the observations used for fitting the model, the known concentrations for the selected observations were artificially censored at either the lower $(\mathrm{CR}=30)$ or higher $(\mathrm{CR}=70)$ level. For example, with $\mathrm{RL}=3, \mathrm{ASF}=12$, and $\mathrm{CR}=70$, there were 36 observations for all 3 years, 11 of which (about 30 percent) were uncensored and 25 of which (about 70 percent) were censored.

For each model-generated trace, the SEAWAVE-QEX model methodology described previously (fig. 4 and associated discussion) was applied to fit the model, generate $\mathrm{N}=100$ conditional traces, and compute estimates of the AMDC for each simulation year. The following statistics were used to evaluate the estimated AMDC:

- Bias - the geometric mean of the estimated AMDCs minus the geometric mean of the known AMDCs, as a percent of the geometric mean of the known AMDCs.

- 80-percent error bounds-(P10, P90), where P10 and P90 are the 10th and 90th percentiles of the estimation errors. The estimation errors are the differences between the estimated and known values of AMDC, expressed as a percent of the known value. For example, if the 80-percent error bounds are $(-10,50)$, most ( 80 percent) of the estimated AMDCs are within -10 and +50 percent of the known value.

Bias was categorized as low (between -10 and 25 percent), moderate (between 25 and 50 percent), or high (greater than 50 percent). No cases had substantial downward (negative) bias (less than -10 percent) —in most cases there was upward (positive) bias. Thus, the estimated values of AMDC generally, on average, were higher than the known values.

Results of the simulation experiments for all three models (atrazine, carbaryl, and chlorpyrifos) indicated that, as expected, both bias and uncertainty were lower for $R L=6$ years compared to $\mathrm{RL}=3$ years. Therefore, only the results for $\mathrm{RL}=3$ years, given in table 1 , are discussed.

For the lower $\mathrm{CR}(\mathrm{CR}=30)$, bias was low for all three models and for all combinations of ASF and CTS (table 1). However, estimation errors (uncertainty) depended on ASF and CTS. For $\mathrm{CR}=30$ and $\mathrm{ASF}=12$ (30 days between observations), estimation uncertainty was high relative to $\mathrm{ASF}=24$ 
Table 1. SEAWAVE-OEX model testing results based on simulated data from the atrazine, carbaryl, and chlorpyrifos models with record length 3 years.

\begin{tabular}{|c|c|c|c|c|c|c|c|c|c|c|c|}
\hline \multirow{2}{*}{$\begin{array}{l}\text { Censoring } \\
\text { rate, } \\
\text { in percent }\end{array}$} & \multirow{2}{*}{$\begin{array}{c}\text { Annual } \\
\text { sampling } \\
\text { frequency, } \\
\text { in samples } \\
\text { per year }\end{array}$} & \multirow{2}{*}{$\begin{array}{c}\text { Correlation } \\
\text { time scale, } \\
\text { in days }\end{array}$} & \multicolumn{3}{|c|}{ Atrazine model } & \multicolumn{3}{|c|}{ Carbaryl model } & \multicolumn{3}{|c|}{ Chlorpyrifos model } \\
\hline & & & 'Bias & ${ }^{2} \mathrm{P} 10$ & ${ }^{2} \mathrm{P} 90$ & 'Bias & ${ }^{2} \mathrm{P} 10$ & ${ }^{2} \mathrm{P} 90$ & 'Bias & ${ }^{2} \mathrm{P} 10$ & ${ }^{2} \mathrm{P} 90$ \\
\hline 30 & 12 & 7 & -7 & -61 & 112 & 19 & -66 & 264 & 16 & -49 & 141 \\
\hline 30 & 12 & 15 & 10 & -48 & 129 & 13 & -49 & 157 & 24 & -36 & 142 \\
\hline 30 & 12 & 30 & 19 & -32 & 107 & 22 & -52 & 192 & 16 & -31 & 90 \\
\hline 30 & 24 & 7 & -5 & -50 & 86 & 23 & -36 & 137 & 19 & -30 & 84 \\
\hline 30 & 24 & 15 & 5 & -33 & 73 & 12 & -35 & 92 & 6 & -30 & 54 \\
\hline 30 & 24 & 30 & 9 & -27 & 59 & 16 & -31 & 86 & 10 & -21 & 59 \\
\hline 30 & 48 & 7 & 3 & -33 & 53 & 15 & -31 & 83 & 10 & -26 & 57 \\
\hline 30 & 48 & 15 & 2 & -26 & 39 & 2 & -35 & 53 & 2 & -21 & 31 \\
\hline 30 & 48 & 30 & 6 & -16 & 36 & 2 & -23 & 36 & 8 & -15 & 40 \\
\hline 70 & 12 & 7 & 15 & -56 & 227 & 21 & -66 & 272 & 24 & -47 & 140 \\
\hline 70 & 12 & 15 & 33 & -54 & 237 & 21 & -60 & 224 & 42 & -41 & 210 \\
\hline 70 & 12 & 30 & 48 & -33 & 266 & 46 & -43 & 269 & 40 & -42 & 190 \\
\hline 70 & 24 & 7 & 32 & -35 & 166 & 48 & -33 & 268 & 19 & -36 & 136 \\
\hline 70 & 24 & 15 & 31 & -21 & 129 & 20 & -41 & 151 & 7 & -31 & 70 \\
\hline 70 & 24 & 30 & 18 & -20 & 78 & 6 & -41 & 97 & 3 & -37 & 52 \\
\hline 70 & 48 & 7 & 31 & -13 & 104 & 45 & -12 & 153 & 13 & -20 & 70 \\
\hline 70 & 48 & 15 & 18 & -13 & 71 & 20 & -24 & 88 & 9 & -22 & 54 \\
\hline 70 & 48 & 30 & 16 & -9 & 45 & 12 & -23 & 67 & 2 & -23 & 36 \\
\hline
\end{tabular}

${ }^{1}$ Difference between geometric means of estimated and known annual maximum daily concentrations, as a percent of the known value.

${ }^{2}$ Tenth (P10) and 90th (P90) percentiles of the estimation errors, where the estimation error is the difference between the estimated and known annual maximum daily concentration, as a percent of the known value.

(15 days between observations) or 48 (approximately 7 days between observations). For ASF $=12$, spacing between samples was equal to (for $\mathrm{CTS}=30$ ), twice (for $\mathrm{CTS}=15$ ), or about 4 times (for $\mathrm{CTS}=7$ ) the CTS. Thus, correlation between neighboring observations was low and the conditional simulations of daily concentrations for days between neighboring observations (which are used to estimate AMDC) were uncertain. Uncertainty generally decreased as spacing between observations became small in relation to CTS. For example, for $\mathrm{CR}=30, \mathrm{CTS}=15$, and $\mathrm{ASF}=48$ (spacing between samples equal to about one-half of the CTS), most of the estimated values for AMDC for carbaryl were between -35 and 53 percent of the known values compared to -49 and 157 percent for $\mathrm{CR}=30, \mathrm{CTS}=15$, and $\mathrm{ASF}=12$ (spacing between samples equal to twice the CTS). In addition to higher spacing between observations (relative to CTS), higher SSD also causes higher estimation uncertainty. The maximum value of the SSD $\left(\sigma[1+0.5 \alpha]^{1 / 2}\right.$, which occurs when the seasonal wave equals its maximum value of 0.5 ) was about 0.49 for atrazine, 0.54 for carbaryl, and 0.37 for chlorpyrifos. Thus, estimation uncertainty generally was highest for the carbaryl model and lowest for the chlorpyrifos model. For example, for $\mathrm{CR}=30, \mathrm{ASF}=24$, and $\mathrm{CTS}=15$, most of the estimated values of AMDC for the carbaryl model were between -35 and 92 percent of the known values compared to -30 and 54 percent for the chlorpyrifos model. The dependence of estimation uncertainty on the SSD was diminished as the observations became closely spaced with respect to CTS. For example, for $\mathrm{CR}=30, \mathrm{ASF}=48$, and CTS $=30$, the 80 -percent error bounds for the carbaryl model (-23 to 36 percent) were similar to the error bounds for the chlorpyrifos model ( -15 to 40 percent) and the atrazine model (-16 to 36 percent).

As expected, increasing the $\mathrm{CR}$ increased bias of the estimated AMDCs (table 1). For $\mathrm{CR}=70$, the estimated AMDC had moderate upward bias (between 25 and 50 percent) for many cases. However, none of the cases had high upward bias (greater than 50 percent). The cases with moderate upward bias tended to occur when the spacing between observations was high in relation to CTS. Increasing the CR also increased estimation uncertainty, especially when the spacing between observations was high in relation to CTS. For example, for $\mathrm{CR}=70, \mathrm{ASF}=24$, and $\mathrm{CTS}=15$, most of the estimated values for AMDC for the carbaryl model were between -41 and 151 percent of the known values compared to -35 and 
92 percent for $\mathrm{CR}=30, \mathrm{ASF}=24$, and $\mathrm{CTS}=15$. The effect of high censoring rates on estimation uncertainty diminished as the spacing between observations became small in relation to CTS. For example, for $\mathrm{CR}=70, \mathrm{ASF}=48$, and $\mathrm{CTS}=15$, most of the estimated values for AMDC for the carbaryl model were between -24 and 88 percent of the known values compared to -35 and 53 percent for $\mathrm{CR}=30, \mathrm{ASF}=48$, and CTS $=15$.

Overall, based on the model testing, if the model assumptions are satisfied, the SEAWAVE-QEX model should produce reasonable estimates of AMDCs with as few as 3 years of data, ASF as low as 12 samples per year, and $\mathrm{CRs}$ as high as 70 percent. The estimates should be relatively unbiased (bias between -10 and 25 percent) for low CRs (less than 30 percent), but can have moderate upward bias (between about 25 and 50 percent) for higher CRs. The estimates can have high uncertainty, especially when the CR is high and the spacing between observations is large in relation to the CTS. However, provided estimation uncertainty is quantified (for example, using confidence intervals instead of point estimates), the estimates should be useful for evaluating pesticide exposure risk and uncertainty.

\section{Model Assumptions and Limitations}

The simulation experiments described in the "Model Testing" section provide evidence that the SEAWAVE-QEX modeling methodology can be a useful and robust tool for estimating concentration extremes based on sparse monitoring data. For the models tested, the estimated AMDCs produced by the model were relatively unbiased and had reasonable uncertainty. Note, however, that the model testing assumed that in each case, the model assumptions were satisfied because the "known" concentrations were generated from the model. In the examples used for selecting the models that were tested, the period of record was long enough and the sampling frequent enough to provide reasonable assurance that the model assumptions were met. When applying the model in practice, the normalized residuals (eq. 11) should be examined in an effort to verify the following assumptions:

- The normalized residuals are approximately normally distributed with mean equal to zero and variance equal to one. Plots of the normalized residuals with time of year (for example, fig. 7) should be examined to identify any obvious seasonality remaining in the mean or standard deviation, as well as any obvious nonnormality (skewness, outliers, and so forth).

- The normalized residuals have exponential correlation function. The empirical correlogram (for example, fig. 8) should be examined for obvious discontinuity at the origin or nonexponential decay as the time lag increases.
The shorter the sampling record, the sparser the sampling frequency, or the more highly censored the data, the more difficult the assumptions are to verify; therefore, more caution should be taken when using the model results. Model verification can be especially difficult when a large percentage of the data (more than 50 percent) are censored, in which case a large percentage of the normalized residuals are generated values from a conditional trace and not observed residuals. The generated residuals, by definition, satisfy the model assumptions.

In addition to verifying model assumptions, the following general limitations of the methodology should be noted:

- Alternative, more data intensive, methods may be available for estimating concentration extremes for certain pesticides, such as atrazine, that have been extensively monitored through various sampling programs (Mosquin and others, 2012). The SEAWAVE-QEX model is proposed as an alternative - not a replacement - for other methods, with the primary goal of increasing the geographic extent, hydrologic conditions, and pesticide use characteristics of sites that can be analyzed. Comparing SEAWAVE-QEX to other approaches is beyond the scope of this report.

- Measurement error is assumed to be negligible. The SEAWAVE-QEX model was designed to handle sparse sampling and censoring, but the model was not designed to handle measurement error (differences between the actual concentration and the observed concentration because of sample collection and preservation techniques or laboratory analytical methods). For the model, measurement error is assumed to be small in relation to the standard deviation of the actual concentrations ( $\sigma$ in eq. 6 ) and, for practical purposes, can be ignored. The conditional traces of daily concentrations from the model are "exact interpolators" in that the simulated daily concentrations coincide with the observed concentrations on days when samples were collected (unless the observation is censored, in which case the simulated concentration is less than the censoring limit).

- The generated conditional simulations of daily pesticide concentrations from the SEAWAVE-QEX model should not be interpreted as actual daily concentrations. The simulations are designed to mimic the statistical properties of actual data, not to predict actual concentrations. Estimated concentration extremes derived from the conditional simulations for individual sites should not be reported without careful consideration of model assumptions and estimation uncertainty. 


\section{Data Preparation and Screening}

The simulation experiments described in the "Model Testing" section were used in conjunction with practical considerations involving actual monitoring datasets, such as variable ASF, variable spacing between samples, and gaps in the record, to develop a stepwise screening procedure for determining which datasets are appropriate for SEAWAVE-QEX model applications (fig. 4, data preparation and screening). The following data preparation and screening procedure steps were used for this report. The R function swaveqexMerge (see appendix) can be used for completing the data preparation and screening.

Step 1. Assemble daily streamflow data and compute flow anomalies. - Daily streamflow data from a streamflowgaging station, at or near the pesticide sampling site, is used to compute the flow anomalies. Generally, the streamflow-gaging station should have upstream drainage area within 5 percent of the drainage area upstream from the pesticide sampling site, and no major diversions or other flow modifications should be between the sampling site and the streamflow-gaging station. The daily streamflow record should consist of complete calendar years starting on January 1 of the beginning year of the pesticide observations and ending on December 31 of the ending year of the pesticide observations, but excluding leap days. Each year, therefore, should have 365 values. Leap days are excluded because the SEAWAVE-QEX model uses a fixed period of 365 days per year for all of the computational algorithms. Missing daily streamflow values are allowed at this step, and every day should have a streamflow record (with placeholders for missing values inserted for days with missing record). The MTFA (eq. 3) and STFA (eq. 4) are computed using the daily streamflow record. If part of the streamflow record is missing, the long-term mean required for computing the MTFA ( $\mathrm{M}$ in eq. 3 ) is computed using the nonmissing streamflow record, but the MTFA and STFA for a given day are missing if there are any missing streamflow values for the 30-day period up to and including the given day.

Step 2. Merge pesticide data and daily streamflow data and determine appropriate period of record.-Pesticide observations with missing streamflow anomalies should be removed. These observations cannot be used by the model and removing them, rather than substituting missing values, is required because the algorithms used for fitting the model do not allow missing values for the observed concentrations. Let NOBSG denote the number of pesticide observations and NUCG the number of uncensored observations in a generic year. If, after removing observations with missing flow anomalies, there are fewer than 3 individual years of record that meet the minimum requirements that $\mathrm{NOBSG} \geq 6$ and $\mathrm{NUCG} \geq 2$, the dataset is not appropriate for analysis using the SEAWAVEQEX model. Otherwise, continue with the data screening. If the beginning or ending year of the pesticide record do not meet the minimum requirements ( $\mathrm{NOBSG} \geq 6$ and $\mathrm{NUCG} \geq 2$ ), increase the beginning year or decrease the ending year, as required, so that both the beginning and ending year of record meet the minimum requirements. Note that years in the middle of the record that do not meet $\mathrm{NOBSG} \geq 6$ and $\mathrm{NUCG} \geq 2$ should be included; however, if there is a long gap ( 3 or more consecutive years) that fails to meet the minimum requirements, consider adjusting the beginning and ending year, if possible, to exclude the gap and still maintain at least 3 years that meet the minimum requirements.

Step 3. Thin the pesticide data to maintain at least 3 days between consecutive observations. - Most pesticide monitoring datasets, such as those described in the "SEAWAVE-QEX Model Applications" section of this report, have sustained high-frequency sampling (more than two samples per week) for, at most, 1 or 2 years, and even then only for short periods such as 1-3 months. Including all of those high-frequency samples can result in undue influence of those years for fitting the SEAWAVE-QEX model, especially with regard to selecting the best-fit seasonal wave and estimating the linear regression coefficients. The seasonal wave is meant to model "typical" seasonal behavior of pesticide concentrations during a span of several years; not fit the observations in any single year as closely as possible. Therefore, thinning to at least 3 days between samples (at most two samples per week) is advised.

Step 4. Determine if the pesticide data are sufficient for SEAWAVE-QEX model application.-The fourth and final data preparation step is to verify that the pesticide observations remaining after the first three steps satisfy the following minimum data requirements:

- at least 3 individual years with 6 or more observations, 30 percent or more of which are uncensored;

- at least 30 observations for all years combined; and

- at least 10 uncensored observations for all years combined.

These steps should cull most of the sites for which the data are too sparse for analysis, while at the same time keeping as many sites as possible for use in investigations using the simulated daily concentrations from the SEAWAVE-QEX model. The minimum data requirements given in step 4 were motivated by the simulation experiments described in the "Model Testing" section of this report, which indicated that the model results should be reasonable provided there are at least 3 years of pesticide data, ASF consists of 12 or more (equally spaced) observations per year, and at least 30 percent of the observations are uncensored (or, equivalently, at most 70 percent are censored). Those data constraints were relaxed somewhat to accommodate common issues with actual datasets, such as nonuniform spacing between samples, nonuniform ASF, and gaps in the record. As with any model, results should be examined in each case to help confirm that the simulated daily concentrations are reasonable. 


\section{SEAWAVE-0EX Model Applications}

For each of the four pesticides considered in this report (atrazine, carbaryl, chlorpyrifos, and fipronil), available concentration data from USGS NWQN were screened to determine datasets that could be analyzed using the SEAWAVE-QEX model. Sample collection and preservation methods, laboratory analytical techniques, quality control procedures, and data preparation methods are described in this section and are similar to previous studies (Martin, 2009; Ryberg and others, 2010). The concentration data used in this report are provided in a separate data release (Vecchia and Williams-Sether, 2018), and the discharge data are available in the USGS National Water Information System (U.S. Geological Survey, 2017). Self-contained R functions described in the appendix of this report can be used to verify the results, to complete additional analyses with the data provided, or to analyze user-provided datasets.

\section{Pesticide Data-Processing Steps}

Pesticide concentration data for this report are based on flow-weighted, depth- and width-integrated water samples collected and preserved using standard USGS methods and analyzed by the USGS National Water Quality Laboratory using gas chromatography/mass spectrometry (see Ryberg and others, 2010, and references therein, for details). Methods developed by Martin (2009) and modified as described in appendixes 1-4 of Ryberg and others (2010) were used to adjust raw (laboratory reported) concentrations for possible recovery bias and to determine appropriate censoring limits to use for nondetections. The data adjustment process consisted of the following steps (see appendix 1 in Ryberg and others, 2010).

Step 1. Identification of laboratory reporting levels."Routine" reporting levels (those excluding raised reporting levels caused by matrix interference or other analytical difficulties) were identified for each pesticide. The laboratory reporting level is the "less-than" concentration value reported for samples in which the pesticide was not detected. The reporting level from the USGS laboratory changed through time and was not generally interpretable as a method detection limit (MDL).

Step 2. Reassignment of censoring limit for routine nondetections.-Detailed analyses of quality assurance/ quality control data were used to determine the maximum long-term method detection level (maxLT-MDL) for each pesticide analyte. The detection level may have changed through time, but generally did not indicate any consistent patterns (increasing or decreasing) or large changes for the pesticides during the period of record (1992-2012) used for this report. The maxLT-MDL is the maximum of the MDLs. The maxLT-MDL was determined to be 0.004 micrograms per liter $(\mu \mathrm{g} / \mathrm{L})$ for atrazine, $0.03 \mu \mathrm{g} / \mathrm{L}$ for carbaryl, $0.003 \mu \mathrm{g} / \mathrm{L}$ for chlorpyrifos, and $0.01 \mu \mathrm{g} / \mathrm{L}$ for fipronil (table 1 in Martin, 2009). These values are the default censoring limits assigned to routine nondetections for each site. The default censoring limit may be lowered as described in step 5 .

Step 3. Rounding concentrations to a consistent level of precision.-The precision (number of decimal places reported for samples with detected and quantified pesticide concentration) changed though time. Concentrations were rounded to a consistent level of precision depending on various concentration ranges (table 4 in Martin, 2009).

Step 4. Adjustment of concentrations for temporal changes in recovery.-Ideally, the gas chromatography/mass spectrometry analytical method should have 100 percent recovery (quantified concentration equal, on average, to actual concentration). However, because of instrument drift between calibrations, complexity of analytical techniques, and other factors, the actual recovery may vary above or below 100 percent through time. Quality control data from "spiked" samples (samples with known pesticide concentration) were used to model changes in recovery through time, and concentration values for samples with detected and quantified concentrations were adjusted to represent 100 percent recovery. Recovery adjusted concentrations were re-rounded as described in step 3. The recovery adjustment was not applied to the censoring limit (maxLT-MDL) used for nondetections.

Step 5. Reassignment of censoring limit for selected sites to the median of low-level detections.- The default censoring limit assigned for routine nondetections (" $<$ maxLT-MDL") was lowered for some pesticide-site combinations to reflect site-specific differences in detection sensitivity. Some pesticide-site combinations can have frequent occurrences of low-level detections, which are concentration values for which the pesticide was detected and quantified at a value less than maxLT-MDL. For sites with 10 or more low-level detections, the censoring limit was lowered to the median concentration of the low-level detections, denoted as qlow50. For such cases, the concentration value for routine nondetections for that site is recoded to " $<$ qlow50" rather than " $<$ maxLT-MDL". Finally, all quantified concentrations that are less than the censoring limit (either maxLT-MDL or qlow50, depending on the site) are recoded as censored values.

\section{Overview of SEAWAVE-0EX Model Results}

A broad overview of the SEAWAVE-QEX parameter estimation results for each pesticide is provided in this section. The parameter estimates for each pesticide and site (best-fit seasonal wave, estimated regression coefficients and approximate $p$-values, estimated values of the SSD parameters, and CTS) are provided in the model archive (see appendix). $\mathrm{R}$ functions described in the appendix and provided in the model archive can be used to verify the parameter estimates, generate diagnostic plots (similar to figs. 5-8), and generate conditional traces of daily pesticide concentration for use in investigations of pesticide exposure risk and uncertainty. 
To facilitate comparisons of the relative magnitudes of the regression coefficients among sites and pesticides, the estimated regression coefficients (eq. 8) were multiplied by scaling factors:

$$
\begin{aligned}
\text { CSWAVE }= & 0.5 b_{1} ; \text { CMTFA }=\text { SDMTFA } b_{2} ; \\
& \text { CSTFA }=\text { SDSTFA } b_{3}
\end{aligned}
$$

where

$b_{1}, b_{2}, b_{3}$ are the estimated regression coefficients for the seasonal wave, MTFA, and STFA;

CSWAVE is the scaled coefficient for the seasonal wave;

CMTFA is the scaled coefficient for the MTFA;

SDMTFA is the standard deviation of the MTFA;

CSTFA is the scaled coefficient for the STFA; and

SDSTFA is the standard deviation of the STFA.

Loosely interpreted, the higher the magnitude (absolute value) of a scaled coefficient, the more variability of the observed pesticide concentrations is explained by that variable and the more important that variable is in the model. To simplify the notation and discussion of results in this section, SSD is used to denote the estimated seasonal standard deviation $\left(S S D^{*}=\sigma^{*}\left(1+\alpha^{*} W^{*}\right)^{1 / 2}\right.$, eq. 11) and CTS is used to denote the estimated correlation time scale $\left(C T S^{*}\right)$. For $\alpha^{*}>0$ (nonconstant SSD), the minimum and maximum values of SSD (which occur when $W^{*}=-0.5$ and $W^{*}=0.5$, respectively) differ. For $\alpha^{*}=0$, and minimum and maximum values of SSD both equal the same constant value $\left(\sigma^{*}\right)$. The maximum value of the estimated seasonal standard deviation $\left(\sigma^{*}\left(1+0.5 \alpha^{*}\right)^{1 / 2}\right)$ is denoted by maxSSD.

\section{Atrazine}

For atrazine, 112 USGS sampling sites were identified for the SEAWAVE-QEX model application (table 2). Atrazine is one of the most widely used and commonly detected pesticides in streams throughout the Nation (Stone and others, 2014). Consequently, many sites had long RLs and low CRs. A total of 900 site years were analyzed, with 99 sites having $R L \geq 5$ years and 45 sites having $R L=10$ years. Many sites had more than 10 years of record available, but a maximum RL of 10 years was used. When selecting the period of record for sites with more than 10 years of data, or for sites with gaps in the record, preference was given to including the most recent years. The total number of observations (NOBS) generally was large, and the percent of the observation that were uncensored (PUC) was high: 85 sites had NOBS $\geq 60$ and 100 sites had PUC $\geq 80$.

The scaled coefficients for the seasonal wave, MTFA, and STFA (CSWAVE, CMTFA, and CSTFA in eq. 12) for the atrazine sites are shown in figure 15. Sites are ordered with respect to increasing USGS station number, and the site numbers are given in table 2. Most (88) sites had CSWAVE $\geq 0.4$ and all but one of the coefficients was statistically significant (approximate $p$-value less than 0.05 ) (fig. 15A). Only 24 sites had CSWAVE $<0.4$, including 11 sites among sites 93-112 (these sites are in the Western United States; table 2). The values for CMTFA (fig. 15B) generally were smaller in magnitude compared with CSWAVE. However, CMTFA was significant for many (51) sites and the significant coefficients were evenly distributed between positive and negative values. The values for CSTFA (fig. 15C) were similar in magnitude to CMTFA and most (74) were significant. However, unlike CMTFA, most (68) of the significant values for CSTFA were positive.

The estimated SSDs and CTSs for the atrazine sites are shown in figure 16. The SSD (fig. 16A) generally was small in relation to CSWAVE (fig. 15A): most (93) sites had $\operatorname{maxSSD}<0.4$ whereas most (88) sites had CSWAVE $\geq 0.4$. The CTS (fig. 16B) was variable: 48 sites had CTS $\leq 10$ days and 64 sites had CTS $>10$ days. There was no readily apparent correlation between the values of CTS and SSD or between the values of CTS and CSWAVE. Generally, sites with lower maxSSD, higher CTS, or both, should have lower uncertainty in estimated pesticide concentration extremes computed using conditional simulations from the SEAWAVE-QEX model.

\section{Carbaryl}

For carbaryl, 38 USGS sampling sites were identified for SEAWAVE-QEX model application (table 3). Compared to atrazine, carbaryl concentrations tended to be much more highly censored. Consequently, there were only 38 sites that met the minimum data requirements for carbaryl. A total of 308 site years were analyzed, with 36 sites having $R L \geq 5$ years and 13 sites having $R L \geq 10$ years. When selecting the period of record for sites with gaps in the record, preference was given to including the most recent years. NOBS generally was large (34 sites had NOBS $\geq 60$ ) and PUC was moderate to low (only 9 sites had PUC $>40$ ).

The scaled coefficients for the seasonal wave, MTFA, and STFA for the carbaryl sites are shown in figure 17. Sites are ordered with respect to increasing USGS station number and the site number is given in table 3 (note that the site numbers for carbaryl differ from the site numbers for atrazine). Most (28) carbaryl sites had CSWAVE $\geq 0.4$ and all but 3 of the coefficients were significant (fig. 17A). The values for CMTFA (fig. 17B) generally were smaller in magnitude compared with CSWAVE, and only nine of the coefficients were significant. The values for CSTFA (fig. 17C) generally were smaller in magnitude compared with CSWAVE, but unlike CMTFA, most (27) of the coefficients were significant and 26 of the significant coefficients were positive.

The estimated SSDs and CTSs for the carbaryl sites are shown in figure 18. The SSD (fig. 18A) generally was similar in magnitude to CSWAVE (fig. 17A): most (36 sites) had $\operatorname{maxSSD} \geq 0.4$ and most (28) sites had CSWAVE $\geq 0.4$. This similarity between the values of maxSSD and CSWAVE for carbaryl is in contrast to atrazine, for which maxSSD generally was smaller than CSWAVE. Also, unlike atrazine, which had variable CTS (fig. 16B), most (34) of the carbaryl sites had $\mathrm{CTS}<10$. Because of the larger values of maxSSD and lower values of CTS for carbaryl (compared to atrazine), estimated 
Table 2. U.S. Geological Survey water-quality sampling sites, period of record, and number of observations used for application of SEAWAVE-OEX model for atrazine.

[USGS, U.S. Geological Survey; km², square kilometers; NOBS, number of observations; NUC, number of uncensored observations; PUC, percent uncensored observations]

\begin{tabular}{|c|c|c|c|c|c|c|c|c|c|}
\hline $\begin{array}{l}\text { Site } \\
\text { number }\end{array}$ & $\begin{array}{c}\text { USGS } \\
\text { station } \\
\text { number }\end{array}$ & Site name & $\begin{array}{c}\text { Drainage } \\
\text { area, } \\
\text { in } \mathbf{k m}^{2}\end{array}$ & $\begin{array}{l}\text { Starting } \\
\text { year }\end{array}$ & $\begin{array}{l}\text { Ending } \\
\text { year }\end{array}$ & $\begin{array}{l}\text { Record } \\
\text { length, } \\
\text { in years }\end{array}$ & NOBS & NUC & PUC \\
\hline 1 & 01184000 & $\begin{array}{l}\text { Connecticut River at Thompsonville, } \\
\text { Connecticut }\end{array}$ & 25,012 & 1997 & 2006 & 10 & 107 & 65 & 61 \\
\hline 2 & 01349150 & Canajoharie Creek near Canajoharie, New York & 155 & 1998 & 2007 & 10 & 145 & 144 & 99 \\
\hline 3 & 01356190 & Lisha Kill northwest of Niskayuna, New York & 49 & 2001 & 2010 & 10 & 98 & 39 & 40 \\
\hline 5 & 01374987 & Kisco River below Mount Kisco, New York & 46 & 2000 & 2008 & 9 & 186 & 66 & 35 \\
\hline 6 & 01463500 & Delaware River at Trenton, New Jersey & 17,574 & 2003 & 2012 & 10 & 99 & 97 & 98 \\
\hline 7 & 01464907 & $\begin{array}{l}\text { Little Neshaminy Creek at Valley Road near } \\
\text { Neshaminy, Pennsylvania }\end{array}$ & 71 & 1999 & 2004 & 6 & 77 & 76 & 99 \\
\hline 8 & 01472157 & French Creek near Phoenixville, Pennsylvania & 158 & 1999 & 2004 & 6 & 58 & 57 & 98 \\
\hline 12 & 01555400 & $\begin{array}{l}\text { East Mahantango Creek at Klingerstown, } \\
\text { Pennsylvania }\end{array}$ & 116 & 1997 & 2000 & 4 & 48 & 48 & 100 \\
\hline 13 & 01578310 & Susquehanna River at Conowingo, Maryland & 70,161 & 1996 & 2004 & 9 & 65 & 65 & 100 \\
\hline 14 & 01621050 & Muddy Creek at Mount Clinton, Virginia & 43 & 1997 & 2001 & 5 & 66 & 66 & 100 \\
\hline 15 & 01654000 & Accotink Creek near Annandale, Virginia & 62 & 1997 & 2001 & 5 & 63 & 50 & 79 \\
\hline 16 & 02087580 & Swift Creek near Apex, North Carolina & 56 & 2002 & 2011 & 10 & 116 & 94 & 81 \\
\hline 17 & 02089500 & Neuse River at Kinston, North Carolina & 7,020 & 2003 & 2012 & 10 & 142 & 138 & 97 \\
\hline 18 & 02091500 & Contentnea Creek at Hookerton, North Carolina & 1,898 & 1997 & 2006 & 10 & 119 & 110 & 92 \\
\hline 19 & 02169570 & Gills Creek at Columbia, South Carolina & 164 & 2001 & 2006 & 6 & 59 & 58 & 98 \\
\hline 23 & 02335870 & Sope Creek near Marietta, Georgia & 86 & 2003 & 2012 & 10 & 127 & 121 & 95 \\
\hline 24 & 02338000 & Chattahoochee River near Whitesburg, Georgia & 6,252 & 2003 & 2012 & 10 & 144 & 141 & 98 \\
\hline 25 & 02350080 & Lime Creek near Cobb, Georgia & 162 & 2001 & 2007 & 7 & 89 & 77 & 87 \\
\hline 26 & 02359170 & Apalachicola River near Sumatra, Florida & 49,771 & 2008 & 2012 & 5 & 52 & 52 & 100 \\
\hline 27 & 0242354750 & $\begin{array}{l}\text { Cahaba Valley Creek at Cross Creek Road at } \\
\text { Pelham, Alabama }\end{array}$ & 71 & 2003 & 2012 & 10 & 99 & 99 & 100 \\
\hline 28 & 02444490 & Bogue Chitto Creek near Memphis, Alabama & 138 & 1999 & 2004 & 6 & 73 & 73 & 100 \\
\hline 29 & 03086000 & Ohio River at Sewickley, Pennsylvania & 50,496 & 2001 & 2007 & 7 & 88 & 83 & 94 \\
\hline 30 & 03216600 & $\begin{array}{l}\text { Ohio River at Greenup Dam near Greenup, } \\
\text { Kentucky }\end{array}$ & 159,235 & 1998 & 2007 & 10 & 132 & 129 & 98 \\
\hline 31 & 03267900 & $\begin{array}{l}\text { Mad River at Saint Paris Pike at Eagle City, } \\
\text { Ohio }\end{array}$ & 798 & 1999 & 2004 & 6 & 103 & 100 & 97 \\
\hline 32 & 03303280 & $\begin{array}{l}\text { Ohio River at Cannelton Dam, at Cannelton, } \\
\text { Indiana }\end{array}$ & 249,355 & 2003 & 2012 & 10 & 125 & 125 & 100 \\
\hline
\end{tabular}


Table 2. U.S. Geological Survey water-quality sampling sites, period of record, and number of observations used for application of SEAWAVE-QEX model for atrazine. - Continued

[USGS, U.S. Geological Survey; km², square kilometers; NOBS, number of observations; NUC, number of uncensored observations; PUC, percent uncensored observations]

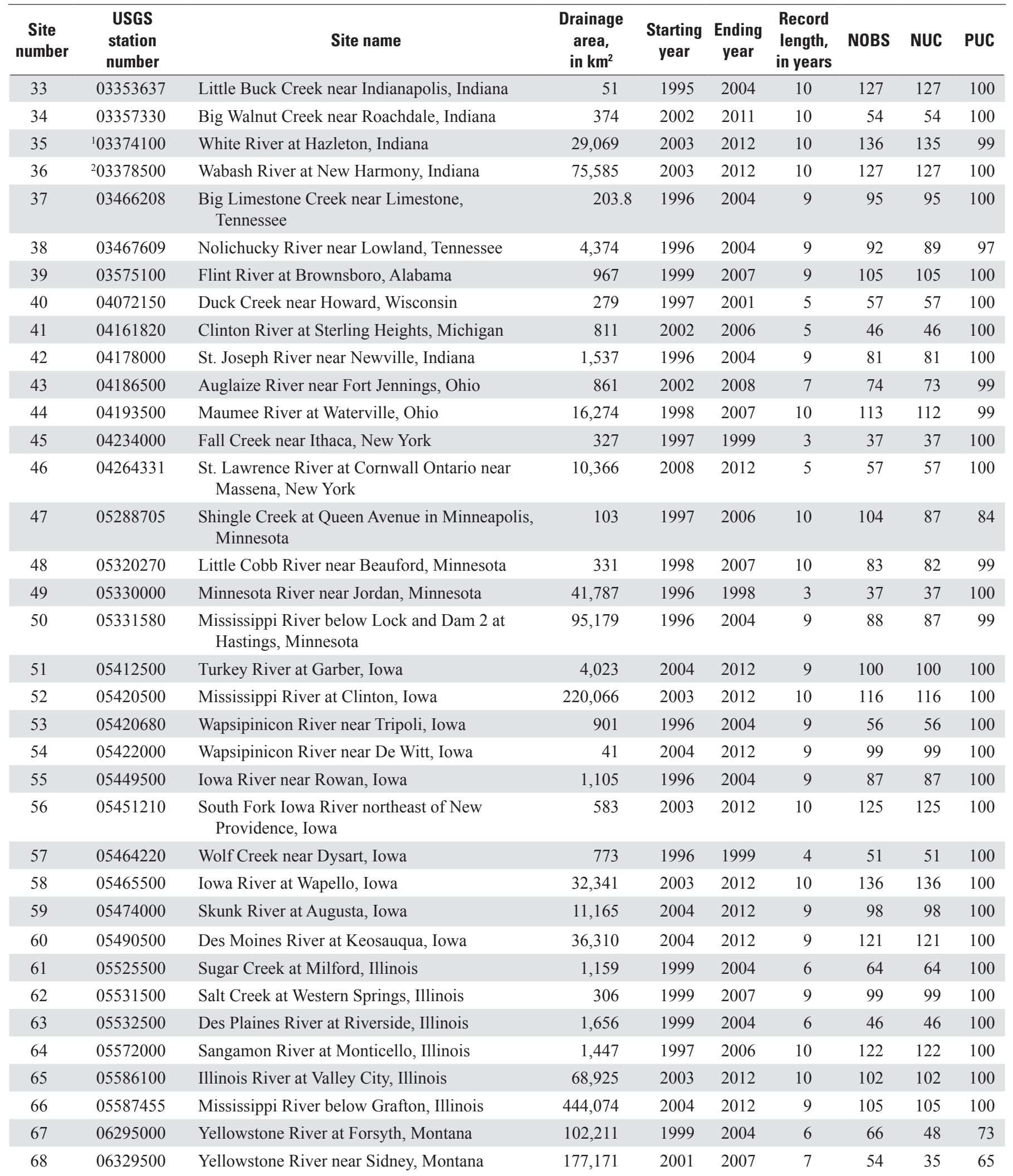


Table 2. U.S. Geological Survey water-quality sampling sites, period of record, and number of observations used for application of SEAWAVE-QEX model for atrazine. - Continued

[USGS, U.S. Geological Survey; km², square kilometers; NOBS, number of observations; NUC, number of uncensored observations; PUC, percent uncensored observations]

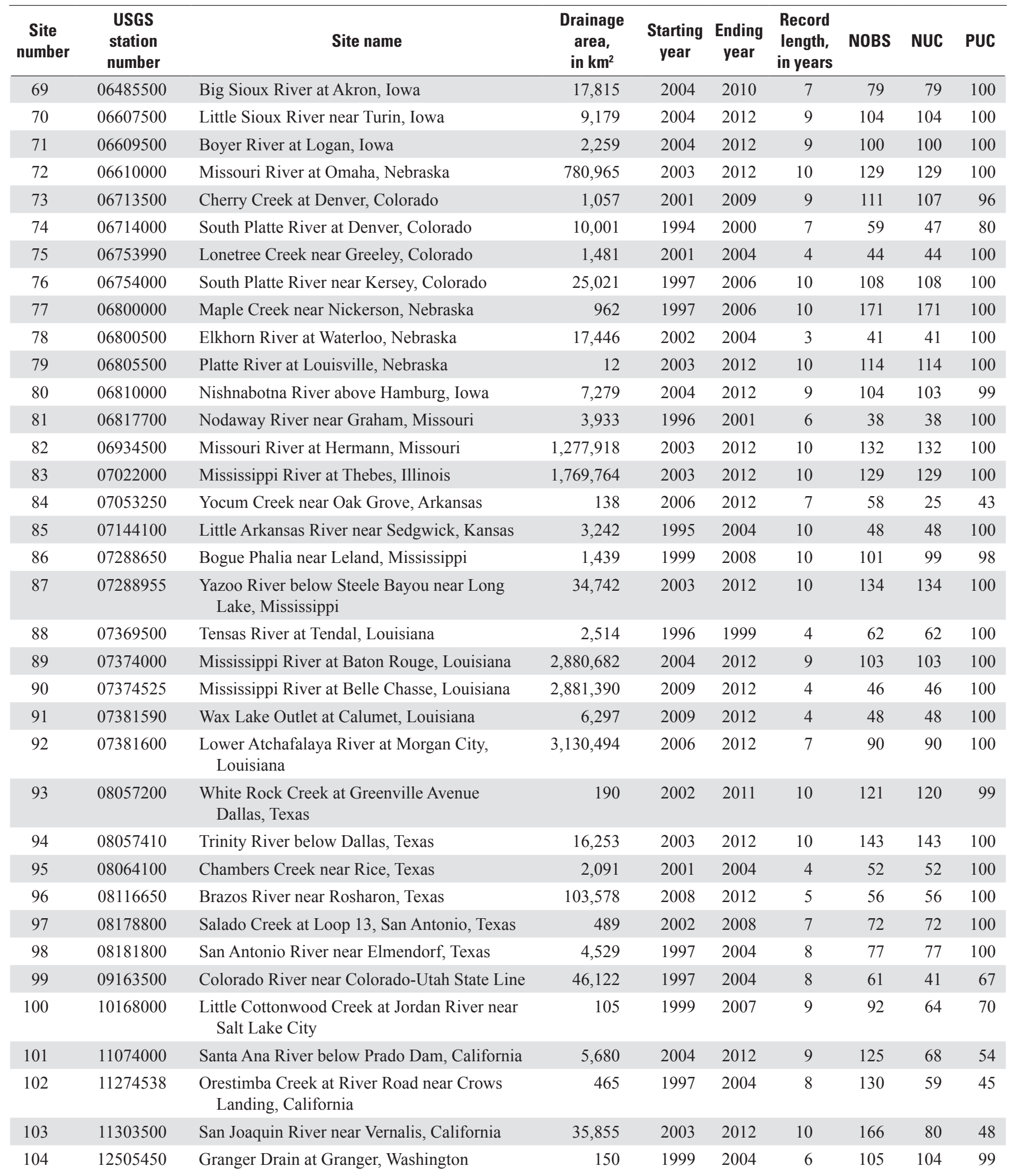


Table 2. U.S. Geological Survey water-quality sampling sites, period of record, and number of observations used for application of SEAWAVE-QEX model for atrazine. - Continued

[USGS, U.S. Geological Survey; km², square kilometers; NOBS, number of observations; NUC, number of uncensored observations; PUC, percent uncensored observations]

\begin{tabular}{|c|c|c|c|c|c|c|c|c|c|}
\hline $\begin{array}{l}\text { Site } \\
\text { number }\end{array}$ & $\begin{array}{c}\text { USGS } \\
\text { station } \\
\text { number }\end{array}$ & Site name & $\begin{array}{c}\text { Drainage } \\
\text { area, } \\
\text { in } \mathrm{km}^{2}\end{array}$ & $\begin{array}{l}\text { Starting } \\
\text { year }\end{array}$ & $\begin{array}{l}\text { Ending } \\
\text { year }\end{array}$ & $\begin{array}{l}\text { Record } \\
\text { length, } \\
\text { in years }\end{array}$ & NOBS & NUC & PUC \\
\hline 105 & 12510500 & Yakima River at Kiona, Washington & 14,060 & 1999 & 2008 & 10 & 91 & 78 & 86 \\
\hline 106 & 13092747 & $\begin{array}{l}\text { Rock Creek above Highway 30/93 crossing at } \\
\text { Twin Falls, Idaho }\end{array}$ & 632 & 1997 & 2005 & 9 & 127 & 98 & 77 \\
\hline 107 & 13154500 & Snake River at King Hill, Idaho & 62,321 & 1998 & 2007 & 10 & 115 & 87 & 76 \\
\hline 109 & 14201300 & Zollner Creek near Mount Angel, Oregon & 41 & 1999 & 2008 & 10 & 120 & 120 & 100 \\
\hline 110 & 14206950 & Fanno Creek at Durham, Oregon & 82 & 2001 & 2011 & 11 & 142 & 102 & 72 \\
\hline 111 & 14211720 & Willamette River at Portland, Oregon & 28,922 & 2003 & 2012 & 10 & 155 & 136 & 88 \\
\hline 112 & 14246900 & $\begin{array}{l}\text { Columbia River at Beaver Army Terminal near } \\
\text { Quincy, Oregon }\end{array}$ & 619,784 & 2003 & 2012 & 10 & 100 & 59 & 59 \\
\hline
\end{tabular}

${ }^{1}$ Streamflow data are for White River at Petersburg, Indiana (U.S. Geological Survey station number 03374000).

${ }^{2}$ Streamflow data are for Wabash River at Mt. Carmel, Illinois (U.S. Geological Survey station number 03377500).

carbaryl concentration extremes computed using conditional simulations from the SEAWAVE-QEX model generally should have high uncertainty compared to atrazine.

\section{Chlorpyrifos}

For chlorpyrifos, 34 USGS sampling sites were identified for SEAWAVE-QEX model application (table 4). A total of 292 site years were analyzed, with 30 sites having RL $\geq 5$ and 14 sites having $R L \geq 10$. When selecting the period of record for sites with gaps in the record, preference was given to including the most recent years. NOBS was variable (28 sites had NOBS $\geq 60$ and 5 sites had NOBS $<40$ ) and PUC was low (only 9 sites had $\mathrm{PUC} \geq 40$ and 17 sites had $\mathrm{PUC}<25$ ).

The coefficients for the seasonal wave, MTFA, and STFA for the chlorpyrifos sites are shown in figure 19. Sites are ordered with respect to increasing USGS station number and the site number is given in table 4. CSWAVE was variable (fig. 19A): 18 sites had CSWAVE $\geq 0.4,16$ sites had CSWAVE $<0.4$, and all but 4 of the coefficients were significant. The values for CMTFA (fig. 19B) generally were smaller in magnitude compared with CSWAVE; however, 12 coefficients were significant and most (11) of the significant coefficients were positive. This result is in contrast to atrazine and carbaryl (figs. $15 B$ and $17 B$ ), for which the values of CMTFA were evenly split between positive and negative values. However, similar to atrazine and carbaryl, the values of CSTFA for chlorpyrifos (fig. 19C) were mostly positive and many (15) were significant.

The estimated SSDs for chlorpyrifos (fig. 20A) were variable: 20 sites had $\operatorname{maxSSD} \geq 0.4$ and 14 sites had $\operatorname{maxSSD}<0.4$. The estimated values of CTS (fig. 20B) also were variable:
18 sites had $\mathrm{CTS} \leq 10$ and 16 sites had $\mathrm{CTS}>10$. The combination of variable SSD and variable CTS indicates that uncertainty of the estimated chlorpyrifos concentration extremes computed using conditional simulations from the SEAWAVEQEX model should have variable uncertainty.

\section{Fipronil}

For fipronil, 33 USGS sampling sites were identified for SEAWAVE-QEX model application (table 5). A total of 219 site years were analyzed, with 23 sites having $R L \geq 5$ years and 4 sites having $R L \geq 10$ years. When selecting the period of record for sites with gaps in the record, preference was given to including the most recent years. NOBS was variable ( 22 sites had NOBS $\geq 60$ and 5 sites had NOBS $<40$ ) and PUC was variable ( 16 sites had $\mathrm{PUC}>40$ and 10 sites had $\mathrm{PUC}<25$ ).

The coefficients for the seasonal wave, MTFA, and STFA for the fipronil sites are shown in figure 21. Sites are ordered with respect to increasing USGS station number and the site number is given in table 5. CSWAVE (fig. $21 \mathrm{~A}$ ) generally was small ( 29 sites had CSWAVE $\leq 0.4$ and only 4 sites had CSWAVE $>0.4$ ) and all but 7 of the coefficients were significant. The values for CMTFA (fig. 21B) generally were comparable in magnitude compared with CSWAVE, 23 coefficients were significant, and (like atrazine and carbaryl) the significant coefficients were equally split between positive and negative values. Similar to the other pesticides, many (16) of the values of CSTFA for fipronil (fig. 21C) were significant and most (15) of the significant coefficients were positive. However, the values of CSTFA for fipronil generally were small in comparison to the other pesticides. 

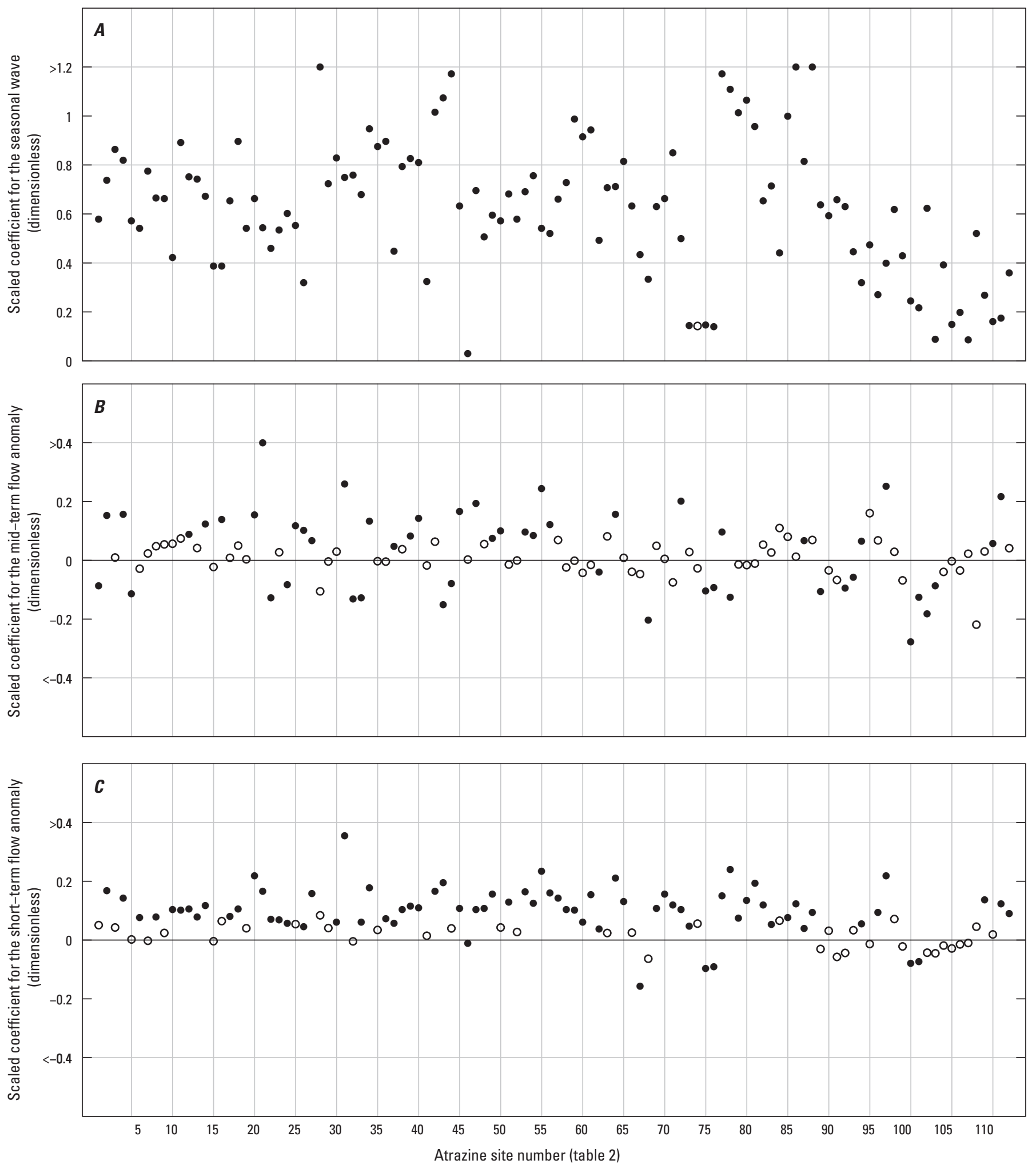

EXPLANATION

- Significant $(p<0.05)$ coefficient

$\bigcirc$ Nonsignificant coefficient

Figure 15. Estimated regression coefficients from SEAWAVE-QEX model results for atrazine. $A$, scaled coefficient for seasonal wave; $B$, scaled coefficient for mid-term flow anomaly; $C$, scaled coefficient for short-term flow anomaly. 

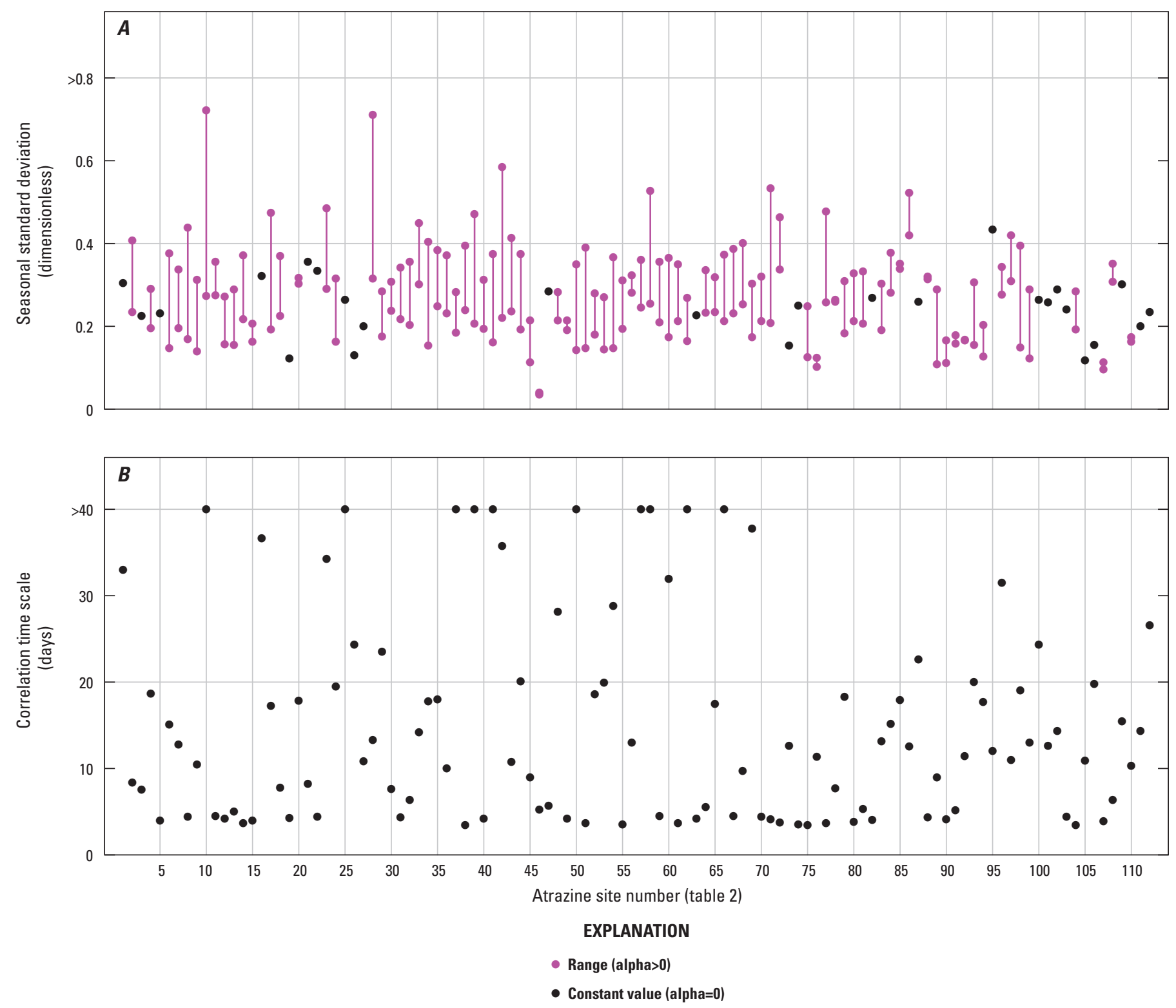

Figure 16. Estimated seasonal standard deviations and correlation time scales from SEAWAVE-OEX model results for atrazine. $A$, seasonal standard deviation; $B$, correlation time scale. 
Table 3. U.S. Geological Survey water-quality sampling sites, period of record, and number of observations used for application of SEAWAVE-OEX model for carbaryl.

[USGS, U.S. Geological Survey; km², square kilometers; NOBS, number of observations; NUC, number of uncensored observations; PUC, percent uncensored observations]

\begin{tabular}{|c|c|c|c|c|c|c|c|c|c|}
\hline $\begin{array}{c}\text { Site } \\
\text { number }\end{array}$ & $\begin{array}{c}\text { USGS } \\
\text { station } \\
\text { number }\end{array}$ & Site name & $\begin{array}{c}\text { Drainage } \\
\text { area, } \\
\text { in } \mathrm{km}^{2}\end{array}$ & $\begin{array}{c}\text { Starting } \\
\text { year }\end{array}$ & $\begin{array}{l}\text { Ending } \\
\text { year }\end{array}$ & $\begin{array}{l}\text { Record } \\
\text { length, } \\
\text { in years }\end{array}$ & NOBS & NUC & PUC \\
\hline 1 & 01356190 & Lisha Kill northwest of Niskayuna, New York & 49 & 2002 & 2008 & 7 & 70 & 23 & 33 \\
\hline 2 & 01374987 & Kisco River below Mount Kisco, New York & 46 & 2000 & 2008 & 9 & 186 & 54 & 29 \\
\hline 3 & 01464907 & $\begin{array}{l}\text { Little Neshaminy Creek at Valley Road near } \\
\text { Neshaminy, Pennsylvania }\end{array}$ & 71 & 1999 & 2004 & 6 & 77 & 28 & 36 \\
\hline 5 & 01654000 & Accotink Creek near Annandale, Virginia & 62 & 1994 & 2000 & 7 & 79 & 39 & 49 \\
\hline 6 & 02087580 & Swift Creek near Apex, North Carolina & 56 & 2002 & 2009 & 8 & 92 & 41 & 45 \\
\hline 7 & 02089500 & Neuse River at Kinston, North Carolina & 7,020 & 2003 & 2012 & 10 & 128 & 42 & 33 \\
\hline 8 & 02091500 & Contentnea Creek at Hookerton, North Carolina & 1,897 & 1997 & 2008 & 12 & 142 & 35 & 25 \\
\hline 9 & 02169570 & Gills Creek at Columbia, South Carolina & 164 & 1996 & 2005 & 10 & 86 & 19 & 22 \\
\hline 13 & 0242354750 & $\begin{array}{l}\text { Cahaba Valley Creek at Cross Creek Road at Pelham, } \\
\text { Alabama }\end{array}$ & 71 & 2001 & 2010 & 10 & 98 & 23 & 23 \\
\hline 14 & 03216600 & Ohio River at Greenup Dam near Greenup, Kentucky & 159,235 & 1997 & 2002 & 6 & 80 & 16 & 20 \\
\hline 15 & 03353637 & Little Buck Creek near Indianapolis, Indiana & 51 & 1995 & 2004 & 10 & 127 & 34 & 27 \\
\hline 16 & 04161820 & Clinton River at Sterling Heights, Michigan & 811 & 2003 & 2006 & 4 & 38 & 16 & 42 \\
\hline 17 & 05288705 & $\begin{array}{l}\text { Shingle Creek at Queen Avenue in Minneapolis, } \\
\text { Minnesota }\end{array}$ & 103 & 2003 & 2010 & 8 & 76 & 19 & 25 \\
\hline 18 & 05531500 & Salt Creek at Western Springs, Illinois & 306 & 1999 & 2007 & 9 & 99 & 30 & 30 \\
\hline 19 & 05532500 & Des Plaines River at Riverside, Illinois & 1,656 & 1999 & 2004 & 6 & 53 & 17 & 32 \\
\hline 26 & 08178800 & Salado Creek at Loop 13, San Antonio, Texas & 489 & 2002 & 2008 & 7 & 72 & 16 & 22 \\
\hline 27 & 08181800 & San Antonio River near Elmendorf, Texas & 4,529 & 1997 & 2004 & 8 & 77 & 16 & 21 \\
\hline 28 & 10168000 & $\begin{array}{l}\text { Little Cottonwood Creek at Jordan River near Salt } \\
\text { Lake City }\end{array}$ & 105 & 1999 & 2009 & 11 & 109 & 34 & 31 \\
\hline 29 & 11074000 & Santa Ana River below Prado Dam, California & 5,680 & 2003 & 2012 & 10 & 133 & 23 & 17 \\
\hline 30 & 11274538 & $\begin{array}{l}\text { Orestimba Creek at River Road near Crows Landing, } \\
\text { California }\end{array}$ & 465 & 1992 & 2000 & 9 & 104 & 24 & 23 \\
\hline 31 & 11303500 & San Joaquin River near Vernalis, California & 35,855 & 1993 & 1999 & 7 & 85 & 22 & 26 \\
\hline 32 & 11447360 & Arcade Creek near Del Paso Heights, California & 98 & 2001 & 2008 & 8 & 82 & 39 & 48 \\
\hline 33 & 12128000 & Thornton Creek near Seattle, Washington & 31 & 2001 & 2007 & 7 & 74 & 20 & 27 \\
\hline 34 & 12505450 & Granger Drain at Granger, Washington & 150 & 2002 & 2004 & 3 & 83 & 23 & 28 \\
\hline 35 & 12510500 & Yakima River at Kiona, Washington & 14,060 & 1999 & 2004 & 6 & 69 & 11 & 16 \\
\hline 36 & 14201300 & Zollner Creek near Mount Angel, Oregon & 41 & 1999 & 2005 & 7 & 94 & 21 & 22 \\
\hline 37 & 14206950 & Fanno Creek at Durham, Oregon & 82 & 2001 & 2005 & 5 & 73 & 35 & 48 \\
\hline 38 & 14211720 & Willamette River at Portland, Oregon & 28,922 & 2006 & 2011 & 6 & 104 & 22 & 21 \\
\hline
\end{tabular}



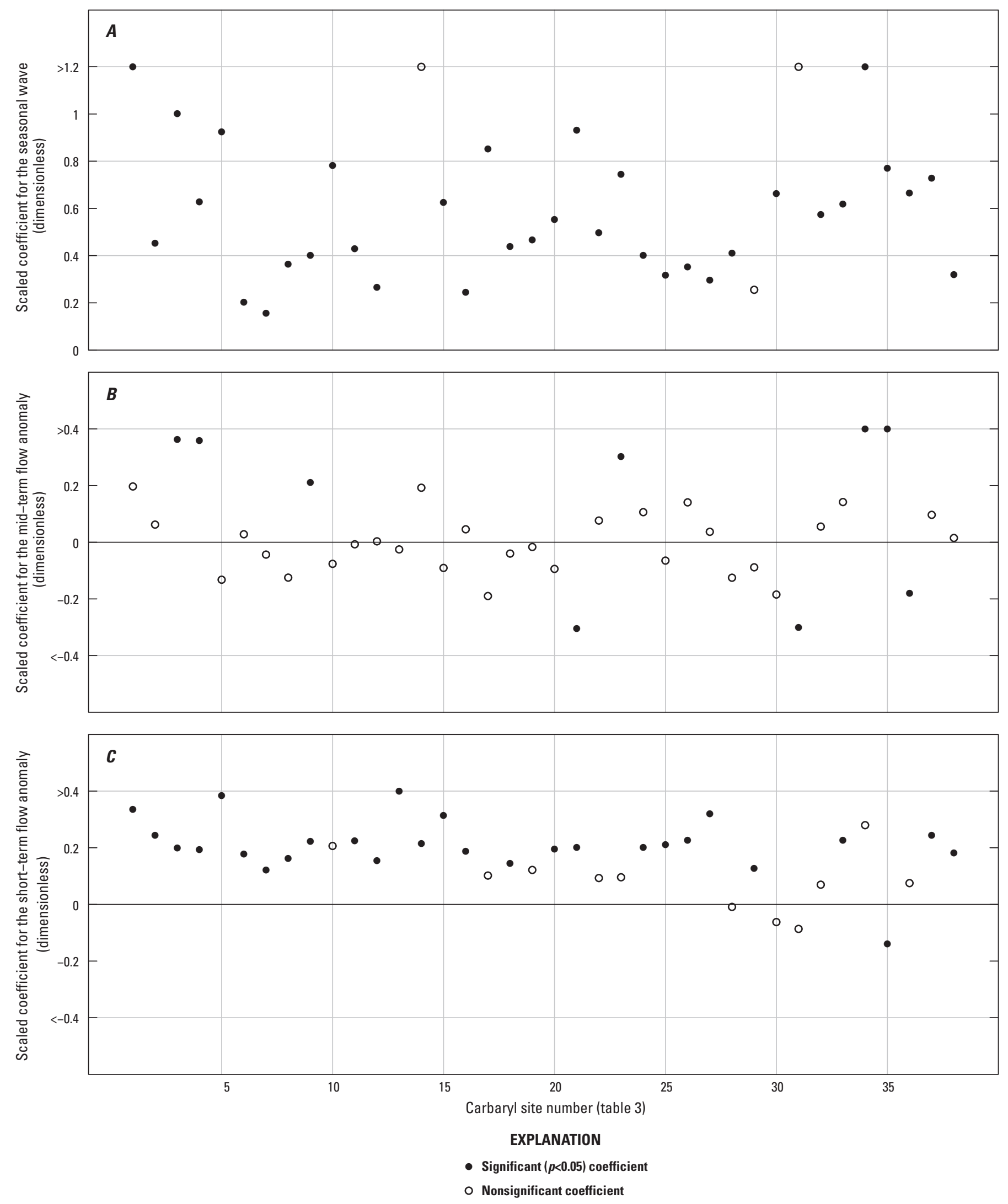

Figure 17. Estimated regression coefficients from SEAWAVE-OEX model results for carbaryl. $A$, scaled coefficient for seasonal wave; $B$, scaled coefficient for mid-term flow anomaly; $C$, scaled coefficient for short-term flow anomaly. 

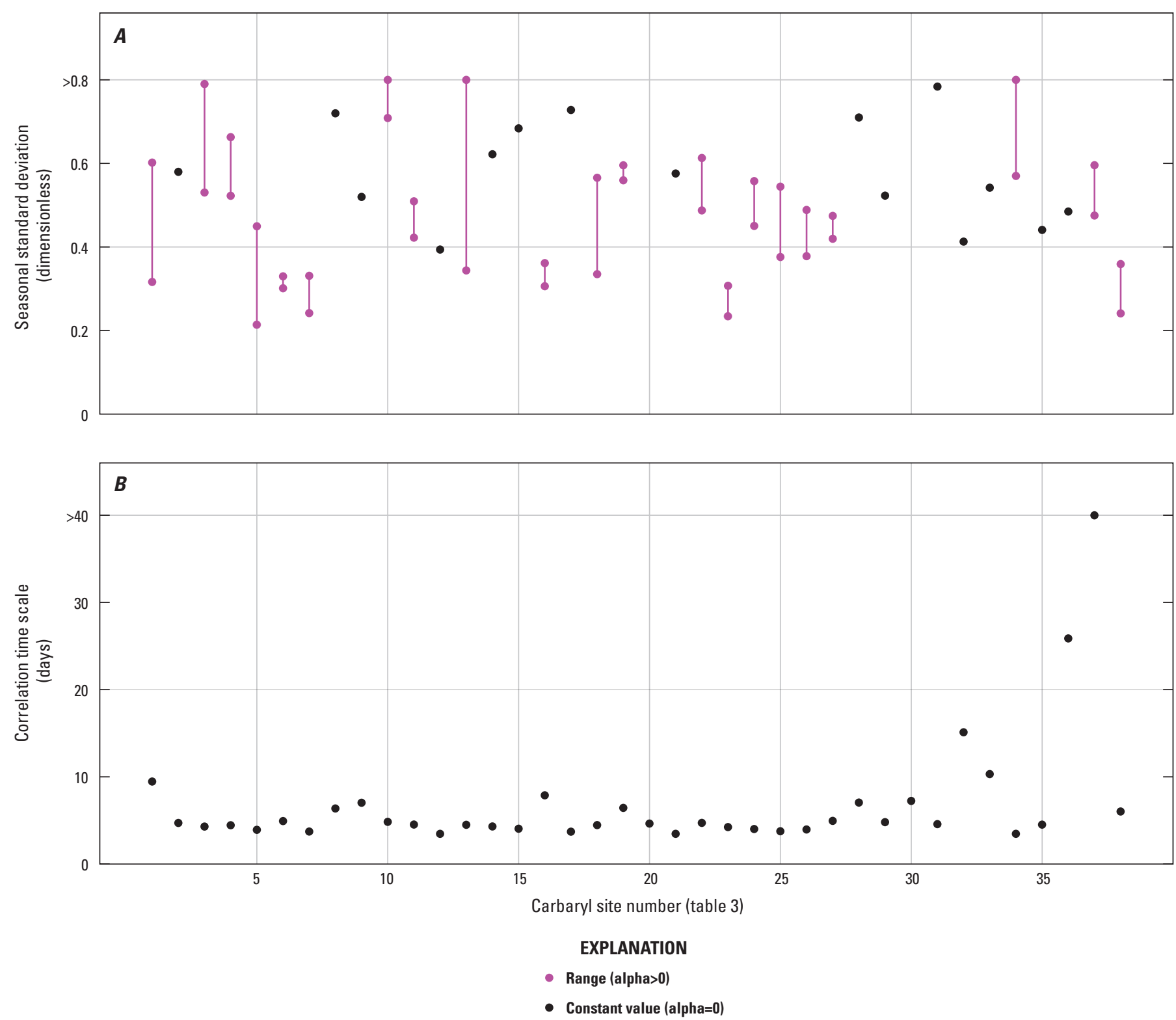

Figure 18. Estimated seasonal standard deviations and correlation time scales from SEAWAVE-QEX model results for carbaryl. $A$, seasonal standard deviation; $B$, correlation time scale.

The estimated SSDs for fipronil (fig. 22A) generally were small in comparison to the other pesticides: 29 sites had $\operatorname{maxSSD} \leq 0.4$ and only 4 sites has $\operatorname{maxSSD}>0.4$. Like atrazine and carbaryl, the estimated values of CTS for fipronil (fig. 22B) were variable: 20 sites had CTS $<10$ and 14 sites had CTS $>10$. However, unlike the other pesticides, for fipronil there was a statistically significant positive correlation between the values of SSD and CTS - the Kendall's rank correlation $(r)$ between $\sigma^{*}$ and $C T S^{*}$ was $r=0.353(p=0.004)$.
Consequently, all four of the sites with large estimated SSD (maxSSD $>0.4$ ) also had high estimated CTS (CTS $>20)$. This positive correlation between SSD and CTS, combined with the generally small values of maxSSD, indicate that uncertainty of the estimated fipronil concentration extremes computed using conditional simulations from the SEAWAVE-QEX model generally should have low uncertainty compared to the other pesticides. 
Table 4. U.S. Geological Survey water-quality sampling sites, period of record, and number of observations used for application of SEAWAVE-QEX model for chlorpyrifos.

[USGS, U.S. Geological Survey; km², square kilometers; NOBS, number of observations; NUC, number of uncensored observations; PUC, percent uncensored observations]

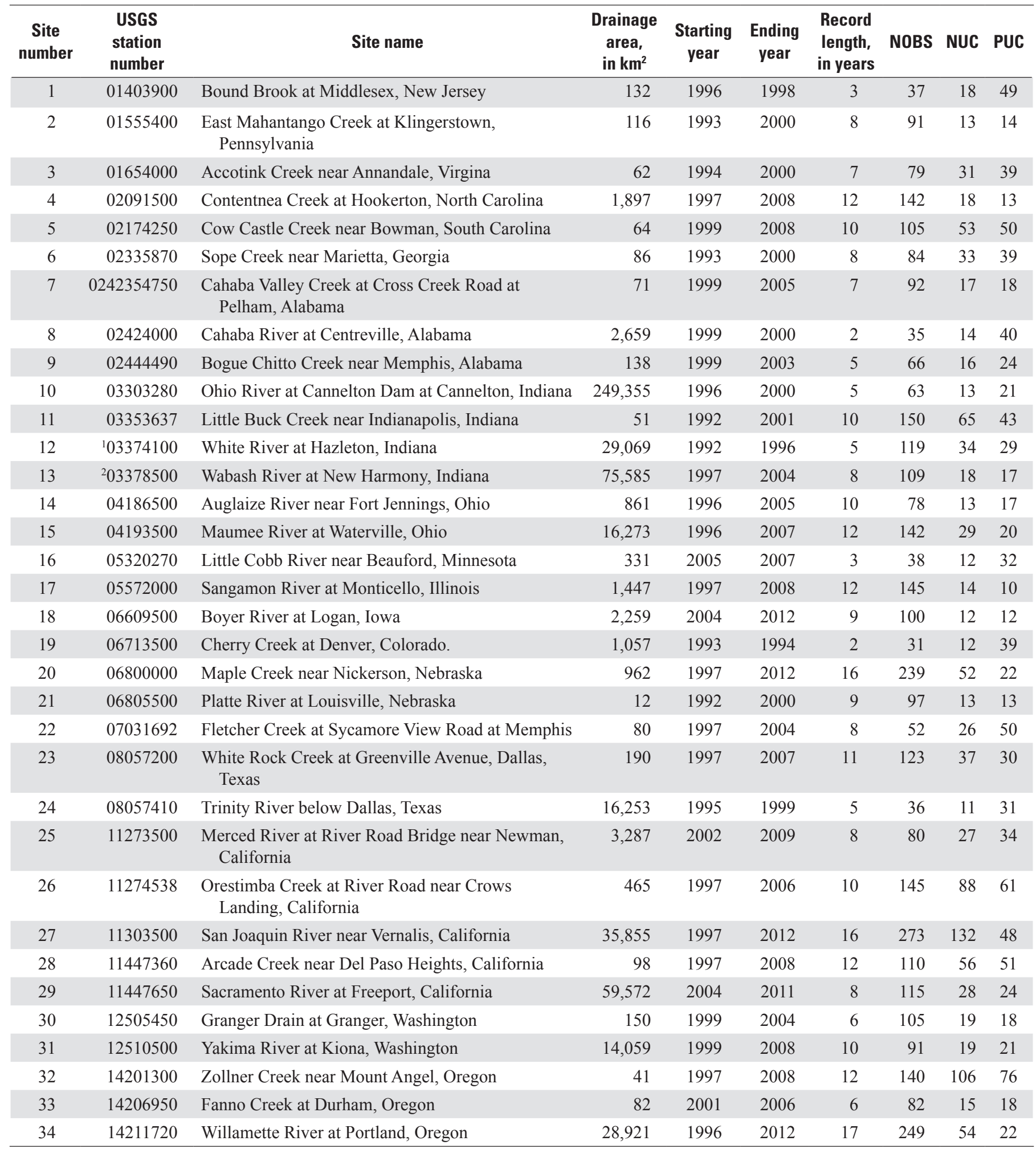

${ }^{1}$ Streamflow data are for White River at Petersburg, Indiana (U.S. Geological Survey station number 03374000).

${ }^{2}$ Streamflow data are for Wabash River at Mt. Carmel, Illinois (U.S. Geological Survey station number 03377500). 

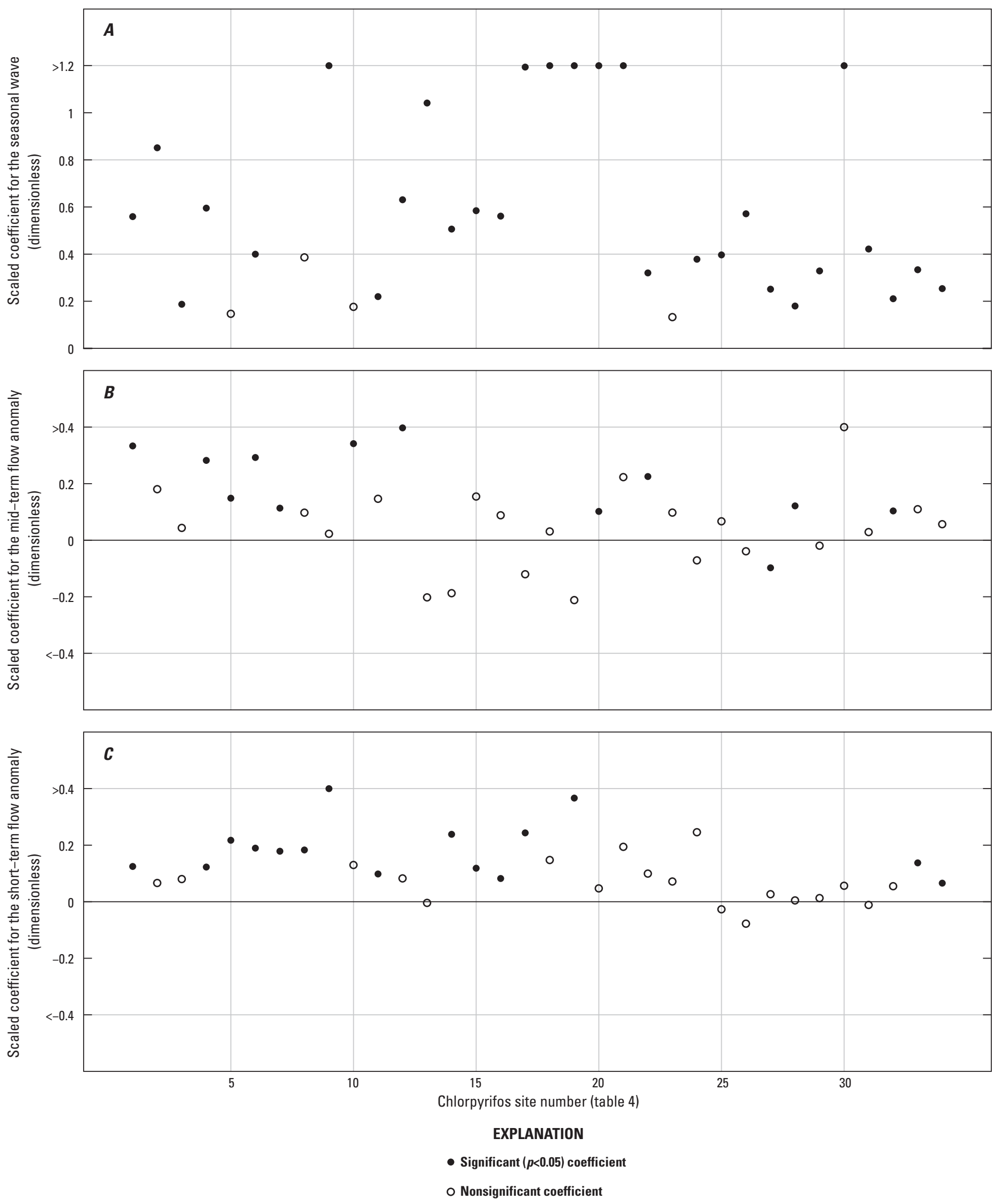

Figure 19. Estimated regression coefficients from SEAWAVE-OEX model results for chlorpyrifos. $A$, scaled coefficient for seasonal wave; $B$, scaled coefficient for mid-term flow anomaly; $C$, scaled coefficient for short-term flow anomaly. 

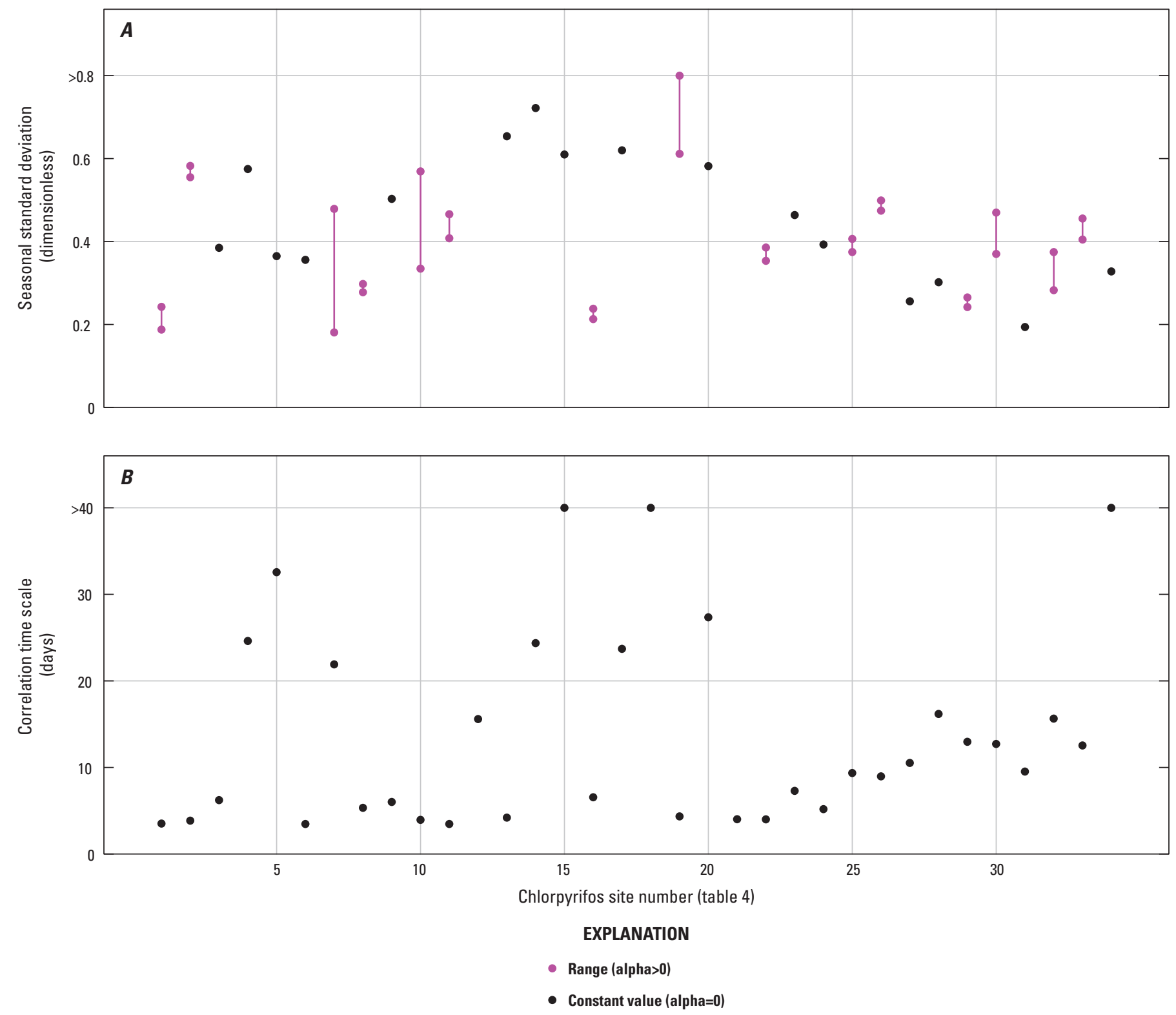

Figure 20. Estimated seasonal standard deviations and correlation time scales from SEAWAVE-0EX model results for chlorpyrifos. $A$, seasonal standard deviation; $B$, correlation time scale. 
Table 5. U.S. Geological Survey fipronil water-quality sampling sites, period of record, and number of observations used for application of SEAWAVE-QEX model.

[USGS, U.S. Geological Survey; km², square kilometers; NOBS, number of observations; NUC, number of uncensored observations; PUC, percent uncensored observations]

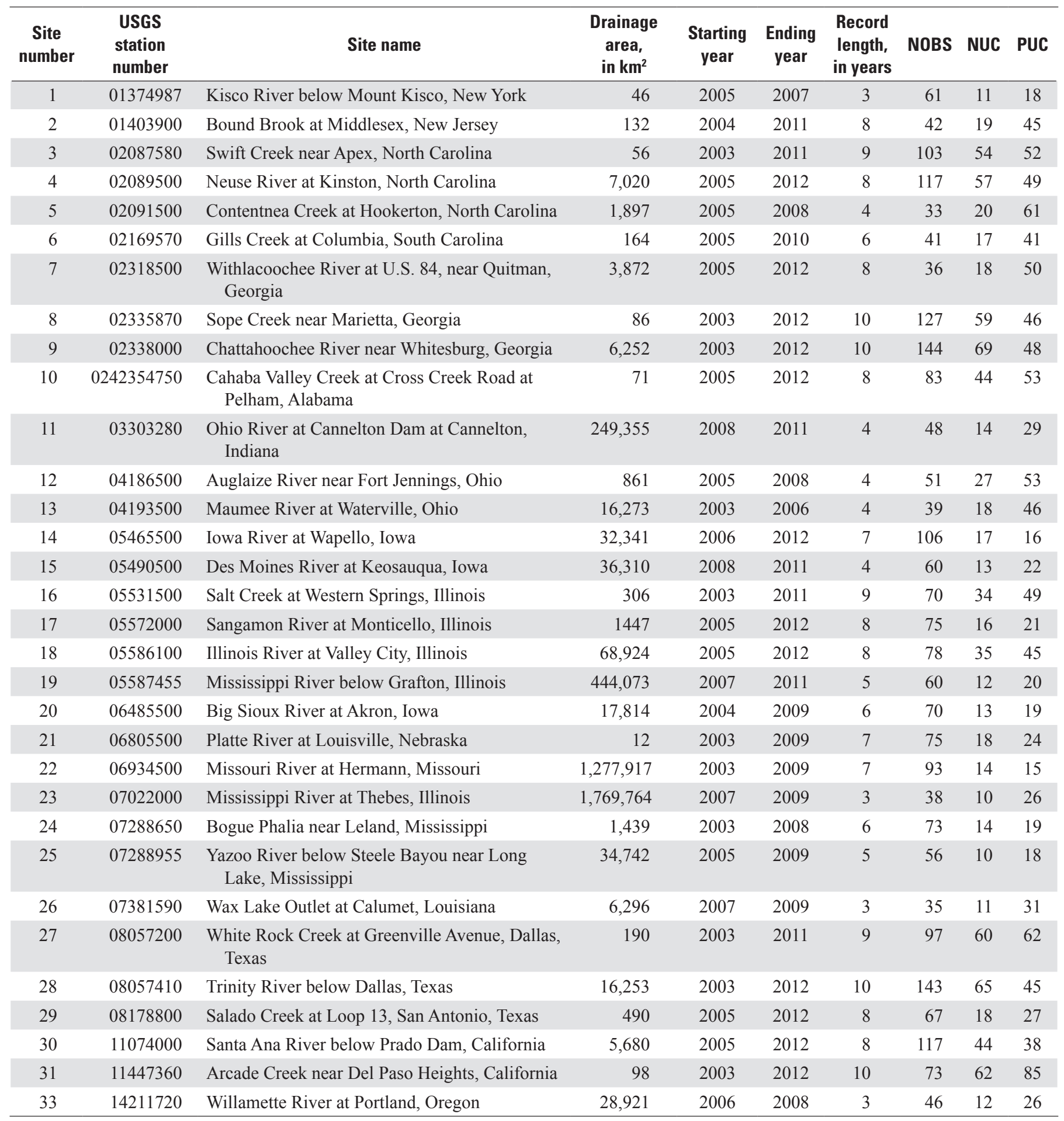



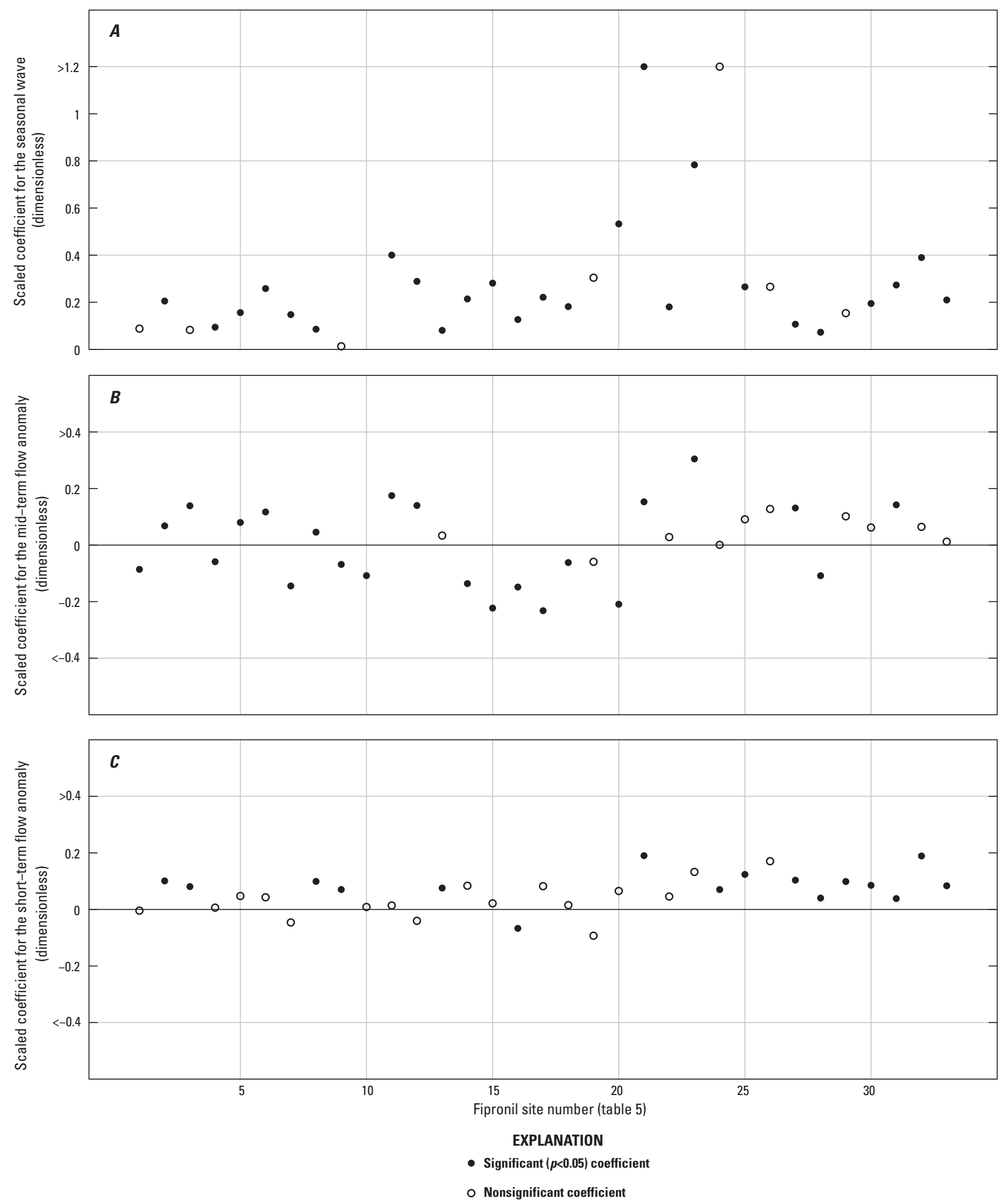

Figure 21. Estimated regression coefficients from SEAWAVE-OEX model results for fipronil. $A$, scaled coefficient for seasonal wave; $B$, scaled coefficient for mid-term flow anomaly; $C$, scaled coefficient for short-term flow anomaly. 

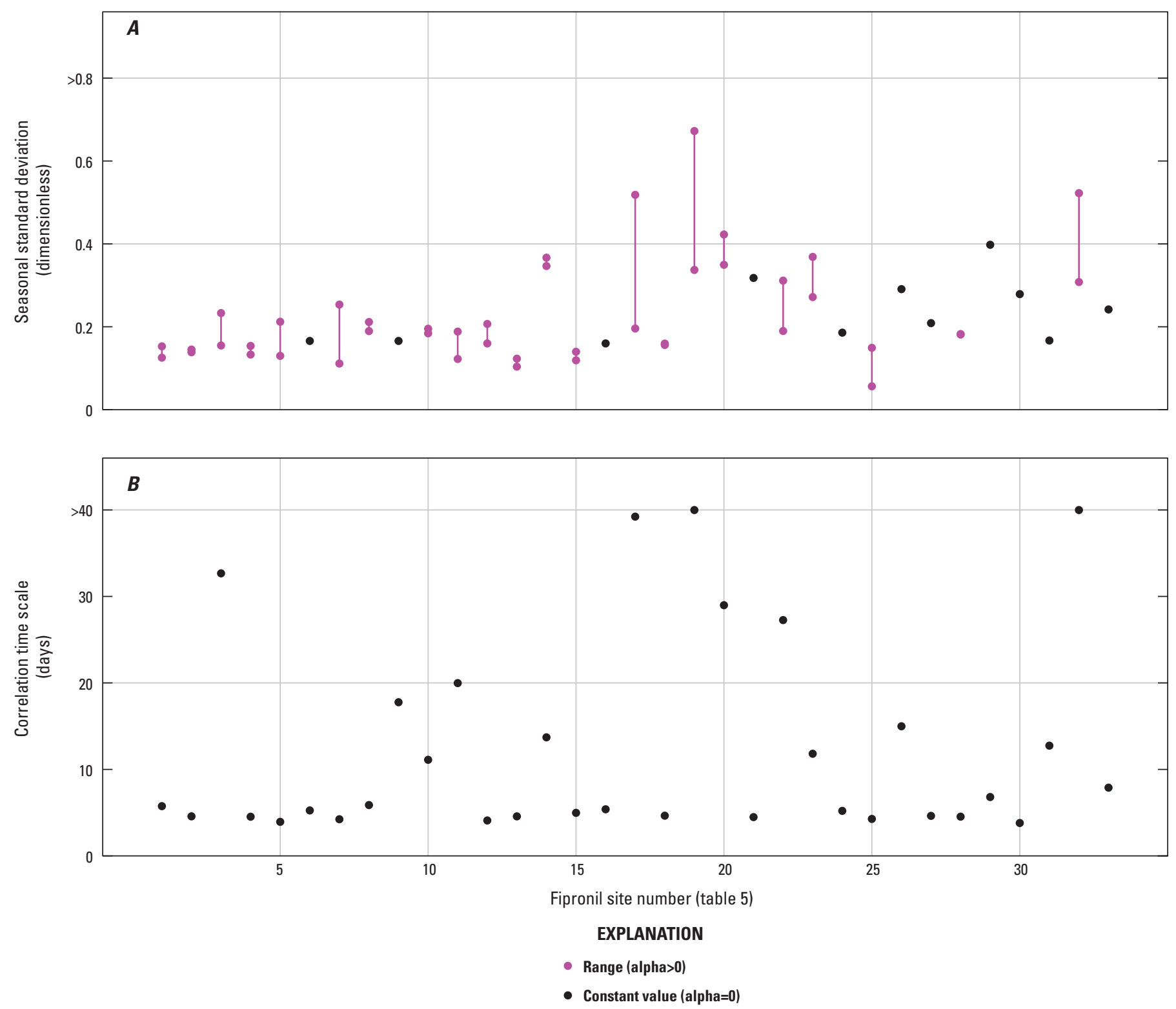

Figure 22. Estimated seasonal standard deviations and correlation time scales from SEAWAVE-QEX model results for fipronil. $A$, seasonal standard deviation; $B$, correlation time scale. 


\section{Summary and Conclusions}

To accurately characterize extreme pesticide concentrations in streams, daily sampling may be necessary during active pesticide runoff periods. However, the cost of sample collection and analysis prohibits this high sampling frequency for most monitoring programs. Sampling frequencies of every 4 days, 10 times per month, or more frequently also are uncommon among programs monitoring pesticide concentrations in streams. Sampling frequencies of weekly to monthly are more common and are referred to in this report as sparse monitoring data.

A new model methodology was developed for using sparse and potentially highly censored pesticide monitoring data to estimate pesticide concentration extremes, such as the annual maximum daily concentration. The new methodology is based on a statistical model, called SEAWAVE-QEX (seasonal wave with streamflow adjustment and extended capability to produce simulated daily concentrations). The SEAWAVE-QEX model expresses log-transformed daily pesticide concentration in terms of a seasonal wave, flow-related variability, long-term trend, and serially correlated errors. The seasonal wave models seasonality in pesticide concentration because of site-specific timing and duration of the pesticide application season. Flow-related variability is modeled using two variables that are called mid-term and short-term flow anomalies, and the variables are computed using antecedent daily discharge. The model errors are assumed to have seasonal standard deviation that can increase with increasing pesticide concentration and serial correlation that is modeled using an exponential correlation function. The SEAWAVEQEX model can be used to simulate daily concentrations that are equal to (for days with uncensored observations) or less than (for days with censored observations) the monitoring data and that consist of randomly generated values for days with no observations. The simulated daily concentrations reproduce the statistical time series characteristics of actual daily pesticide concentrations, such as serial correlation, seasonal means and variances, and flow-related variability. The simulated daily concentrations are called conditional simulations, because the simulated concentrations are conditioned on the observed monitoring data. The conditional simulations can be used to estimate concentration extremes, such as the annual maximum daily concentration, or to estimate bias factors.

This report describes the SEAWAVE-QEX modeling methodology, model testing, and data requirements. Selfcontained $\mathrm{R}$ functions for fitting the model parameters and generating conditional simulations of daily concentrations are provided in an accompanying model archive (appendix). The model can be applied to datasets with as few as 3 years of record, as few as 30 total observations, and as few as 10 uncensored observations. Model testing indicated that, provided the model assumptions are verified, estimated annual maximum daily concentrations produced by the model should be relatively unbiased (bias between -10 and 25 percent) for low censoring rates (less than 30 percent), but can have moderate upward bias (between about 25 and 50 percent) for higher censoring rates. The estimates can have high uncertainty, especially when the censoring rate is high and the spacing between observations is large in relation to the correlation time scale of the model errors. However, provided estimation uncertainty is quantified (for example, using confidence intervals instead of point estimates), the estimates should be useful for evaluating pesticide exposure risk and uncertainty. The model was applied to atrazine, carbaryl, chlorpyrifos, and fipronil data from the U.S. Geological Survey (USGS) National Water Quality Network (NWQN). A total of 112 sites were analyzed for atrazine, 38 for carbaryl, 34 for chlorpyrifos, and 33 for fipronil. Uncertainty in the estimated concentration extremes computed using conditional simulations from the SEAWAVE-QEX model increases as the standard deviation of the model error increases or the correlation time scale of the model error decreases. Based on the parameter estimation results for the sites analyzed, uncertainty generally should be highest for carbaryl, lowest for fipronil, and mixed for atrazine and chlorpyrifos.

\section{References Cited}

Crawford, C.G., 2004, Sampling strategies for estimating acute and chronic exposures of pesticides in streams: Journal of the American Water Resources Association, v. 40, no. 2, p. 485-502, accessed October 24, 2017, at http:// onlinelibrary.wiley.com/doi/10.1111/j.1752-1688.2004. tb01045.x/abstract.

Cressie, N.C., 1991, Statistics for spatial data: New York, Wiley, $900 \mathrm{p}$.

Johnson, H.M., Domagalski, J.L., and Saleh, D.K., 2011, Trends in pesticide concentrations in streams of the western United States, 1993-2005: Journal of the American Water Resources Association, v. 47, no. 2, p. 265-286, accessed October 24, 2017, at http://onlinelibrary.wiley.com/ doi/10.1111/j.1752-1688.2010.00507.x/full.

Kalkhoff, S.J., Vecchia, A.V., Capel, P.D., and Meyer, M.J., 2012, Eleven-year trend in acetanilide pesticide degradates in the Iowa River, Iowa: Journal of Environmental Quality, v. 41, no. 5, p. 1566-1579, accessed October 24, 2017, at https://dl.sciencesocieties.org/publications/jeq/ abstracts/41/5/1566.

Lerch, R.N., Sadler, E.J., Sudduth, K.A., Baffaut, C., and Kitchen, N.R., 2011, Herbicide transport in Goodwater Creek experimental watershed-I. Long-term research on atrazine: Journal of the American Water Resources Association, v. 47, no. 2, p. 209-223, accessed October 24, 2017, at http://onlinelibrary.wiley.com/doi/10.1111/j.17521688.2010.00503.x/abstract. 
Martin, J.D., 2009, Sources and preparation of data for assessing trends in concentrations of pesticides in streams of the United States, 1992-2006: U.S. Geological Survey Scientific Investigations Report 2009-5062, 41 p, accessed October 24, 2017, at https://pubs.usgs.gov/sir/2009/5062.

Mosquin, P., Whitmore, R.W., and Chen, W., 2012, Estimation of upper centile concentrations using historical atrazine monitoring data from community water systems: Journal of Environmental Quality, v. 41, no. 3, p. 834-844, accessed October 24, 2017, at https://www.ncbi.nlm.nih.gov/ pubmed/22565265.

R Core Team, 2016. R-A language and environment for statistical computing: R Foundation for Statistical Computing, Vienna, Austria, accessed July 31, 2017, at https://www.Rproject.org.

Rowe, G.L., Jr.; Kenneth, Belitz; Demas, C.R.; Essaid, H.I.; Gilliom, R.J.; Hamilton, P.A.; Hoos, A.B.; Lee, C.J.; Munn, M.D.; and Wolock, D.W., 2013, Design of Cycle 3 of the National Water-Quality Assessment Program, 2013-23Part 2-Science plan for improved water-quality information and management: U.S. Geological Survey Open-File Report 2013-1160, 110 p., accessed October 24, 2017, at https://pubs.usgs.gov/of/2013/1160/.

Ryberg, K.R., and Gilliom, R.J., 2015, Trends in pesticide concentrations and use for major rivers of the United States: Science of the Total Environment, v. 538, p. 431-444, accessed October 24, 2017, at https://www.ncbi.nlm.nih. gov/pubmed/26318227.

Ryberg, K.R., Vecchia, A.V., Gilliom, R.J., and Martin, J.D., 2014, Pesticide trends in major rivers of the United States, 1992-2010: U.S. Geological Survey Scientific Investigations Report 2014-5135, 63 p., accessed October 24, 2017, at https://doi.org/10.3133/sir20145135.

Ryberg, K.R., Vecchia, A.V., Martin, J.D., and Gilliom, R.J., 2010, Trends in pesticide concentrations in urban streams in the United States, 1992-2008: U.S. Geological Survey Scientific Investigations Report 2010-5139, 42 p.

Stone, W.W., Gilliom, R.J., and Ryberg, K.R., 2014, Pesticides in U.S. streams and rivers-Occurrence and trends during 1992-2011: Environmental Science and Technology, v. 48, n. 19, p. 11025-11030, accessed October 24, 2017, at http:// pubs.acs.org/doi/abs/10.1021/es5025367.

Sullivan, D.J., Vecchia, A.V., Lorenz, D.L., Gilliom, R.J., and Martin, J.D, 2009, Trends in pesticide concentrations in corn-belt streams, 1996-2006: U.S. Geological Survey Scientific Investigations Report 2009-5132, 75 p., accessed October 24, 2017, at https://pubs.usgs.gov/sir/2009/5132/.
U.S. Environmental Protection Agency, 2010a, Reevaluation of human health effects of atrazine-Review of experimental animal and in vitro studies and drinking water monitoring frequency: Federal Insecticide, Fungicide and Rodenticide Act Scientific Advisory Panel, Docket Number EPA-HQ-OPP-2010-0125-0008, April 26-29, 2010, accessed July 18, 2017, at https://archive.epa.gov/scipoly/ sap/meetings/web/pdf/042610transcript.pdf.

U.S. Environmental Protection Agency, 2010b, Re-evaluation of human health effects of atrazine-Review of non-cancer effects and drinking water monitoring frequency: Federal Insecticide, Fungicide and Rodenticide Act Scientific Advisory Panel, Docket Number EPA-HQ-OPP-2010-0481, September 14-17, 2010, accessed July 18, 2017, at https:// www.regulations.gov/docket?D=EPA-HQ-OPP-2010-0481.

U.S. Environmental Protection Agency, 2011, Re-evaluation of human health effects of atrazine-Review of cancer epidemiology, non-cancer experimental animal and in vitro studies and drinking water and monitoring frequency: Federal Insecticide, Fungicide and Rodenticide Act Scientific Advisory Panel, Docket Number EPA-HQ-OPP-20110399, accessed July 18, 2017, at http://atrazinefacts.com/ docs/EPA\%20Issue\%20Paper\%20for\%20July\%202011\%20 SAP-EPA-HQ-OPP-2011-0399-0013.pdf.

U.S. Environmental Protection Agency 2012, Problem formulation for the reassessment of ecological risks from the use of atrazine: Federal Insecticide, Fungicide and Rodenticide Act Scientific Advisory Panel, Docket Number EPAHQ-OPP-2012-0230, September 11-14, 2012, accessed July 18, 2017, at https://www.epa.gov/sites/production/ files/2015-06/documents/061212minutes.pdf.

U.S. Geological Survey, 2017, U.S. Geological Survey water data for the Nation: National Water Information System database, accessed December 14, 2017, at https://doi. org/10.5066/F7P55KJN.

Vecchia, A.V., and Williams-Sether, T., 2018, Data files to support SEAWAVE-QEX model for simulating concentrations of selected pesticides in the continental United States, 1992-2012: U.S. Geological Survey data release, https:// doi.org/10.5066/F7NV9H50.

Vecchia, A.V., Martin, J.D., and Gilliom, R.J., 2008, Modeling variability and trends in pesticide concentrations in streams: Journal of the American Water Resources Association, v. 44, no. 5, p. 1308-1324.

Vecchia, A.V., Gilliom, R.J., Sullivan, D.J., Lorenz, D.L., and Martin, J.D., 2009, Trends in concentrations and use of agricultural herbicides for Corn Belt rivers, 1996-2006: Environmental Science and Technology, v. 43, no. 24, p. 9096-9102. 

Appendix 


\section{Appendix. Description of R Functions and Model Archive for Running SEAWAVE-0EX.}

$\mathrm{R}$ functions are provided for merging daily discharge and pesticide concentration data, preparing the data for analysis, fitting the seasonal wave with streamflow adjustment and extended capability (SEAWAVE-QEX) model parameters, and generating conditional simulations of daily pesticide concentrations. In many cases, the R functions complete straightforward tasks described in the main body of this report and require little explanation. Some tasks, such as maximum likelihood estimation of the seasonal variance and serial correlation parameters and conditional simulation of daily concentrations, have additional explanation. The functions are listed and described in the following section, and the code for creating the functions and instructions for running the model are provided in the "Model Archive" section of this appendix.

\section{SEAWAVE-0EX Functions}

\section{Function: swaveqexMerge}

Purpose: Merges daily discharge and pesticide concentration data, completes data screening steps, produces rough data plots, and creates object for input to swaveqexFit.

Required R libraries: waterData

Usage

> qexfitinput <- swaveqexMerge( cdatin, qwstnum, ddstnum, yrbeg, yrend, getdd="WD")

cdatin is a data frame with the pesticide concentration data

- the first column should be the station number (character)

- the second column should be the date, in "yyyy-mm-dd" format (character)

- the concentration value should be in a column named "final_value" (numeric)

- the remark should be in a column named "final_remark" (character)

qwstnum is the station number from cdatin to analyze (character).

ddstnum is the station number for daily discharge (character, usually the same as qwstnum). If getdd is omitted or gettdd="WD", the waterData package is used to download daily discharge for the specified U.S. Geological Survey station number (ddstnum). If getdd="File", the daily discharge data are assumed to be in a tab-delimited text file called dd_ddstnum.txt in the current working directory. The first column of the text file for daily discharge should be the date (in yyyy-mm-dd format) and the second column should be the discharge value. The text file should not have a header and there should be no missing values.

yrbeg and yrend are the beginning and ending calendar years for analysis (numeric). If unknown, the entire period of record can be analyzed by setting yrbeg $=0$ and $y$ rend $=3000$.

\section{Examples}

qexfitinput <- swavqexMerge(SWqexAtrazineData,"03353637","03353637",1993,2002)

Prepares the atrazine data for Little Buck Creek near Indianapolis, Indiana (USGS station number 03353637 in the SWqexAtrazineData dataframe) for 1993-2002.

qexfitinput <- swavqexMerge(SWqexAtrazineData,"03353637","03353637",1993,2002,getwd="File")

looks for discharge data in a file called dd_03353637.txt in the current working directory.

Output

Rough data plots (sent to the default plot device). These plots can be used to adjust yrbeg and yrend and see if data are sufficient for analysis. 
An object (list) named qexfitinput or any other user-specified name, for input to swaveqexFit

\section{Function: swaveqexFit}

Purpose: Uses input object prepared by swaveqexMerge to estimate the model parameters, produce diagnostic plots, and generate conditional simulations of daily concentration.

Required R libraries: tmvtnorm, survival

Other functions required (described later): swaveqexPESTpdo, swaveqexCSIM

Usage

$>$ qexfitout <- swaveqexFit(qexfitinput,outfolder,ncs=50)

qexfitinput is an object (list) produced by swaveqexMerge.

outfolder is a character name for the folder to save the diagnostic plots and conditional simulations. The folder needs to be created ahead of time. For example, "outatrazine $\backslash$ " will save the results in a folder called outatrazine in the default working directory.

ncs is the number of conditional simulations to generate (default is 50 , maximum is 250 ).

Output

A Portable Document Format (PDF) file called "PlotsXXX.pdf", where XXX is the qwstnum used to produce qexfitinput. This file contains diagnostic plots similar to figures 5-8 of this report.

A tab-delimited text file called "CSIMSXXX.txt" (where XXX is the qwstnum) with daily output information for the period of record, including columns with the observed concentrations, daily discharges, and ncs conditional simulations. See the "Model Archive" section of this appendix for description of the CSIMXXX.txt file.

A list with three elements, saved as qexfitout or any other user specified name, with the parameter estimates and other information as follows:

qexfitout[[1]] is the station number for pesticide concentration data (character)

qexfitout[[2]] is a vector of length 25 with the output names (character)

qexfitout[[3]] is a vector of length 25 with the output values (numeric)

The output names and descriptions are as follows:

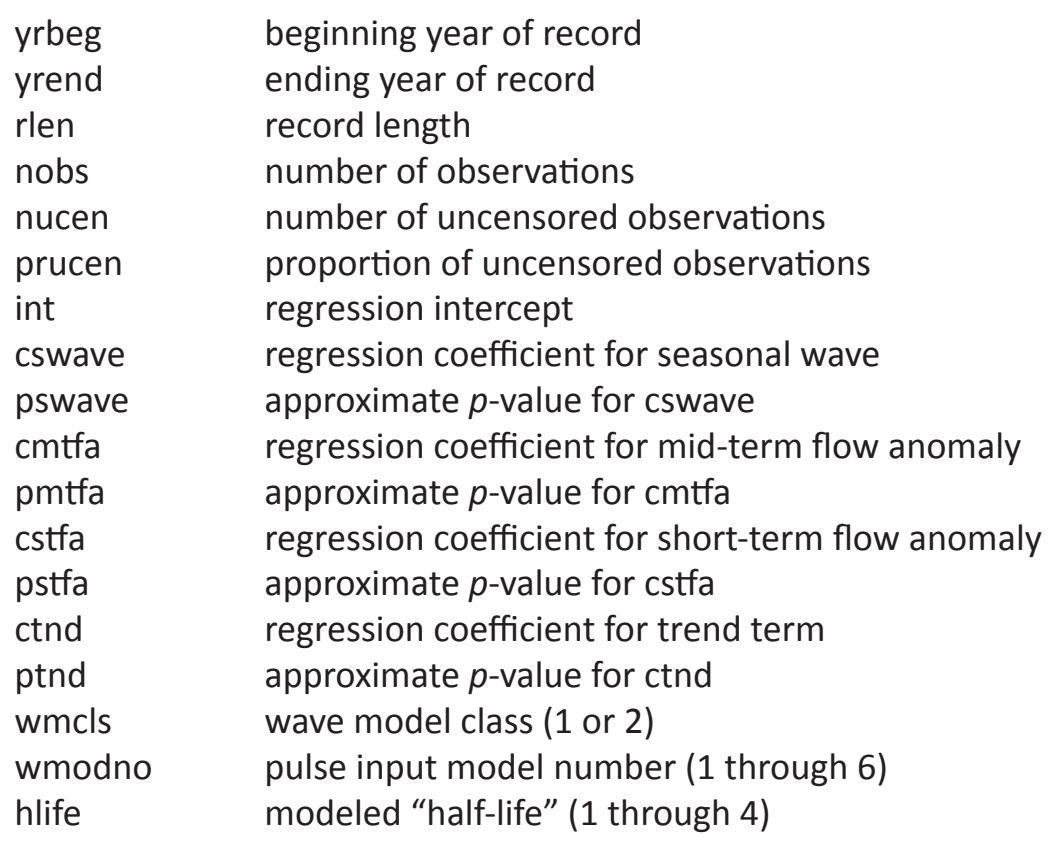




$\begin{array}{ll}\text { wshft } & \text { phase shift } \\ \text { sigma } & \text { estimated error standard deviation } \\ \text { alph } & \text { estimated value of alpha } \\ \text { cts } & \text { estimated correlation time scale } \\ \text { n2LIIK } & \text { negative } 2 \text { times the log-likelihood value } \\ \text { sdmtfa } & \text { standard deviation of the mid-term flow anomaly } \\ \text { sdstfa } & \text { standard deviation of the short-term flow anomaly }\end{array}$

\section{Function: swaveqexPESTpdo}

Purpose: Selects the best wave model and computes estimates of the regression coefficients and maximum pseudo-likelihood estimates of the seasonal standard deviation and serial correlation parameters.

Required R libraries: tmvtnorm, survival

Other functions used (described later): estsigxx, evalmodlikxx, compwaveconvxx

This function is called internally from swaveqexFit. User does not need to call this function.

Additional details: With highly censored data, exact maximum likelihood estimation is intractable. An alternative method, based on the pseudo-likelihood function is used. This method has been determined to be comparable (in terms of bias and efficiency) to exact maximum likelihood while being much simpler to compute (Besag, 1977; Zeger and Brookmeyer, 1986).

\section{Function: estsigxx}

Purpose: Finds iterative solution for sigma to maximize the pseudo-likelihood given values for alpha and cts. User does not need to call this function.

\section{Function: evalmodlikxx}

Purpose: Computes value of negative 2 times the log-pseudo-likelihood. User does not need to call this function.

\section{Function: compwaveconvxx}

Purpose: Computes the seasonal wave given the model class, model number, model half-life, and phase shift. Function used internally.

\section{Function: swaveqexCSIM}

Purpose: Computes conditional simulations of daily pesticide concentration given estimated model parameters and other information passed from swaveqexFit. Input and output are processed within swaveqexFit.

\section{Required R libraries: tmvtnorm}

Other functions required (described later): impcenvals, condsim

\section{Function: impcenvals}

Purpose: Imputes values for censored normalized residuals. Input and output are processed within swaveqexCSIM. Function used internally.

Required R libraries: tmvtnorm

Additional details: The imputed values for each block of consecutive censored residuals are generated at random from a truncated conditional multivariate normal distribution for the censored residuals given the closest uncensored values before and after the block. This process relies on the assumption of an exponential correlation function, for which the residuals have a first-order Markov dependence structure and, thus, only the closest uncensored values are required.

\section{Function: condsim}


Purpose: Computes a conditional trace for the normalized residuals given the uncensored residuals and the imputed censored residuals. Input and output are processed within swaveqexCSIM and are not important for user.

Required R libraries: tmvtnorm

Additional details: The values for each block of days in between the observed/imputed values are generated at random from a conditional multivariate normal distribution given the closest values before and after the block. This process relies on the assumption of an exponential correlation function, for which the residuals have a first-order Markov dependence structure and, thus, only the closest values before and after the block are required.

\section{Model Archive}

The following files are available for download at https://doi.org/10.3133/sir20175159.

- swaveqexFunctions_V1.R

Text file with the code required to create the SEAWAVE-QEX functions.

- $\quad$ swaveQEX.Rdata

$\mathrm{R}$ workspace containing the following dataframes:

- SWqexAtrazineData, SWqexCarbaryIData, SWqexChlorpyrifosData, SWqexFipronilData

The atrazine, carbaryl, chlorpyrifos, and fipronil dataframes used for the applications in this report.

- SWqexAtrazineSites, SWqexCarbarylSites, SWqexChlorpyrifosSites, SWqexFipronilSites

The site lists and other information for each pesticide (see tables 2-5 of this report).

- SWqexAtrazinePest, SWqexCarbarylPest, SWqexChlorpyrifosPest, SWqexFipronilPest

The SEAWAVE-QEX parameter estimates for each pesticide/site using the period of record (yrbeg, yrend) that is specified in the site list files. See description of output for the swaveqexFit function for the variable names.

\section{Instructions for Running SEAWAVE-QEX}

A recent version of $R$ (v.3.3.0 or later) is required, and installing Rstudio is recommended. The user libraries waterData, tmvtnorm, and survival also need to be installed.

Step 1. Open the swaveQEX.Rdata workspace containing the dataframes described previously.

Step 2. Create the SEAWAVE-QEX functions in your user environment using the source command:

> source("swaveqexFunctions.txt")

Step 3. Before running the model, attach the following required libraries:

$$
\begin{aligned}
& \text { > library("survival") } \\
& >\text { library("tmvtnorm") } \\
& \text { > library("waterData") }
\end{aligned}
$$

SEAWAVE-QEX should now be fully functional. Start by verifying some of the results from the report, provided in the dataframes. For example, reproduce the results for the example model for carbaryl (figs. 9 and 10 and related discussion). This site is the second site in the carbaryl site list (USGS station number 01374987; the second row of the dataframe SWqexCarbarylSites; also the second row in table 3 of the report). The data first need to be prepared using swaveqexMerge: 
> Kisco <- swaveqexMerge(SWqexCarbaryIData,"01374987","01374987",2000,2008)

This command will create an object named Kisco in your workspace that is ready for swaveqexFit. Before running swaveqexFit, create a folder in the default directory called CarbarylOutput or some other name for storing the output files. Also, make sure that no plotting devices are open. Then, run swaveqexFit:

> KiscoPest <- swaveqexFit(Kisco,"CarbarylOutput)।",ncs=100)

This command will create the object KiscoPest in your workspace with the SEAWAVE-QEX parameter estimates. To make the results easier to view, a dataframe can be created with the first column consisting of the parameter names and the second column consisting of the parameter estimates:

$>$ KiscoPest <- data.frame(KiscoPest[[2]],KiscoPest[[3]])

The parameter estimates should be identical to the values in the second row of the SWqexCarbarylPest dataframe.

The two files named "Plots01374987.pdf" and "CSIM01374987.txt" also should be in the CarbarylOutput folder. Look at the plots in the PDF file. The first plot should look similar to figure 9. The points labeled as "observed concentrations" (the uncensored observations) should be identical to figure 9 because those points do not change depending on the conditional simulation. However, the conditional trace (including the points labeled "simulated censored concentrations") are randomly generated and will differ for each plot. The estimated annual maximum concentrations (which are the average of ncs=100 values) may differ slightly for each plot.

The second plot should look like figure 10 of the report. Note that the curves showing the fitted seasonal wave and +/- two seasonal standard deviations (and the solid points) should be identical to figure 10. However, the open points (corresponding to simulated censored observations) are from the conditional trace and will be different for each plot.

Now look at the CSIM01374987.txt file. The file should look similar to the following:

\begin{tabular}{|c|c|c|c|c|c|c|c|c|c|c|}
\hline date & year & jday & qobs & cobs & crem & estreg & estcmu & $\operatorname{csim} 1$ & csim2 & csim3 \\
\hline $2000-01-01$ & 2000 & 1 & 24.0 & & & 1.11 & 2.14 & 0.20 & 0.10 & 2.38 \\
\hline $2000-01-02$ & 2000 & 2 & 24.0 & & & 1.11 & 3.48 & 0.22 & 0.41 & 1.05 \\
\hline $2000-01-03$ & 2000 & 3 & 29.0 & & & 1.28 & 3.11 & 0.58 & 1.08 & \\
\hline $2000-01-04$ & 2000 & 4 & 32.0 & & & 1.37 & 3.23 & 0.91 & 2.88 & 1.85 \\
\hline $2000-01-05$ & 2000 & 5 & 61.0 & & & 2.22 & 9.26 & 1.34 & 1.47 & 1.2 \\
\hline
\end{tabular}

This is a tab-delimited text file with a row for each day of the period analyzed and the following columns:

date (column 1): YYYY-MM-DD format

year (column 2): the calendar year

jday (column 3): integer day

qobs (column 4): observed daily discharge (cubic foot per second)

cobs (column 5): observed concentrations (micrograms per liter, blanks for missing values)

crem (column 6): concentration remark ( $<$ for censored value, blank for missing or uncensored values)

The remaining columns ( 7 through ncs +8 ) contain transformed model generated concentrations (TC):

$\mathrm{TC}=\operatorname{Round}(1000 \mathrm{C}, 2)$, where $\mathrm{C}$ is concentration, in micrograms per liter. $\mathrm{TC}$ is obtained by multiplying the model generated concentration by 1,000 and rounding to 2 decimal places. To obtain concentration, in micrograms per liter, out to 5 decimal places, divide TC by 1,000 .

Note that missing values of TC are coded as numeric value -9

estreg (column 7): Fitted value of TC from the regression model

estmu (column 8): Mean of the ncs (for example, ncs=100) conditional traces

csim1, $\operatorname{csim} 2, \operatorname{csim} 3, \ldots$ (columns 9 through ncs +8 ): conditional traces of TC. 


\section{References Cited}

Besag, Julian, 1977, Efficiency of Pseudoliklihood estimation for simple Gaussian fields: Biometrika, v. 64, no. 3 p. 616-618.

Zeger, S.L., and Brookmeyer, Ron, 1986, Regression analysis with censored autocorrelated data: Journal of the American Statistical Association, v. 81, no. 395, p. 722-729.

For more information about this publication, contact

Director, USGS Dakota Water Science Center, North

Dakota Office

821 East Interstate Avenue

Bismarck, ND 58503

(701) 250-7400

For additional information visit https://nd.water.usgs.gov

Publishing support provided by the

Rolla Publishing Service Center 




\section{$\frac{\mathbb{2}}{3}$}

